\title{
The Distribution of Social Services in Madagascar, 1993-99
}

\author{
Peter Glick, Cornell University
}

Mamisoa Razakamanantsoa, INSTAT

December, 2002 


\section{Acknowledgments}

We thank Jesko Hentschel, Bart Minten, Mead Over, Jean Razafindravonona, Stefano Paternostro, David Sahn, David Stifel, and Steve Younger for their comments on this report or on the issues raised by it. The study has also benefited from discussions with Jee-Peng Tan of the World Bank on recent trends in school enrollments, and from comments from participants at a seminar on the findings given at USAID Madagascar. In addition to their substantive input, Bart Minten and Jean Razafindravonona provided valuable logistical support for this study. Finally, we thank USAID Madagascar for funding this work through the Ilo project. 


\begin{abstract}
While a number of benefit incidence studies of public expenditures have been carried out for African countries, there are very few studies that look at how the incidence of such expenditures has been changing over time. We use three rounds of nation-wide household surveys to analyze the distribution of public expenditures on education and health services in Madagascar over the decade of the 90s, a period of little economic growth but significant changes in social sector organization and budgets.
\end{abstract}

Education and health services for the most part are found to be distributed more equally than household expenditures: therefore they serve to redistribute welfare from the rich to the poor. By stricter standards of progressivity, however, public services do poorly. Few services other than primary schooling accrue disproportionately to the poor in absolute terms. When we further adjust for differences in the numbers of potential beneficiaries in different expenditure quintiles (e.g., school-age children in the case of education), none of the education or health benefits considered appear to target the poor while several target the non-poor. We also find significant disparities in the use of services between rural and urban areas, and by province. On the other hand, for both education and health services, no notable gender differences exist in coverage.

With regard to changes over the decade, primary enrollments rose sharply and also become significantly more progressive; since the country experienced little or no growth in household incomes during the period, this apparently reflects supply rather than demand side factors. The improvement in equity in public schooling occurred in part because the enrollment growth was in effect regionally targeted: it occurred only in rural areas, which are poorer. 


\section{TABLE OF CONTENTS}

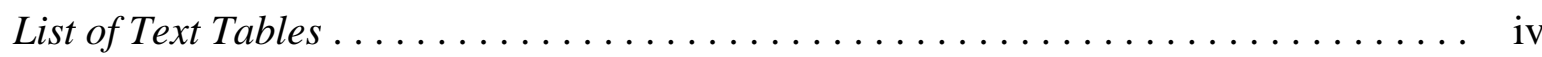

List of Text Figures .................................... $\mathrm{v}$

List of Appendix Tables .................................... vi

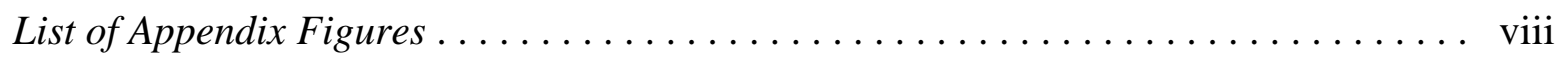

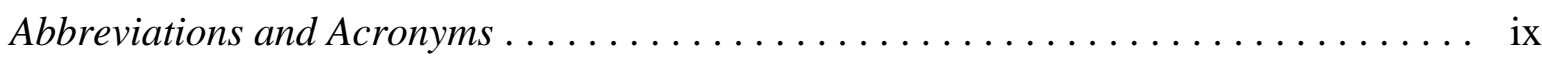

I. INTRODUCTION $\ldots \ldots \ldots \ldots \ldots \ldots \ldots \ldots \ldots \ldots \ldots \ldots \ldots \ldots \ldots \ldots \ldots$

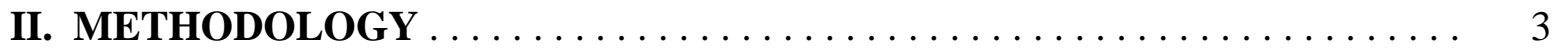

Program Coverage, Utilization of Services, and Benefits Incidence ........... 3

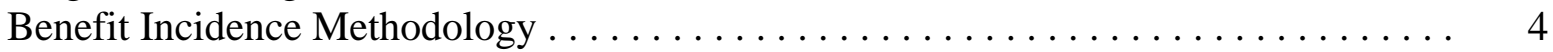

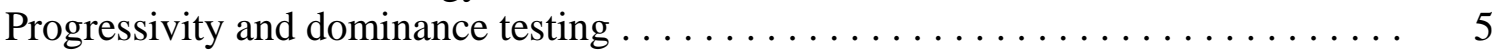

Limitations of Benefit Incidence Analysis . . . . . . . . . . . . . . . . . . . 8

III. HISTORICAL AND INSTITUTIONAL BACKGROUND . . . . . . . . . 11

Economic stagnation and poverty in Madagascar ................. 11

The education sector in Madagascar $\ldots \ldots \ldots \ldots \ldots \ldots \ldots \ldots \ldots \ldots \ldots, 12$

The health sector in Madagascar .............................. 15

IV. PROGRAM COVERAGE FOR SOCIAL SERVICES 1993-1999 . . . . . . 17

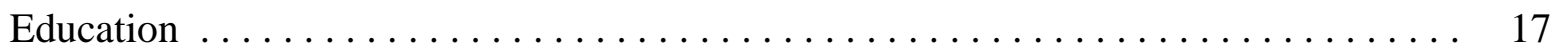

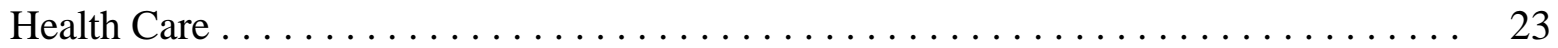

Prenatal Care ............................................ 28

Vaccinations ......................................... 28

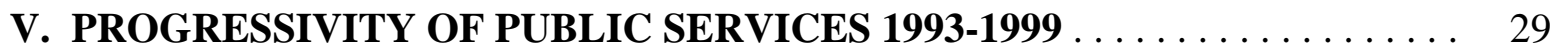

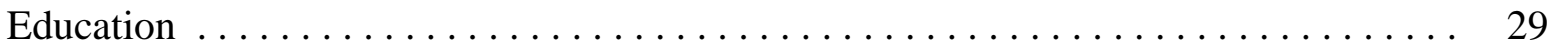

Health Care ....................................... 31

Prenatal Care ........................................... 32

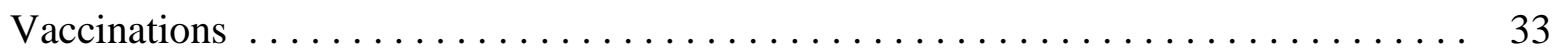

Robustness to Alternative Welfare Rankings of Households ............. 33

Summary: Incidence of Public Social Services in Madagascar . . . . . . . . . . . . . . 34

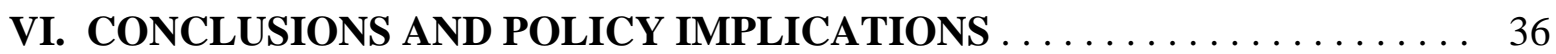

Options for making social spending more progressive $\ldots \ldots \ldots \ldots \ldots \ldots \ldots \ldots . \ldots \ldots$

General lessons from the EPM ........................ 37

Expanding access: removing constraints on the poor's participation ......... 39

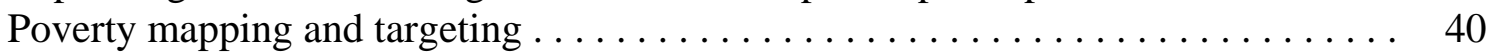

Private sector growth and public spending progressivity $\ldots \ldots \ldots \ldots \ldots \ldots \ldots \ldots, 41$

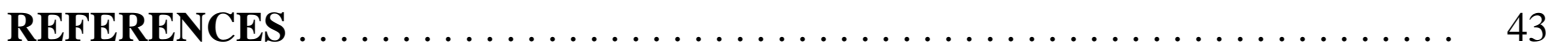




\section{LIST OF TEXT TABLES}

Table 1 - GDP and Poverty Rates for the EPM Survey Years $\ldots \ldots \ldots \ldots \ldots$

Table 2 - Public spending on education, Madagascar 1990-2000 . . . . . . . . . . . . 47

Table 3 - Public spending by level of education, Madagascar 1990-2000 . . . . . . . . 47

Table 4 - Public Health expenditures $1997-99 \ldots \ldots \ldots \ldots \ldots \ldots \ldots \ldots$

Table 5 - Functional composition of recurrent (non-salary) Public health budget

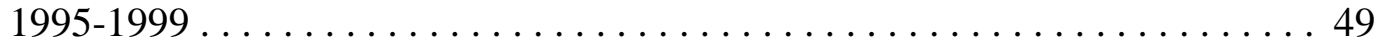

Table 6 - School enrollment rates of children age 6-14 by expenditure quintile 1993/94-1999 . . . . . . . . . . . . . . . . . . . . . . . . . . . . . . . . 50

Table 7 - Rural and urban enrollment rates, 1993/94-1999 _............... 50

Table 8 - School enrollment rates of children age 6-14 by province (Faritany), 1993/94-1999 ................................... 51

Table 9 - Gross and net primary enrollment ratios by expenditure quintile 1993/94-1999 ................................... 52

Table 10 - Gross and net secondary enrollment ratios by expenditure quintile 1993/94-1999 ................................... 53

Table 11 - Gross and net university enrollment ratios by expenditure quintile

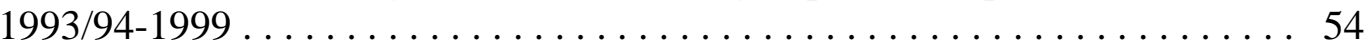

Table 12 - Fees per student 1993/4 and 1999 by school level and type . . . . . . . . . . 55

Table 13 - Household schooling costs per student by school level and type

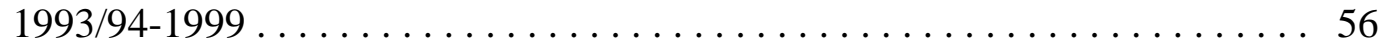

Table 14 - Rates of reported illness/injury and treatment by expenditure quintile

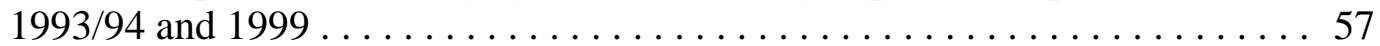

Table 15 - Formal care consultations per capita by provider type and expenditure

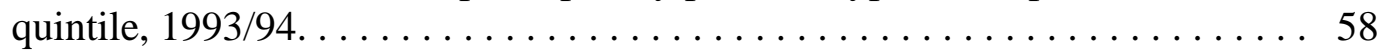

Table 16 - Formal care consultations per capita by provider type and expenditure

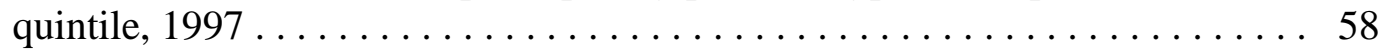

Table 17 - Formal care consultations per capita by provider type and expenditure

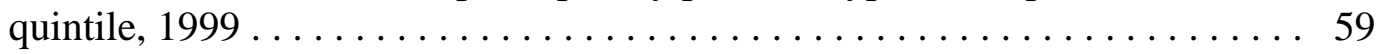

Table 18 - Rural and urban consultations per capita by provider type, 1993/94 . . . . . 60

Table 19 - Rural and urban consultations per capita by provider type, 1997 . . . . . . . 60

Table 20 - Rural and urban consultations per capita by provider type, 1999 . . . . . . . 61

Table 21 - Health care costs per visit by provider and location, 1993/94-1999 . . . . . . . 62

Table 22 - Women 15-49 giving birth in the last 12 months: consultation rates for prenatal care by expenditure quintile $1993 / 94$ and $1999 . \ldots \ldots \ldots \ldots \ldots 63$ 


\section{LIST OF TEXT TABLES continued}

Table 23 - Women 15-49 giving birth in the last 12 months: rural and urban consultation rates for prenatal care 1993/94 and 1999 . . . . . . . . . . . . . . . 64

Table 24 - Women 15-49 giving birth in the last 12 months: consultation rates for formal prenatal care by Faritany, 1993/94 and $1999 \ldots \ldots \ldots \ldots \ldots$. . . . . 65

Table 25 - Children 12-23 months: Rates of completed vaccinations by expenditure

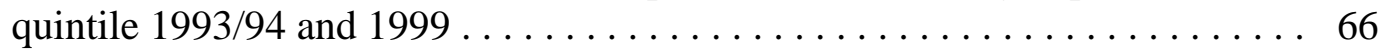

Table 26 - Children 12-23 months: Rural and Urban rates of completed vaccinations,

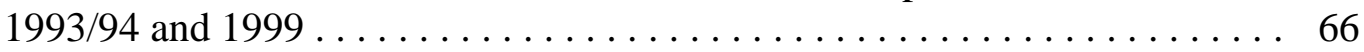

\section{LIST OF TEXT FIGURES}

Figure 1 - Concentration curves and welfare dominance . . . . . . . . . . 67

Figure 2 - Enrollment rates by age: 1993,1997, and $1999 \ldots \ldots \ldots \ldots$. . . . . . 68 


\section{LIST OF APPENDIX TABLES}

Table A1 - Expenditures of MINESEB by level of education/program 1994-1999 _ . . 69

Table A2 - Evolution of school enrollments by school level, 1990-1999 . . . . . . . . 70

Table A3 - Number of teachers by school level and type, 1993-1999 . . . . . . . . . 71

Table A4 - Probit model of current enrollment, rural children age 6-14, 1993/4 -1999... 72

Table A5 - Dominance test results for public education services, 1993/4 . . . . . . 73

Table A6 - Test results for Extended Gini coefficients for public education services, 1993/94. . . . . . . . . . . . . . . . . . . . . . . . . . . . . . . . . 73

Table A7 - Dominance test results for public education services, $1999 \ldots \ldots \ldots \ldots$

Table A8 - Test results for Extended Gini coefficients for public education services,

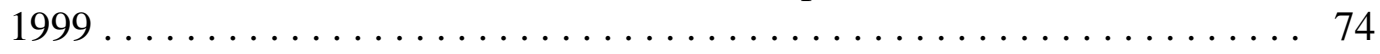

Table A9 - Cross-survey dominance test results for Primary schooling, 1993/4-1999 . . 75

Table A10 - Cross-survey test results for Extended Gini coefficients for Primary

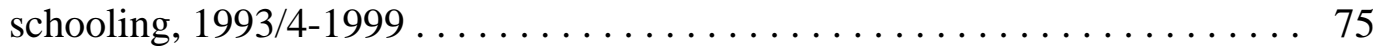

Table A11 - Cross-survey dominance test results for secondary schooling,

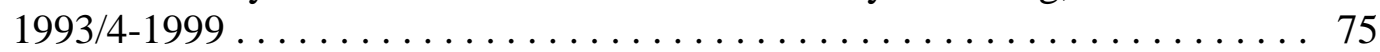

Table A12 - Cross-survey test results for Extended Gini coefficients for secondary

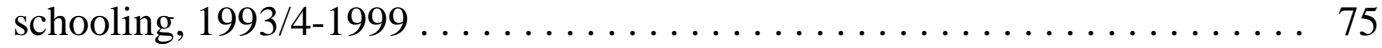

Table A13 - Cross-survey dominance test results for University, 1993/4-1999 _ . . . . 75

Table A14 -Cross-survey test results for Extended Gini coefficients for University,

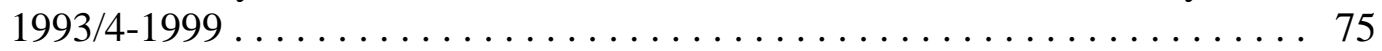

Table A15 - Dominance test results for outpatient public health services, 1993/4 . . . . 76

Table A16 - Test results for Extended Gini coefficients for outpatient public health

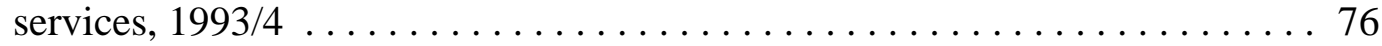

Table A17 - Dominance test results for outpatient public health services, $1997 \ldots$. . . . 76

Table A18 - Test results for Extended Gini coefficients for outpatient public

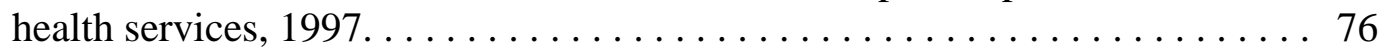

Table A19 - Dominance test results for outpatient public health services, 1999 . . . . . 77

Table A20 - Test results for Extended Gini coefficients for outpatient public health

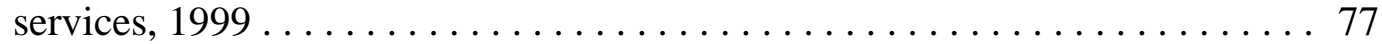

Table A21 - Cross-survey dominance test results for outpatient hospital care,

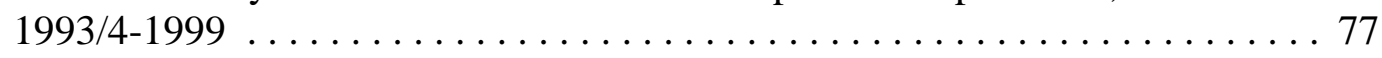

Table A22 - Cross-survey test results for Extended Gini coefficients for outpatient

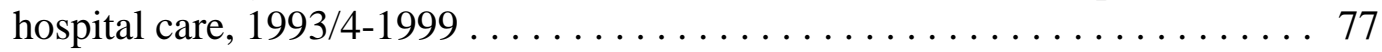

Table A23 - Cross-survey dominance test results for basic care, 1993/4-1999 . . . . . . 78 
Table A24 - Cross-survey test results for Extended Gini coefficients for basic care, 1993/4-1999 . . . . . . . . . . . . . . . . . . . . . . . . . . . . 78

Table A25 - Cross-survey dominance test results for all public care, 1993/4-1999

Table A26 - Cross-survey test results for Extended Gini coefficients for all public

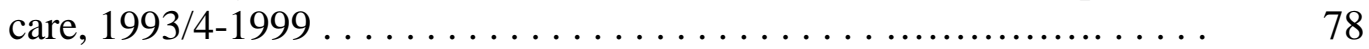

Table A27 - Dominance test results for public pre-natal care, 1993/4 . . . . . . . . . . . . 79

Table A28 - Test results for Extended Gini coefficients for public pre-natal care,

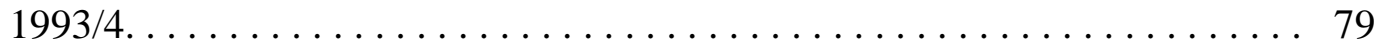

Table A29 - Dominance test results for public prenatal care, $1999 \ldots \ldots \ldots \ldots \ldots$. . . . 80

Table A30 - Test results for Extended Gini coefficients for public prenatal care, 1999. . 80

Table A31 - Cross-survey dominance test results for all public prenatal care, 1993/4-1999

Table A32 - Cross-survey test results for Extended Gini coefficients for all public prenatal care, $1993 / 4-1999 . \ldots \ldots \ldots \ldots \ldots \ldots \ldots \ldots \ldots \ldots \ldots . \ldots \ldots$

Table A33 - Dominance test results for immunizations, 1993/4 . . . . . . . . . . . 82

Table A34 - Test results for Extended Gini coefficients for immunizations, 1993/4 . . . 82

Table A35 - Dominance test results for immunizations, 1999 . . . . . . . . . . . . 82

Table A36 - Test results for Extended Gini coefficients for immunizations, 1999 . . . . 82

Table A37 - Cross-survey dominance test results for 1 or more vaccinations,

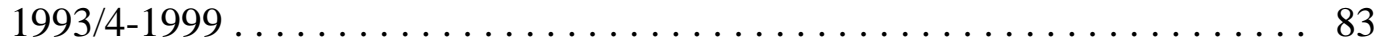

Table A38 - Cross-survey test results for Extended Gini coefficients for 1 or more vaccinations, $1993 / 4-1999 \ldots \ldots \ldots \ldots \ldots \ldots \ldots \ldots \ldots \ldots \ldots \ldots . \ldots \ldots$

Table A39 - Cross-survey dominance test results for all vaccinations, 1993/4-1999 _ . . 83

Table A40 - Cross-survey test results for Extended Gini coefficients for all

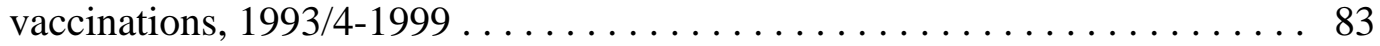




\section{LIST OF APPENDIX FIGURES}

Figure A1 - Concentration curves for public schooling, 1993/94 _... . . . . . . . 84

Figure A2 - Concentration curves for public schooling, 1999............. 85

Figure A3 - Concentration curves for public schooling, 1993/94-1999. . . . . . . . . 86

Figure A4 - Concentration curves for marginal benefits: public primary enrollments, 1993/94-1999 ................................... 87

Figure A5 - Concentration curves for out-patient public health services, 1993/94 _ . . . 88

Figure A6 - Concentration curves for out-patient public health services, 1997 . . . . . 89

Figure A7 - Concentration curves for out-patient public health services, 1999 . . . . . 90

Figure A8 - Concentration curves for out-patient public health services, 1993/94-1999. . 91

Figure A9 - Concentration curves for public prenatal care, 1993/94 _ . . . . . . . . . 92

Figure A10 - Concentration curves for public prenatal care, 1999 . . . . . . . . . . . 93

Figure A11 - Concentration curves for public prenatal care, 1993/94 -1999 . . . . . . 94

Figure A12 - Concentration curves for vaccinations (children 12-23 months),

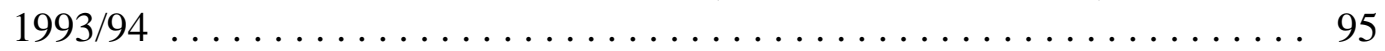

Figure A13 - Concentration curves for vaccinations (children 12-23 months), 1999 . . . 96

Figure A14 - Concentration curves for vaccinations (children 12-23 months),

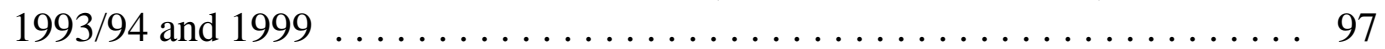

Figure A15 - Concentration curves for marginal benefits: vaccinations,

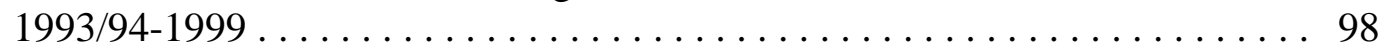




\section{ABBREVIATIONS AND ACRONYMS}

$\begin{array}{ll}\text { BEPC } & \text { Brevet d'Enseignement du Premier Cycle } \\ \text { CEPE } & \text { Certificat d'Etudes Primaires Elémentaires (Primary Level Diploma) } \\ \text { CFNPP } & \text { Cornell Food and Nutrition Policy Program } \\ \text { CSSP } & \text { Centres de Soins de Santé Primaire } \\ \text { EPM } & \text { Enquête Permanente auprès des Ménages (Permanent Household Survey) } \\ \text { FMG } & \text { Francs Malagashe (Malagasy Francs) } \\ \text { FOFIFA } & \text { Ministere de la Recherche Appliquee au Developpement (French translation) ) } \\ \text { HIPC } & \text { Highly Indebted Poor Countries } \\ \text { IMF } & \text { International Monetary Fund } \\ \text { INSTAT } & \text { Institute National de la Statistique (National Statistics Institute) } \\ \text { MinESEB } & \text { Ministère de l'Enseignement Secondaire et de l'Education de Base } \\ \text { MinESUP } & \text { Ministère de l'Enseignement Supérieure } \\ \text { USAID } & \text { United States Agency for International Development }\end{array}$

\section{CURRENCY EQUIVALENT (1999)}

US $\$ 1.00=6283 \mathrm{FMG}$ 


\section{INTRODUCTION}

It is generally agreed that governments in poor countries should heavily subsidize the provision of education and health services, both of which are understood to be essential for economic growth and poverty reduction. ${ }^{1}$ This reflects both efficiency considerations, because of positive externalities to improved education and health status, and equity ones, because many of the poor in developing countries would not be able to pay privately for social services that could break the intergenerational transmission of poverty. Also from an equity standpoint, governments in poor countries are usually unable to mitigate income inequalities though transfer payment systems. In these contexts, directing social service spending to the poor offers a politically and administratively feasible means of redistributing welfare (Younger 1999). Since public resources are usually very limited in poor countries, it is important to assess whether they are being spent in ways that accord with the objectives of increasing economic efficiency and growth and improving equity.

For Africa, benefit incidence studies from a number of countries have shown that social spending in education and health does serve to redistribute welfare. However, the magnitude of the redistribution is modest (Sahn and Younger 2000; Castro-Leal et. al. 1999), and even this degree of progressivity has much to do with the generally highly unequal distribution of incomes against which public subsidies are compared. In fact, while many services are distributed more equally than incomes, they still accrue disproportionately to the well-off in absolute terms.

What is generally lacking in this literature, especially for Africa, are dynamic analyses, that is, studies of how the incidence of these services has changed over time. Given that the use of education and (children's) health services represent investments in human capital, such changes may have highly significant implications for future levels of poverty and inequality. We provide such an analysis in this paper for Madagascar for the decade of the 90s, using three rounds of comparable, nation-wide household surveys, from 1993, 1997, and 1999. Madagascar during the 1990s provides an interesting setting to examine these dynamics. Although this period was for the most part one of stagnant incomes, growth did begin to pick up, especially in urban areas, after 1997. Further, the decade witnessed significant changes in social sector budgets and organization. In health, the government undertook a major overhaul of the public health system beginning in the mid-1990s. This included a decentralization of both resources and decision-making to local health districts, and it also involved a major expansion of cost recovery (fee increases) at all public facilities. It is important to understand how this has affected program coverage (utilization) as well as its progressivity. The impacts on progressivity are not clear a priori. On the one hand, decentralization should favor the poor by shifting resources and control from urban centers to rural areas, which are poorer. On the other hand, a good deal of evidence from developing countries indicates that poor households are more sensitive to prices of health services (Strauss and Thomas 1995), so we might anticipate, all things equal, that fee increases would lead to a less pro-poor pattern of utilization of health services.

\footnotetext{
${ }^{1}$ Strauss and Thomas (1995) critically review developing country evidence of the effects of better schooling and health on productivity. For Madagascar specifically, Glick (1999) looks at the effects of education on the earnings of urban wage employees.
} 
In education, a similar plan for decentralization has not proceeded as far, but there have been significant changes in budgetary allocations to education. Public expenditures on education rose sharply starting in the mid-90s after a number of years of steady decline. Official statistics indicate a significant rise in primary enrollments over the same period (World Bank 2002). It is important for policymakers to understand how this expansion of benefits has affected the progressivity of expenditures. Have the new benefits been targeted to the poor, or instead were they, in the terminology of Lanjouw and Ravallion (1999), “captured” by the well-off?

To address these questions, we employ a methodology for analyzing benefit incidence that uses standard tools, Lorenz curves and benefit concentration curves, supplemented by statistical dominance tests based on estimators that have appeared recently in the literature. We use these methods to compare, and test for differences in, the progressivity of different forms of education and health expenditures both at a given point in time and across survey years. Standard benefit incidence is a very useful tool for examining how tax or subsidy policy alters the distribution of welfare in the population. However, schooling and many types of health services are targeted at specific groups in the population-e.g., school age children, pregnant women, and infants. Therefore we also apply our methodological tools to analyze the distribution of program 'coverage' of the target population across the income distribution. This sometimes leads to different inferences about equity in the distribution of benefits than the standard approach.

The analysis makes use primarily of three nationally and regionally representative household surveys collected by the Malagasy national statistical office (Direction des Statistiques des Ménages, Institut National de la Statistics) in 1993/94, 1997 and 1999. The first survey, Enquete Permanente Aupres des Menages, collected from April 1993 to April 1994, was a multi-purpose survey of 4,508 households similar in design to the World Bank's Living Standard Measurement Study (LSMS) surveys conducted in other African countries. The 1997 and 1999 surveys, Enquete Prioritaire Aupres des Menages, were three-month priority surveys of 6,350 and 5,120 households, respectively. ${ }^{2}$ We will refer to the set of three surveys by their common acronym EPM. The two later surveys were not as broad in scope or as detailed as the first survey, but nevertheless collected detailed information on household expenditures and the utilization of schooling and health services. The richness of the data sets allows us to analyze different levels of education (primary, secondary, university), hospital and basic health care, public prenatal services, and childhood vaccinations. The questions on services were usually similar across surveys, enhancing our ability to make reliable comparisons over time.

The report is organized as follows. In the next section we describe the methodological approach of the study. Section III presents background information on economic trends and poverty in Madagascar as well as institutional and policy backgrounds on the education and health sectors. In section IV we present information on trends in program coverage over the period 1993-99. We discuss patterns of coverage by income (expenditure) quintile as well as by region and gender. This section also considers trends in the evolution of private education and health services. Section V presents the results of the benefit incidence analysis and assesses whether public expenditures on services have become more or less progressive since the early 1990s. In section VI we summarize the results of the study. We also draw a number of policy

\footnotetext{
${ }^{2}$ The main findings of each survey are presented in Institut National de la Statistique (1995,1999,2000).
} 
implications of the results, in particular with regard to how social spending could be more effectively targeted to the poor.

\section{METHODOLOGY}

\section{PROGRAM COVERAGE, UTILIZATION OF SERVICES, AND BENEFIT INCIDENCE}

Benefit incidence analysis (BIA) considers the distribution of public subsidies for services among different groups in the population, in particular, among different income categories. A primary objective of BIA, which we discuss in detail below, is to assess whether public spending is progressive, that is, whether it improves the distribution of welfare, proxied by household income or expenditures. Or more pointedly, whether this spending serves to redistribute resources to the poor. However, this study is not concerned solely with benefit incidence as normally defined. Therefore, before discussing our methodology for BIA, we explain why our scope needs to be broader.

One reason is that we are also concerned with how successful a government program is in reaching its intended beneficiaries, or the "target population”. For example, for primary school education, this population would consist of primary school-age children. For prenatal care, it would be pregnant women, and so on. ${ }^{3}$ Following the terminology used in Younger (2000) and others, we will refer to rates of utilization among the target population as "program coverage" or simply "coverage". This is distinguished from benefit incidence analysis, which considers the distribution of a subsidy over the entire population. ${ }^{4}$ In each of the examples just given, the target population is likely to be somewhat concentrated among the poorer expenditure quintiles, because poor families tend to have more children. Hence comparing coverage rates for poor and rich quintiles will yield different results than comparing benefits per person along the lines of BIA, a point we consider further below. The initial results sections of this study therefore present coverage rates for each of the social services considered in the report: primary enrollment rates for primary age children, rates of prenatal consultations for pregnant women, etc. We do this by expenditure quintile as well as by gender and location.

Second, and related to the foregoing, policymakers are concerned not only with how many (and what kind of) people utilize public education and health services, but education and health services generally, that is, private or publicly provided services. Underlying this perspective is the realization that both schooling and health care have important positive externalities. For example, better schooling confers not only private benefits (higher labor incomes) to the individual receiving it, but also has a range of social benefits, such as improved

\footnotetext{
${ }^{3}$ The "target population" will be assumed to be all potential beneficiaries, for example, for prenatal care, all pregnant women. In fact, for either equity or efficiency reasons, for certain programs the government may try to target specific groups, such as rural residents or the urban poor. The broad categories of services we will consider do not appear to have been created to target particular groups along these lines, but we will nevertheless present participation rates by expenditure quintile.

${ }^{4}$ To avoid ambiguity in terminology, we should point our that the term "coverage" is sometimes used to refer to a particular way of valuing a benefit, namely using a binary indicator for utilization of the service, whether measured per capita or per member of the target population. In our analysis, "coverage" is taken to refer strictly to rates of utlization among the target population. The issue of valuation of benefits is taken up below.
} 
child nutrition from better educated mothers and more informed political participation. Analogous cases in health care are easy to find: the example noted in the Introduction regarding treating an individual for a contagious disease is one. A somewhat different perspective considers education and health to be "merit goods"-goods that are intrinsically desirable. The main objective from either of these angles would be to insure an adequate level and efficient (from a social viewpoint) allocation of these services. The source of the services, and whether government spending on them is redistributive (the focus of BIA), would be of lesser interest, except insofar as there are quality differences between private and public providers. Reflecting these concerns, this study examines trends in the use of private, public, and overall (private or public) education and health services. ${ }^{5}$

\section{BENEFIT INCIDENCE METHODOLOGY}

We implement a standard methodology for analyzing the incidence of public expenditures on services. This involves, first, determining the value of the benefit. For most publicly provided services, the cost actually incurred by households is not a useful indicator of its value, given that these services are largely subsidized. Instead, benefit incidence studies initially relied on government budget or expenditure data to derive unit subsidies in education and health care - expenditures per primary student, expenditure per visit to a health clinic, etc. However, using the government's unit costs of provision to value a benefit is problematic for several reasons. The actual or perceived benefit to the user of a free or heavily subsidized service need not be closely related to the cost of providing the service. In addition, the cost data used in this method are often hard to obtain, potentially very unreliable, and frequently inadequately disaggregated by region or type of service. A more ambitious valuation method is to estimate demand functions for different services and use the parameters and data to calculate the value to each household of the subsidy (the compensating variation). As it is based on consumer price responses, this approach in principle yields the most accurate measure of the private benefit to households of a service. It is quite data intensive, however, in particular requiring accurate information on costs faced by households. Further the discrete-choice estimations methods, hence also the estimates of compensating variation, are generally sensitive to functional form specification. ${ }^{6}$

Instead of these approaches, we use the simpler (but frequently applied) method of representing the benefit with a binary $(0,1)$ indicator for whether a particular public service is used. The analysis then essentially compares the sum of the value of the indicator for all individuals in a socioeconomic group with that for other groups. A disadvantage of this binary approach is that, since the valuation is not in money metric terms, we are unable to sum these indicators for different services to get the value of the total benefit from all services, or all

\footnotetext{
${ }^{5}$ To gain perspective on this, note that if education and health were not characterized by positive externalities and did not qualify as merit goods, the demand for private education and health services would be of no more interest than the demand for any other privately provided good or service. The utilization of public providers by welfare group would still be of interest as it measures the incidence of a public subsidy, that is, the redistributive impact of public spending on the service.

${ }^{6}$ Glick et. al. (2000) do estimate discrete choice models for choice of primary school and health care provider using the 1993 EPM household and community surveys. They do not attempt to estimate compensating variations, but rather simulate the effects of various policies, including changes in the subsidy (price changes) on school enrollments and health care consultations.
} 
services of a given type, to an individual. In addition, it imposes the assumption that the benefit is the same for all recipients. On the other hand, it is very simple to implement since we only require household survey data on enrollments and health care consultations, and it avoids reliance on doubtful unit cost data. Despite its simplicity, the binary method has been shown to yield results very similar to those that employ the cost of provision method. ${ }^{7}$

The purpose of BIA, as noted, is to compare benefits across socioeconomic groups in the population. Typically this refers to different percentiles of the distribution of income or more broadly, welfare. Hence the next step is to rank individuals in the population from poorest to richest. In keeping with the majority of previous studies for developing countries, we use household expenditures rather than income as our measure of welfare, as the former is less subject to transitory fluctuations and measurement error than the latter. The variable we are interested in conceptually is each individual's welfare, but expenditures are only available at the household level. To derive an approximation of individual welfare, we divide expenditures by household size, again following standard practice. This simple per capita scaling ignores possible economies of scale in consumption whereby larger households are at an advantage, all things equal. Since different scalings can lead to different rankings of households and individuals from poor to rich (hence also affect conclusions about the progressivity of public spending), we experiment with alternative scalings of household expenditure to assess the robustness of our findings.

\section{Progressivity and dominance testing}

The final step is to compare public services with regard to their progressivity, that is, how well targeted they are to the poor. This can be done graphically using benefit concentration curves. To illustrate, Figure 1 (previewing some of our results) shows the case of public primary and secondary schooling using the 1999 EPM sample. The cumulative shares of individuals in the population, ranked by per capita household expenditures, are shown on the x-axis, while the $y$-axis shows the cumulative shares of the benefits, or simply, the cumulative share of enrollments, for public primary and secondary schooling; the latter form the benefit concentration curves. ${ }^{8}$ Also depicted is the Lorenz curve for expenditures that shows the cumulative share of expenditures (or welfare) in the population. The degree of convexity of the Lorenz curve indicates that the expenditure distribution is quite unequal.

Two measures of progressivity can be defined. The more standard definition involves comparing the distribution of the benefit to the distribution of welfare (expenditures). Hence if

\footnotetext{
${ }^{7}$ See Younger (1999) and Sahn and Younger (2000). The latter study applies both methods to Madagascar (using the first round of the EPM data) and confirms the similarity of the approaches.

${ }^{8}$ Formally, let B represent the sum of the benefits received by the entire population (e.g., total primary enrollments) and $\mathrm{B}_{i}$ represent benefits received by the population up to the $i$ th percentile of the expenditure distribution. The benefit concentration curve shows the share of the benefit going the population up to ith percentile of the expenditure distribution, or $\mathrm{B}_{i} / \mathrm{B}$.

To some readers a more familiar way of looking at benefit incidence may be a comparison of the benefit shares of different (e.g., lowest and highest) quintiles. Quintile shares are usually presented in tabular form but can also be read off the concentration curves. The share going to quintile $j$ is the cumulative share though quintile $j$ (the vertical distance to the curve from the $\mathrm{X}$-axis at $\mathrm{j}$ ) minus the cumulative share through quintle $j$ - 1 (the distance to the curve at $\mathrm{j}-1$ ). Thus, for example, the share of primary enrollments going to the second quintile is the height of the primary concentration curve at 0.4 on the $\mathrm{X}$-axis minus its height at 0.2 .
} 
the benefit concentration curve is at all points above the curve for household expenditures - that is, if it "dominates" the expenditure curve-the benefit is said to be progressive. For 1999 this is the case both for secondary and (far more strongly) primary school. The school subsidies are distributed more equally than the initial welfare or expenditures, so they serve to make the distribution of welfare more equal. This conforms to the definition of progressivity used in the public finance literature when analyzing a tax or subsidy. ${ }^{9}$

The second measure is stricter and compares the distribution of the benefits to the distribution, not of expenditures, but of the population. For a benefit to be deemed progressive by this definition, poor people would have to receive a disproportionate share of the benefit. For secondary schooling in 1999, this is clearly not the case. For example, say we define the poor to be the poorest two-fifths of the population. While the poor's share of secondary schooling benefits (measured by the vertical distance from 0.40 on the $\mathrm{x}$-axis to the secondary school curve) exceeds its share of expenditure (measured by the vertical distance to the Lorenz curve), it is well below its share of the population, given by the 45-degree line. In other words, less than 40 percent of the secondary enrollments go to the poorest 40 percent of the population.

Following the terminology used by Sahn and Younger (2000) we will call a benefit "per capita progressive” if the benefit curve lies above (dominates) the 45-degree line. This criterion insures that the "poor", no matter where the poverty line is drawn, receive a disproportionate share of the benefit. We will label as "expenditure progressive", or simply "progressive" (since this accords with the standard definition in the fiscal incidence literature), a benefit whose curve lies above the expenditure line. In addition to comparing the distributions of the benefits for each service to these two benchmarks, we also want to rank different services according to their progressivity, as noted. A given subsidy is said to dominate another if its concentration curve is everywhere above the concentration curve for the other. The implications of dominance, or more precisely, welfare dominance, are established formally by Yitzhaki and Slemrod (1991). They prove that for any social welfare function that favors an equitable distribution of income, marginally raising the subsidy of $\mathrm{x}$ while reducing that of $\mathrm{y}$ will improve social welfare if $\mathrm{x}$ 's concentration curve is everywhere above y's. This has obvious relevance for the allocation of public resources among different services; if the government is concerned to improve equity in public spending, it will want (other things being equal) to shift resources to those services that are the most progressive.

Comparing concentration curves for various services to the 45-degree line, to the expenditure distribution, and to each other should go beyond simple visual inspection of graphs. These curves are generated from samples, not from the entire population. Hence they are subject to sampling error, and differences in the curves should be evaluated statistically. A substantial literature has developed in recent years on statistical approaches to dominance testing. These methods test whether the differences in the ordinates of two curves are statistically significant at a given number of points (abscissa). Choosing the number of such points is arbitrary, but a

\footnotetext{
${ }^{9}$ Actually, the textbook definition of progressivity, developed for analysis of taxation, is stricter than this. It requires that the marginal rate of taxation be rising with income level (be greater than the average tax rate at all points in the income distribution), or in the subsidy context, that the marginal subsidy rate be falling with income. Since for dominance we are comparing cumulative subsidies to cumulative income or expenditures, this need not always hold. We thank Steve Younger for pointing this out to us.
} 
stronger test is one that tests for differences at many points. We conduct the tests at 19 evenly spaced ordinates on the X-axis, from 0.05 to 0.95 , and reject the null of equality (no dominance) only if all ordinate pairs are significantly different (in the correct direction) ${ }^{10}$ Conducting these tests requires that we estimate the covariance matrix of the ordinate estimates; we use the estimator proposed by Davidson and Duclos (1997). This estimator has the advantage that it allows for the possible statistical dependence of the two curves. This is a factor when we compare curves drawn from the same sample, as will happen when we compare different services for a given survey year.

Rejection of the null in favor of dominance is robust in these tests in that one can conclude for any social welfare function that favors progressivity that marginal changes in subsidies of the type described above will improve social welfare. However, this robustness comes at a price: it tends to be hard to reject the null, leading to few definitive statistical conclusions that one type of service is more progressive than others. As a result, it may be difficult to say something useful about government spending priorities. Therefore some authors also compare distributions using a less demanding cardinal measure. The most common of these in the Gini coefficient, which in this context is essentially a measure of the correlation of benefit level and ranking in the expenditure distribution. The essential difference from the previous ordinal approach based on Lorenz dominance is that here we are adopting a specific social welfare function (one of any number of potential functions that are equality preferring), represented by the Gini; results about the relative progressivity of two distributions, or two services, based on Gini comparisons need not hold for other equality preferring social welfare functions.

However, a somewhat greater degree of generality can be achieved by using the extended Gini coefficient. Different values of the "parameter of inequality aversion” (Duclos 1999) in the extended Gini formula change the weight given to each point in the expenditure or welfare distribution; by comparing results for progressively larger values of this parameter we can get an idea of how more progressive social welfare functions would rank distributions. ${ }^{11}$ Therefore we also compare the distributions of different services (and of services with the 45-degree line and Lorenz curve benchmarks) using the extended Gini, allowing the inequality aversion parameter to take values ranging from 1.01 to $4.0 .^{12}$ We do this in increments of 0.5 , yielding 7 pairs with

\footnotetext{
${ }^{10}$ This is the same criterion used in similar studies by See Younger (2000) and Sahn and Younger (2000). A less demanding criterion is to reject the null if at least one pair or ordinates differs statistically and the curves do not cross at any other point. However, the statistical relevance of this test is questionable (Howe 1996).

11 The extended Gini coefficient for per capita expenditures is defined as:
}

$$
\mathrm{G}(\mathrm{v})=-\mathrm{v} * \operatorname{Cov}\left\{\mathrm{y},[1-\mathrm{F}(\mathrm{y})]^{(\mathrm{v}-1)}\right\} / \overline{\mathrm{y}}, \quad \mathrm{v}>1
$$

where y measures the individuals' welfare (proxied by expenditures per capita); $F(y)$ is the cumulative density function of the welfare ordering; $\bar{y}$ is mean welfare; and $v$ is the inequality aversion parameter that affects the weighting of each point on the Lorenz curve. G(2) yields the traditional Gini coefficient, while values of v greater than 2 yield measures that give an even greater weight to poorer individuals. Since we are concerned with the distribution of the benefits of social services, we replace y and $\bar{y}$ (but not its distribution $F(y)$ ) in this expression with the value of benefits of a service, to get an analogous measure of that service's concentration. By calculating the extended Gini coefficient for increasing values of v, we can gain a sense of how more progressive (yet still cardinal) social welfare functions value a given public service.

12 The upper limit of 4.0 follows Duclos' (2000) suggestion based on experiments with Canadian data. 
which to compare the two benefits. Statistically, one benefit is deemed more progressive than another if the Gini is significantly lower for the former at each of these values.

\section{LIMITATIONS OF BENEFIT INCIDENCE ANALYSIS}

While it is a valuable tool for assessing the distributional impacts of social spending, BIA is subject to a number of well-known limitations. One, already mentioned, is the inherent difficulty of valuing benefits. Equally important, BIA is static: it only presents a picture of who currently benefits from a given service, that is, how current spending on social services affects the distribution of welfare. We cannot infer what would happen to the distribution of benefits and of welfare as a result of changes in public expenditures on the services. That is, for all but very small changes in the scope of these programs, the marginal incidence will likely be different from the average incidence, which is what BIA shows. The reasons for this have to do with both supply factors and demand factors (Van de Walle 1998). On the supply side, the distribution of new benefits depends on the nature of the increase in the spending on a service. For example, for education, the government can reduce costs (increase the subsidy) to households across the board, it can construct new schools in rural areas, it can raise school quality in existing schools, etc. Enrollments or educational outcomes of the poor will be more strongly affected by some of these policies than others. On the demand side, the responsiveness of households to specific policies in education and health sectors (particularly changes in cost) may vary by income level. ${ }^{13}$

Because we have multiple years of survey data, we are able to deal, at least in part, with the criticism that BIA is static. We can track changes in benefit incidence over time. This is in fact a key objective - to see if the targeting of crucial services to the poor has improved or worsened. In addition to observing how the incidences of different services have changed, we can also calculate the overall change in benefits and the share of different quintiles in the change - the marginal incidence. ${ }^{14}$ Essentially these exercises portray the recent historical record; they are not counterfactual policy simulations in which the effects of specific policies (e.g., improving one dimension of quality), holding other factors equal, are assessed. However, where possible we try to relate observed changes in the distribution of benefits to specifics of education and health sector policy over the period.

A perhaps more fundamental criticism of the standard BI approach when it comes to education and health services concerns its treatment of these services as equivalent to transfers that augment current income or consumption. This is quite problematic conceptually, particularly for education. While schooling of children may bring some direct current utility to parents, it is better characterized as an investment in an asset (human capital) that yields future returns through, among other benefits, higher labor market incomes. For this to be equivalent to a current benefit to household incomes requires a number of less than appealing assumptions, including that capital markets allow parents to borrow against the future returns to education of

\footnotetext{
${ }^{13}$ One way around this limitation is through demand estimation. Responsiveness to changes in specific supply characteristics such as price, quality, or distance are estimated econometrically, which permits simulation of the impacts of changes in these variables. An earlier study (Glick et. al. 2000) conducted such an analysis using the 1993 EPM.

${ }^{14}$ Note a distinction is being made here between the change in average incidence and the marginal incidence. We explain these concepts in more detail in Section V.
} 
their children (Bourguignon et. al. 2002). Instead, one might prefer to recognize the intergenerational (and intertemporal) nature of education investments and view the gains from education subsidies as accruing primarily to the direct recipients when they become adults. This implies a concern with the future distribution of welfare among those who are now children of school age; hence is it the distribution of schooling benefits among this subpopulation that is of interest from this perspective.

Neither measure of progressivity defined above considers this: both expenditure and per capita progressivity are concerned with the distribution of benefits over the entire population, of school-age children and others. Instead, it is necessary to look at education benefits specifically among children in different income groups, i.e., a per child rather than per capita approach. ${ }^{15} \mathrm{~A}$ similar reasoning applies to many types of health services that represent investments in children's human capital, for example, childhood immunizations and prenatal care. An appealing aspect of this approach is that we are really examining, not the distribution of future incomes, which are in any case unknowable as well as endogenous to individual preferences, but of future capabilities in the sense of Sen (1985), which are a function of education and health. ${ }^{16}$

A different path that also leads to the per child focus is to frame the analysis in terms of "needs." (see for example, Castro-Leal et al. 1999). From this perspective, the allocation of benefits across the income distribution should be compared to the distribution of the need for the service. In the example of schooling, needs are the number of children who must be educated. Family size is usually inversely correlated with welfare level, meaning there tend to be disproportionate numbers of children in lower income quantiles; consequently the need for education services is greater among these quantiles. Given these typical demographic patterns, it is possible for public subsidies or enrollments per capita to be equally distributed across the income distribution--or even disproportionately allocated to poorer income quantiles--while enrollments per child remain significantly lower among the poor. In this situation one might hesitate to conclude that the school subsidy is well targeted to the poor, or at least to the poor among the population of interest, which is school-age children. The needs perspective extends easily to health care. For example, Van Doorslaer et. al. (1993) compare income quantile shares of the society's aggregate "need" for curative health care services, based on indicators of ill health, with shares of the total public health subsidy.

From this perspective one would be likely to argue that that an equitable distribution of benefits would be one in which different socioeconomic groups receive benefits in proportion, not to their population (or to their income) but rather to their needs for the service. ${ }^{17}$ This

${ }^{15}$ Selden and Wasylenko (1995) is an example of this approach. Note that one could instead just consider inequality in schooling among children per se, rather than examining how these inequalities are associated with children's placement in the income distribution; for example, Thomas et al. (2001) calculate Gini coefficients for education for the general population. However, comparing per child enrollment across the income distribution has the advantage of providing some insight into the intergenerational transmission of poverty and inequality, as it relates income of the child's parents (i.e., ranking of the current household in the expenditure distribution) to the child's capacity for income generation in the future.

${ }^{16}$ Bourguignon (2002) provides an illuminating discussion of the advantages of focusing on the distribution of capabilities-enhancing assets or endowments, including human capital assets such as health and education, rather than on the distribution of incomes.

${ }^{17}$ Actually, this is one of several possible definitions of equity using this general framework; see Cuyler and Wagstaff (1993). As this literature has recognized, “needs” are often endogenous to behavior and preferences, 
criterion is obviously different — and in many cases, less likely to be met — than progressivity in either of the two senses discussed above.

We will evaluate benefits according to the per child (or more generally, per member of the target population) criterion using the same graphical and statistical methods discussed above. For example, Figure 2 includes a curve representing the cumulative share of the target population-primary school-age children in this example, defined broadly to be children age 6 to 14. This curve lies everywhere above the 45-degree line, reflecting the fact that, due to differences in fertility, poorer quintiles account for a disproportionate share of school-age children; for similar reasons, target population curves will have this shape for prenatal and vaccination services. Although the concentration curve for primary school lies well above the expenditure curve and appears as well to be per capita progressive (it lies above the 45-degree line), this pro-poor bias essentially disappears when we look through a per child lens: the curves representing the cumulative shares of primary enrollment and of primary age children are very close to each other, meaning that public primary benefits per child are not different for lower and higher quintiles. Therefore the public education subsidy, while not inequitable, is not particularly well targeted to poor children. Note that these comparisons of benefits to target population essentially bring us back to the notion of program coverage: that is, the degree to which a government program is successful in reaching its intended beneficiaries. In our analysis, however, we focus also on differences in coverage by income quantile. With regard to dominance testing, we can apply the same statistical tests described above to determine if the benefit curve dominates the target population curve. ${ }^{18}$

An alternative, non-graphical, means of considering this idea is to calculate for each expenditure quantile the ratio of its benefit share to its share of the target (e.g., school-age) population. In the case of schooling we can write the benefit share for the jth quintile as $E_{j} / E$, where $E_{j}$ equals total enrollments for quintile $j$ and $E$ is the sum of enrollments over all quintiles, and the quintile's target population share as $\mathrm{N}_{\mathrm{j}} / \mathrm{N}$, where $\mathrm{N}$ is the total number of school-age children. The ratio of benefit share to target population share (share of 'needs') is then $\frac{E_{j} / E}{N_{j} / N}$.

This ratio equals one if the portion of the benefits accounted for by the quintile is the same as its share of the target population; it is less than (greater than) one if the quintile's share of enrollments is less then (greater than) its the target population share. The ratio can be written equivalently as $\frac{E_{j} / N_{j}}{E / N}$, which is just the quintile-specific child enrollment rate over the overall enrollment rate. Hence we can determine the relation of benefit share to target population share simply by comparing a quintile's coverage rate (per child enrollments) to the mean rate for the

so there is the possibility that this standard of equity in effect provides more benefits to those with 'bad' behavior (e.g., unhealthy lifestyles that can lead to need for care). This is not the place for a detailed discussion of this issue, but we may note that it is a problem as well with standard benefit incidence, since the rankings of the population is based on income or expenditure, which itself is to an extent an outcome of choice (see Bourguignon 2002).

${ }^{18}$ If the benefits are enrollments, this amounts to testing if per child public enrollment rates are positively correlated with ranking in the per capita expenditure distribution. 
entire target population, using the tables on coverage. ${ }^{19}$ Note that, like the graphical analysis, this measure is not comparing absolute benefit levels to needs, which would be just $E_{j} / N_{j}$. Instead, it standardizes on the overall population relation of benefits and needs to permit comparisons across quantiles.

\section{HISTORICAL AND INSTITUTIONAL BACKGROUND}

\section{Economic stagnation and poverty in Madagascar}

Despite being endowed with a rich natural resource base, Madagascar remains one of the poorest countries in the world. Per capita GDP in 1999 was only 154,000 FMG (about US \$235), with some 71 percent of the population estimated to be in poverty and 62 percent estimated to be in extreme poverty (Razafindravonona et. al. 2001). ${ }^{20}$ Persistent poverty reflects the very poor performance of the economy since 1970, which in turn largely reflects the strongly nationalist economic policies of the 1970s and 80s. Emphasizing self-sufficiency and state control of the economy, these policies included nationalization of foreign-owned firms and limitations on foreign investment, overvaluation of the exchange rate combined with trade controls and extensive foreign borrowing, price controls favoring public enterprises, and (in the late 1970s) very high levels of investment in public enterprises yielding very low returns. The inefficiencies generated by these policies, exacerbated by a worsening of Madagascar's external terms of trade after 1978 and a growing burden of external debt, led to negative growth rates of real GDP: from 1971 to 1987 real GDP per capita fell from FMG 254,000 to FMG 171,000 in 1984 prices.

In the mid-1980s the government began to reverse the policies of the previous decade and a half. Among the policies now pursued were exchange rate devaluation, price and trade liberalization, and the restructuring of public enterprises. Together with the establishment of export processing zones, devaluation significantly raised foreign and domestic investment and manufacturing exports between 1988 and 1991. However, this progress, which coincided with the first increases in per capita GDP seen in almost two decades, was interrupted by political strife during 1991-93. This resulted in significant political reform but delayed the economic

\footnotetext{
${ }^{19}$ We can interpret the curves in Fig. 1 in terms of these ratios if we consider them in cumulative terms. Denote the cumulative share of enrollment benefits to the $j$ th quintile as $E_{j}^{c} / E$, where $E_{j}^{c}$ is the total enrollments for children up to $\mathrm{j}$ and $\mathrm{E}$ represents all enrollments, and the target population share up to $\mathrm{j}$ as $\mathrm{N}_{\mathrm{j}} / \mathrm{N}$, where $\mathrm{N}$ is the total number of school-age children up to $\mathrm{j}$. The ratio of benefit share to target population share through $\mathrm{j}$, or $\frac{E_{j}^{c} / E}{N_{j}^{c} / N}$, is shown on the graph as ratio of the height of the schooling concentration curve at $j$ to the height of the school-age child curve. Since the ratio can be written equivalently as $\frac{E_{j}^{c} / N_{j}^{c}}{E / N}$, it shows the per child enrollment rate (or "coverage rate”) up to j, divided by the overall enrollment rate.

${ }^{20}$ Following World Bank (1996), for their analysis Razafindravonona et. al. (2001) define as poor those whose household expenditures are not sufficient to purchase both a reference 2,100 calorie per person daily food basket and minimum non-food needs. The extreme poor are those whose total expenditures are insufficient to purchase just the minimum food basket.
} 
recovery. While sharply depreciating the exchange rate in 1994-95, the leaders of the new populist government also expanded public spending through money creation, resulting in very high levels of inflation in 1994 and 1995. Real per capita GDP resumed its decline during this period.

In 1996, in the context of new agreements with the World Bank and IMF, further economic reforms were initiated. The new economic policy was explicitly directed at poverty reduction, as indicated by its official title "Strategie Nationale de Lutte Contre la Pauvreté". With exchange rate liberalization, tightening of the money supply, and other changes, the economic picture has improved and there is evidence of an incipient turnaround in Madagascar's fortunes. GDP growth during 1997-99 was at about 4 percent per year, faster than the growth of the population (about 3 per cent annually), resulting in a small improvement in per capita income (Razafindravonona et. al. 2001); see Table 1. However, real GDP per capita remains marginally lower than it was in the early 1990s, and much lower than two decades ago.

The poverty rate calculations of Razafindravonona et. al.(2001) using the EPM surveys are consistent with this story. Table 1 reproduces data on poverty headcount ratios from their report. The national averages indicate an increase in poverty from 1993 to 1997, consistent with the economic deterioration experienced in the mid-90s. In 1997 to 1999, however, the poverty rate fell slightly, from 73 to 71 percent, as GDP growth resumed. The table also indicates that poverty is substantially higher in rural areas than urban areas. Further, since the country is more than three-quarters rural, the vast majority of the poor are rural inhabitants. The rural-urban breakdown also reveals that the slight upswing and downswing in national poverty rates over the 1993-99 period was driven by large swings in urban poverty. As a whole, rural areas, which (especially in the subsistence sector) are relatively insulated from macroeconomic shocks, do not show much variation in poverty over the period. Nevertheless, a slight upward trend in rural poverty - from already very high levels - is noticeable. Finally, the figures for province (Faritany) show that there is a great deal of regional variation both in poverty levels and changes in poverty. These differences in poverty by year, zone (rural/urban), and Faritany suggest there will also be important variations in the demand for education and health care, which the analysis below confirms.

\section{The education sector in Madagascar}

The history of the education system after independence in 1960 is one of substantial successes in expanding access to education followed in later years by sharp declines. Education was made free for all students after independence. Together with increases in the share of the government budget allocated to education, this resulted in a rise in gross primary enrollment from 50 percent to over 100 percent by the early 1980s (World Bank 1996). ${ }^{21}$ Similar dramatic increases were seen in secondary and university attendance.

After the early 1980s, however, enrollments at all levels began to decline. The decline was sharpest for primary school: gross primary enrollments fell from about 140 percent in 1980 to less than 80 percent in 1993/4. One reason for this was Madagascar's overall economic deterioration during this period. Falling incomes undoubtedly made it harder for many

\footnotetext{
${ }^{21}$ The gross enrollment rate for primary schooling is the ratio of the total number of students of any age attending primary school to the number of children of 'official' primary school age (6 to 10).
} 
households to afford the costs of school, which include not only direct expenses but also what the child could have contributed to the household's income if not in school. However, it is likely that another contributing factor was the deterioration in the quality of public schools, a reflection of the inadequate share of education in the government budget as well as relative to GDP (World Bank 1996). As Table 2 indicates, in the 1990s government expenditure on education, both as a share of all government spending and as a share of GDP, followed a pronounced U-shaped pattern. This is exactly the inverse of the pattern in expenditures on external debt service by the government during the decade, suggesting that education spending was particularly squeezed by pressure to service the debt (World Bank 2002). As shown, recurrent education expenditure as a share of total public recurrent (non-interest) expenditure dropped from 28 percent in 1990 to 15 percent in 1994 before rising again to 24 percent in 1999. Increases in capital spending for the primary and secondary levels since the mid-90s have been quite substantial (Table 3).

Although overall education spending in real terms is now higher than in 1990 after a fairly precipitous drop in the mid 90s, these levels remain low. The government now spends about 3 percent of GDP on education, lower than the 4 percent average for sub-Saharan Africa; this is a reflection in part of the relatively modest size of the public sector in Madagascar. On a positive note, within the education budget there has been a strong shift in spending from university to lower levels, an outcome of more restrictive policies toward enrollment and student subsidies for university: this level accounted for 32 percent of total public spending on education in 1990 but only 16 percent in 1999 (Table 3). Since university education is almost exclusively the privilege of the very well-off (confirmed in our analysis of the EPM data below) and is thought to have smaller social returns than lower education levels, this reallocation of the budget should be beneficial from both an equity and an efficiency standpoint. ${ }^{22}$ With regard to allocations between primary and secondary levels, we were only able to assemble a data series starting in 1994, presented in Appendix table A.1. This indicates that the distribution of MinESEB $^{23}$ resources between primary and secondary was stable during 1994-1999: for example, primary accounted for about 50 percent of total salary payments to primary and secondary both in 1994 and 1999.

Evidence from a number of sources points to low quality as a major problem in the education sector in Madagascar. In terms of efficiency indicators such as grade repetition and completion rates Madagascar compares poorly with the averages for Sub-Saharan countries (World Bank 1996). A recent analysis of student flow though the education cycle estimates that only 33 percent of students entering the first primary grade will complete primary school-a lower ratio than almost anywhere in Africa — and only 15 percent will complete lower secondary school (World Bank 2002). A major reason for this is that although almost all Fokontany in the country are equipped with a primary school, a substantial minority of local schools do not offer the full primary cycle, reflecting teacher shortages, and many also do not offer instruction for the full school day.

\footnotetext{
${ }^{22}$ With regard to efficiency considerations, a caveat is necessary, at least regarding primary school. Although the existence of high social returns to primary school have long been the conventional wisdom, the (private) returns to primary schooling in wage employment have been found to be quite low in Madagascar (Glick 1999). This conclusion is based on analysis of the 1993/4 EPM. Upcoming work will investigate returns to education using the more recent surveys.

${ }^{23}$ Ministère de l’Enseignement Secondaire et de l’Education de Base.
} 
In Appendix tables A.2 - A.3, we present MinESEB data on the numbers of students and teachers by school level. Information on enrollments, of course, is also found in the EPM household surveys and we will be relying on those data for the bulk of our analysis of education later in the report. However, the ministry data will be used below to corroborate trends uncovered in the EPM, so it is worthwhile to consider what these data say. Table A2 indicates that there has been a large rise in primary enrollments since the mid 1990s: from 1993/4 to 1998/9 (the interval covered by our three EPM surveys) the increase was 34 percent in proportional terms, and occurred at the same rate for public and private primary schools. With an estimated growth of the primary age population of approximately 3 percent per year, this translates into a rise in the primary gross enrollment rate of about 16 percent. It is also noteworthy from the table that the gains were basically a rural phenomenon; the gross enrollment ratio in rural areas rose about 15 percent from 1993/4 to 1997/8 (the last year for which ruralurban breakdowns were available) but stagnated in urban areas. Increases in lower and upper secondary enrollments have been much more modest than for primary school, growing at about the rate of the school age population for lower secondary and by less than that for upper secondary.

The apparent upward trend in the number of children attending primary school since the mid-1990s is very welcome, but it should be emphasized that the prior period represented a low point for primary enrollments. Such enrollments were declining in absolute terms in the early 1990s, and therefore obviously were also falling in relation to the growing number of primary age children, as the calculations in Table A.2 indicate. Hence it may be more accurate to say that primary enrollment rates recovered their levels of the start of the decade. The pattern in enrollments inversely mirrors the changes in public spending on schooling as a share of government spending and GDP noted above. This suggests that the spending reductions earlier in the decade had direct negative effects on enrollments through changes in the supply of teachers, hours of instruction, or school closings, and that enrollments responded after resource levels (and presumably, access to or quality of services) were restored.

From Table A.3, which shows trends in the number of teachers by school level, it is evident that in the public system at least the supply of teachers has not kept pace with the increase in demand for primary schooling. In fact, there were fewer public school primary teachers assigned to classroom duties in 1997/98 than in 1993/94; the growth in overall primary teachers that occurred was entirely in the private sector. This is not surprising since there was a public sector freeze on hiring teachers in effect until 1997. As a result, student to teacher ratios have risen. ${ }^{24}$ The modest increase in the number of public primary teachers seen from 1997/98 to 1998/99 reflects the lifting of the freeze and the hiring of 1,000 new teachers, 90 percent of them in primary. ${ }^{25}$ The table also shows, perhaps surprisingly, that the number of secondary teachers has risen significantly during the 90s in spite of stagnant enrollments at that level. Again, however, all of this growth was in private schools.

\footnotetext{
${ }^{24}$ Analysis of school-level information in the rural community surveys accompanying each EPM confirm this. The median numbers of students in rural public schools enumerated in these surveys were 107,110, and 161, respectively, for 1993, 1997, and 1999. The median estimated student teacher ratio was 38 in 1993, 50 in 1997, and 60 in 1999.

${ }^{25}$ An additional 1,000 teachers (all in primary) were recruited in 1998/99, and the government's economic plan calls for the hiring of 3,000 more teachers.
} 
The last several years have seen the start of a process of decentralization in the public education sector. This is part of the broader shift in Madagascar toward political decentralization, reflected in the constitutional reforms of March 1998 giving more power and autonomy to provincial governments. Eventually this may have significant impacts on the organization of public education. While major changes have yet to be seen, since 1997 the Government has introduced specific measures designed to increase local participation of parents, teachers and administrators (the contrats-programmes) and to place more financial control in the hands of the country's 111 school districts heads. While it is too early to be able to judge the effectiveness of these measures, World Bank (2002) discusses the implementation of these efforts to date.

\section{The health sector in Madagascar}

Health indicators for Madagascar's population are generally comparable to averages for Sub-Saharan Africa, but in some areas, particularly child malnutrition, Madagascar ranks substantially below the average (World Bank 2001). For example, the 1997 Demographic and Health Survey indicates that almost half of children under 5 suffer from stunting (low height for age)—rates which have not improved since 1992. Child immunization rates are also low relative to other countries in the region.

The public health care network in Madagascar is relatively well developed, consisting of approximately 2,100 basic or primary care facilities supported by a network of hospitals that includes 86 first referral hospitals, four regional hospitals, two national university hospitals, and seven specialized institutions. There is a variety of types of basic care facilities, including Dispensaire, post sanitaire, post d'infirmerie, and Centres de Soins de Santé Primaire (CSSP). Hospitals also serve as important sources of primary care for those who have access to them, as the EPM data presented below suggest. Relative to other countries in the region, the private health sector is well developed in Madagascar, though this may be a symptom of dissatisfaction with public sector quality. Private providers are not limited to doctors and clinics but include as well church and NGO-run services and private pharmacies. Facilities run by churches and NGOs are thought to provide higher quality services than analogous public providers (World Bank 2001). Despite this extensive health care infrastructure, as in many developing countries, distance to providers in rural areas is a major constraint on utilization, especially when the primary means of transportation is by foot. ${ }^{26}$

The budget share of health in public spending has risen somewhat over the 1990s and by 1999 was close to $10 \%$ (Table 4), a relatively high share. However, this is equivalent to only about 1.3 percent of GDP; as in education, this reflects the relatively modest size of the public sector overall in Madagascar. In absolute terms actual public spending on health amounts to only about US \$2.30 per capita annually (about 0.70 of which is from donors). In part this

\footnotetext{
${ }^{26}$ For example, in the rural community survey of the 1993/4 EPM, the average recorded distance to a hospital-in those communities where this provider was listed as a significant source of care--was about $10 \mathrm{~km}$; it was $5 \mathrm{~km}$ for a basic care facility. The fact that distance information was only collected if the provider was listed as an important source of care for local residents is important to keep in mind. The average distances would probably be significantly greater for communities where these facilities were not listed.
} 
reflects a very low expenditure rate; for example, only 69 percent of budgeted expenditures was spent in 1998. (World Bank 2001).

Reflecting low public expenditures, health personnel indicators are generally poor even when compared with sub-Saharan averages: the population per doctor is 12,000 , slightly higher than the sub-Saharan averages of 10,800 . The population per nurse is 4,000 , well above the regional average of 2,100 (World Bank 1999). The situation for nurses reflects the closing of paramedical schools during the 90s, a policy recently reversed. Personnel shortages are especially pronounced in rural areas. Problems in other dimensions of quality, such as facility conditions and drug availability, are also widely recognized (World Bank 2001). ${ }^{27}$ It was estimated in the mid-1990s that basic health care facilities were able to meet only 25 percent of their patients’ drug requirements (World Bank 1996), after years in which public sector expenditure on drugs plummeted.

To address these problems, the government undertook a major overhaul of the public health sector beginning in the mid-1990s. A key aspect of the new National Health Policy has been decentralization of both resources and decision-making. Hence since 1995, the public health sector in Madagascar has been organized around 111 health districts, corresponding to Fivondronana administrative units. The budgetary data in Table 5 confirm that, as envisioned, district level allocations of the health budget increased significantly at the expense of central administration after 1995. By increasing the support of district level primary care facilities relative to secondary and tertiary care, decentralization has the potential to achieve both equity and efficiency objectives: equity, because the poor are the most likely to use primary facilities, and efficiency, because primary care centers are the main vehicle for preventative care. However, the effectiveness of the process to date has been constrained by lags in the development of local administrative capacities (World Bank 2001).

A second plank of the new policy has been a major expansion of cost recovery (referred to officially as participation financière). This was implemented systematically in January 1998 when charges for drugs became mandatory at all public primary health facilities. Prior to that, some fees (for services) had been applied in many public facilities, though probably more important than such fees were unofficial payments made to health personnel. Although procedures are currently not standardized, it is typical for a lump sum to be paid for both services and drugs. The revenue implications of participation financière are not trivial: it was estimated to account for $27 \%$ of the non-salary health sector budget in 1999 (World Bank 2001). Related to the cost recovery scheme was the creation in 1997 of a public drug procurement agency (Salama) to purchase essential drugs and sell them at low cost to public and non-profit providers.

To date there has not been any direct study of the impacts of these major changes in health sector policy on demand for care at public and private facilities or on the costs incurred by households for care. ${ }^{28}$ Cost recovery in the health sector is always a contentious issue, with the

\footnotetext{
${ }^{27}$ The community survey collected as part of the 1993 EPM, discussed in Glick et al. (2000), provided detailed information on local health facilities in rural areas. Only 22 percent of public basic care facilities had electricity; 43 percent had a refrigerator, and only a fourth had running water. The figures for hospitals were better but still far from satisfactory: for example, some 30 percent of listed hospitals (secondary and primary) lacked running water. These figures reflect the very poor state of rural infrastructure in Madagascar.

${ }^{28}$ However, INSTAT is planning a small survey to specifically address the effects of health sector policy changes.
} 
main concern being that the poor will respond by seeking less care, unless the negative effect of higher prices is overwhelmed by concomitant improvements in quality or availability. As discussed below, since our household surveys from 1993 to 1999 each contain information on utilization and costs of health services, they should pick up any major trends induced by the policies to date.

\section{PROGRAM COVERAGE FOR SOCIAL SERVICES 1993-1999}

\section{EDUCATION}

Before presenting the EPM information on enrollment, we note some data issues. First, questions on current enrollment status differ slightly in the three surveys. The 1993/94 survey asked both whether the respondent was in school during the last year and whether the individual was planning on continuing his or her studies. In 1997 the question was simply whether the child was 'currently' in school. In 1999 the question referred to whether the child attended school in the previous (1998/99) school year. We use the last year and past school year information for 1993/94 and 1999, and current enrollment for 1997. These slight differences are unlikely to greatly affect comparisons across years in overall enrollment ratios. More problematic is the assignment of students in the 1997 survey to the correct school levels. This information was not collected directly in this year, though in principle it can be inferred from information on the highest diploma obtained. For primary enrollments this procedure is not a problem-current students who report having received no diploma are reasonably presumed to still be in primary school-but for secondary and university levels the inferred enrollments appear to be significantly overestimated relative to the 1993/94 and 1999 surveys. Therefore when analyzing secondary and university enrollments we restrict ourselves to the 1993/94 and 1999 data.

We begin in Table 6 by examining school enrollment rates for children age 6 to 14 by expenditure quintile. The last set of rows indicates the change in enrollment rates from 1993/94 to 1999. In line with the MinESEB figures shown earlier, the household survey data indicate that there has been a significant increase in school enrollments during this period. Nationally, the enrollment rate of children 6 to 14 rose from 0.51 to 0.68 between 1993 and 1999. This change, which is even larger than that implied by the Ministry data, essentially occurred between the 1993 and 1997 surveys. The greatest gains were registered by children in poor households; the increase for the poorest quintile was 25 percentage points. This served to reduce enrollment disparities across income groups compared with 1993/94, though even in 1999 only 56 percent of children from the first quintile were in school compared with 82 percent from the top quintile.

In Tables 7 and 8 enrollment rates of children 6 to 14 by zone (rural/urban) and province or Faritany are shown. Rural enrollments in each year were well below urban enrollments, reflecting differences in income and likely also in school quality and availability. ${ }^{29}$ However,

\footnotetext{
${ }^{29}$ With regard to rural-urban quality differences, MinESEB’s 1997-98 school census (discussed in World Bank 2002) shows higher pupil teacher ratios in rural public and private primary schools, though for lower secondary schools these ratios are higher in urban areas. There is evidence that primary enrollment decisions are sensitive to school quality (Glick et. al. 2000). Regarding availability, rural Fokontany usually have a local primary school, but
} 
Table 7 reveals another striking aspect of the increase in enrollments since 1993, again consistent with the story told by the MinESEB data: it has occurred almost exclusively in rural areas. This has narrowed the rural-urban gap, though rural enrollments remained considerably below urban in 1999 (64 percent compared with 81 percent). There are also large disparities by Faritany (Table 8). However, two of the poorest provinces in 1993, Toliara and Fianaransoa, enjoyed the largest increases in enrollment rates from 1993/94 to 1999: 23 percent and 26 percent, respectively. Since the poorest Faritany are also the most rural, this and the last two tables are essentially telling the same story.

Tables 9 through 11 show gross and net enrollment ratios by school level and quintile. The gross enrollment ratio is the ratio (multiplied by 100) of the total number of enrollments to the total number of school-age children for a given level, e.g., primary. The net enrollment ratio, on the other hand, is the ratio of enrollments of school-age children to the total number of school-age children. "School-age" is defined as 6-10 for primary school, 11-17 for secondary, and 18-22 for university. ${ }^{30}$ For reasons cited above, for 1997 only information on primary is presented. $^{31}$ For the country as a whole, the primary gross enrollment ratios in 1997 and 1999 were 102 and 114 percent, respectively, up very dramatically from 83 in 1993/94. For secondary school the gross enrollment ratio was 21 in 1999 compared with 19 in 1993/94. The university gross enrollment rate, tiny to begin with, actually declined from 2.6 to 1.6, consistent with the tightening of university enrollments and financial aid occurring throughout the decade. The increases in school enrollments since 1993 thus have taken place almost completely at the primary level.

With respect to cross-country comparisons, the gross enrollment levels for primary (in 1999) are favorable compared with the averages for all other developing countries (84.0), and even more so when compared with sub-Saharan Africa alone (74.9). ${ }^{32}$ For secondary school Madagascar is basically at the average for sub-Saharan Africa of 20.0 but well below that for all developing countries (33.1). The poorer showing for secondary reflects the low primary completion rates in Madagascar. Although Madagascar scores well for primary school in terms of gross enrollment, caution is necessary in making comparisons with other countries: gross enrollment ratios will be higher in the presence of a large degree of grade repetition, and primary school grade repetition is unusually high in Madagascar. ${ }^{33}$ That said, Madagascar's relatively good standing is a legacy of its strong policies to expand access to schooling after Independence. It bears stressing that even with the recent improvements, primary enrollments remain

distances to lower and upper secondary schools are typically very large and this may influence decisions regarding both secondary and primary enrollment.

${ }^{30}$ The official school ages are based on on-time entry and no grade repetition. Primary school (not counting a year of pre-school) consists of five grades. Upon successful completion of primary, resulting in attainment of the CEPE certificate, students take four years of lower secondary and three years of upper secondary, culminating in the Baccalaureate degree. Finally, university is also divided into lower and upper levels, of three and two (or more) years, respectively.

${ }^{31}$ We note also that given the nature of the 1997 questionnaire, it was not possible to exclude preschool students from the primary category. As a result, the primary enrollment ratios for that year are slightly overestimated.

${ }^{32}$ The averages for other countries are Unesco figures cited in World Bank (2002).

${ }^{33}$ In addition, dropping out before completion-also very significant for primary schooling in Madagascar, as noted earlier-means that the gross and net enrollment figures for a given level are weighted toward the lower grades in the level. 
substantially below the levels achieved an earlier era; in 1980, gross primary enrollment reached 130 percent. $^{34}$

The tables also show that there are significant differences in enrollments of poor and affluent children. This is the case at all school levels but especially at post-primary levels. In 1999 net primary enrollments of children in the first expenditure quintile were 53 percent compared with 78 percent for those in the richest, though this is smaller disparity than in 1993/94. For secondary school just 4 percent of secondary age children from the first quintile were in secondary school in 1999 compared with 34 percent for the fifth quintile, a gap that was much the same in 1993/94.

Private schools account for a minority of primary enrollments, just under 20 percent in 1999. This is nonetheless quite high for countries in the region, as comparative data presented in World Bank (2002) make clear. Wealthy households, particularly those in the top quintile, are far more likely than the poor to enroll their children in private primary schools. As the table indicates, there has been no overall growth in the importance of private schooling at this level; private and public enrollments have expanded at about the same rate. However, an interesting development not revealed in the table is that church-run schools no longer dominate private primary schooling as they did at the start of the period: secular private schools accounted for only 14 percent of all private primary enrollments in the 1993 EPM but about 50 percent in 1999. For secondary schooling (Table 10) the private sector figures more prominently, accounting for about 40 percent of enrollments in 1999, again primarily among upper expenditure groups. This too is markedly higher than in most African countries: thus by regional standards, the private education sector (including church-based providers) in Madagascar is well developed. As with primary school, there is little evidence of any change in the relative importance of private secondary schooling since 1993, though again there seems to have been a significant shift within the private system toward secular schools. ${ }^{35}$

We return to Table 7 to examine enrollments by zone and school type. Rural-urban differences are found at both the primary and secondary levels but are strikingly large for the latter. In 1999, just 9 percent of rural secondary age children were in secondary school compared with 35 percent of urban children. In addition to differences in average household incomes, this reflects lack of access to secondary schools in rural areas, which has been shown to be a major constraint on secondary attendance. ${ }^{36}$ The table also indicates that private schooling, at both levels, is far more prevalent in urban than rural areas.

\footnotetext{
${ }^{34}$ We should also note that an estimate (in Table A2) based on MinESEB enrollment data and using extrapolations of the school age population based on the 1993 census puts the gross primary enrollment ratio in 1999 rather lower-108 - than the figure of 114 derived from the 1999 EPM. Methodologically this MinESEB-based calculation is more comparable to the estimate of 1980 gross enrollments of 130 percent cited in the text. We discuss differences in the EPM and MinESEB data below.

${ }^{35}$ With the exception of a recently opened Catholic university, university education is all public in Madagascar, so we do not attempt a sector breakdown for this level.

${ }^{36}$ In the 1993 EPM community survey, the average distances to the nearest lower and upper secondary schools in rural areas were 15 and 41 kilometers, respectively. In the econometric analysis of Glick et al. (2000) distance to the nearest lower secondary school had strong negative impacts on secondary enrollment.
} 
Finally, a laudable aspect of Malagasy society is that girls generally have the same access to schooling as boys. As Tables 8 through 10 indicate, enrollments at each school level are about evenly divided among boys and girls. ${ }^{37}$

The enrollment data presented above suggest that a fairly remarkable rise in enrollments - and specifically in primary enrollments-occurred in rural areas between 1993 and 1997, followed by a much more modest increase in 1997-99. Given the very low rates of schooling prevailing in 1993, this is without doubt a very favorable development. However, there is need for caution in interpreting the EPM data, at least in terms of the implied magnitude of the changes. As noted, in some regions the jumps in enrollment are extremely large, and in one case (Fianarantsoa) a very large increase in schooling is recorded between 1993/94 and 1997 even though poverty rates remained essentially the same (compare Tables 1 and 8). This also describes the situation for rural areas overall, since the rural poverty rate was similar in 1993/94 and 1997. In qualitative terms, as noted, the trends observed in the EPM data do receive strong corroboration from the ministry enrollment data: in particular, a rise in primary enrollment rates during the period occurring largely in rural areas. The lack of a comparable improvement in urban areas in both data sources is consistent with the estimates of Razafindravonona et. al. (2001) showing that while poverty in rural areas did not rise significantly in the key period 199397, it did increase in urban areas. In terms of degree, the MinESEB school data imply a weaker if still impressive rise in overall gross primary enrollment rates for the equivalent period (93/94 to 98/99): roughly 16 percent, compared with 31 percent for the EPM (compare Table A2 and Table 9).

To investigate this further, we calculated enrollment rates using a third source of data on schooling over this period - the Demographic and Health Surveys from 1992 and 1997. In contrast to the EPM and ministry data, these surveys show no notable changes in enrollment rates for children 6 to 14 in either rural or urban areas. ${ }^{38}$ This is particularly unexpected, not to say disturbing, given that (like EPM) the DHS are large surveys designed to be representative nationally, at the urban and rural level, and within each Faritany at the urban and rural levels. In view of this conflict, what can be concluded about the evolution of enrollments over the period?

One concern was that the sampling frame was changed between the 1993/4 and 1997 EPMs. The sampling frame for the earlier survey was based on administrative records because the results of the 1993 national census were not ready at that time, while the 1997 (and 1999) surveys were based on the 1993 census. Although each of the EPM surveys are in principle representative at the necessary level of disaggregation, it was necessary to consider whether the change in the sampling frame had nevertheless in some way affected comparability of the earlier and later surveys. For example, if the communities sampled in a Faritany in1997 happened to be

\footnotetext{
${ }^{37}$ Analyzing the 1993 data, Glick et al. (2000) noted the fact that the share of total secondary enrollments that were female was somewhat less than half. This suggests a female disadvantage given the approximately equal number of males and females in the relevant age group, though the small totals and consequent large margin of error should be kept in mind. They also found that among primary school completers in rural areas, girls were significantly less likely than boys to go on to secondary school.

${ }^{38}$ The 1992 and 1997 DHS (both administered in the last several months of the year) asked whether an individual is "still in school." The schooling rates so defined for children 6-14 are 0.79 and 0.77 in urban areas for 1992 and 1997 (similar to the EPM estimates) and 0.52 for rural areas in both years. As shown earlier, the 1993 and 1997 EPM estimates for rural areas are 0.46 and 0.63 , respectively.
} 
wealthier or have better educated household heads than the average for the Faritany (or if the 1993 communities were nonrepresentative in the opposite direction), this could lead to a spurious recorded increase in children's enrollments.

We investigated this issue this issue, first, by estimating a probit regression model for current enrollment on the pooled sample of rural children age 6-14 from all three surveys, including as explanatory variables the survey year as well as controls for household characteristics and region. Including these covariates should control for the spurious sampling effects just noted, since we would expect these effects to operate largely through changes in these variables. The results are shown in the appendix table A4. The probit coefficients on the 1997 and 1999 year dummies are positive and highly significant (1993 is the excluded category). That is, controlling for possible changes over the years in the average characteristics of the head and of the household in our surveys, the impacts of survey year remain large, though the implied increases are somewhat smaller than the changes in mean enrollments observed above. ${ }^{39}$ Adding covariates such as household per capita expenditures as well as more disaggregated area (Fivondranona) controls did not alter the size of the survey year effects. This gives us confidence that the increases in mean enrollments from 1993 to 1997-99 are not spurious, that is, driven by changes in the sampling frame.

Second, note that if the observed increase in school enrollments merely reflected differences in the sampling, we might expect to see higher enrollments at all ages in 1997 and 1999 compared with 1993, since we would be shifting from a relatively low-schooling to a highschooling sample. ${ }^{40}$ On the other hand, "true" enrollment increases-i.e., that are responses to temporal changes in school supply or household conditions-are not likely to be experienced to the same degree by all age levels, because school entry (or re-entry) should be costlier for older children. A child of say, 13, who is not in school or had never enrolled is likely to be working on the family farm or enterprise and would have acquired firm-specific human capital. For such a child the opportunity costs of entering or re-entering school would be high relative to a younger child with no work experience. All things equal, then, we would expect improvements in school supply conditions or changes in household circumstances over time to result in enrollment rates rising the most among younger (and especially entry-age) children. In fact this is exactly what we see in the data for 1993, 1997 and 1999 (Figure 2). The increase in enrollment rates after 1993 is highest for children 6 to 10 (the latter still constitutes a plausible age for entry in Madagascar), and quite small for children over $12 .^{41 \mathrm{i}}$

Based on these results and the strong qualitative agreement of MinESEB and EPM data, we conclude that there has indeed been a significant improvement in primary enrollments in rural areas. However, the improvement may not be as large as the dramatic changes suggested by the

\footnotetext{
${ }^{39}$ As table A.4 indicates, the implied increase in the probability of enrollment (interpretable as the change in the predicted enrollment rate) in 1997 relative to 1993, controlling for other variables, was about 10 percentage points. The effect of 1999 over 1993 was about 12 percent. These figures compare to the changes in rural mean enrollments of 17 percent and 18.4 percent, respectively (Table 6).

${ }^{40}$ Actually, this need not be the case if the difference in enrollment rates between the two sampled areas is normally largest for younger children. However, as best we can tell (by comparing rural and urban areas to represent 'low' and 'high' schooling areas), this is not the case: the gap in enrollment rates is similar across the age distribution ${ }^{41}$ This is, of course, is consistent with the finding that enrollments increased strongly in primary but not higher levels.
} 
EPM numbers, a conclusion we base partly on the fact that incomes were generally stagnant during the period, as well as on the lack of any major schooling initiatives targeting rural (or for that matter urban) areas. On the other hand, as we noted earlier, public education spending began to emerge from a trough in the mid-90s, and this may have led to improvements in access or quality than encouraged greater enrollment. The fact that the year effects in the probit model are strong even when we control for the effects of the standard household determinants of education demand further support the idea that there were changes on the supply side. It has also been suggested that enrollments rose as well as a result of increased community or NGO projects in education during the period (UNDP and INSTAT 1999). Finally, the period 1991-93 in Madagascar witnessed substantial political turmoil, resulting in a new constitution and populist government. During the crisis, government employees, including teachers, went on strike. However, the increase in school enrollment is not explained simply by the return of teachers to work, since the government data indicate that the increases did not occur until at least 1995-96. Rather, the renewal of political stability and its promise of economic growth may have made more parents willing to enroll their children in primary school by raising the expected returns to schooling.

Finally, we examine trends in schooling costs. Data on the direct (monetary) costs of schooling are available only in the 1993/94 and 1999 surveys. Table 12 shows that most or all primary and secondary students pay some sort of fee, no matter the area (rural or urban) or the school type (public, private confessional, private secular). However, fees invariably are much higher for either type of private school than for public schools, and for secondary relative to primary. With respect to public-private differences, for example, in rural areas in 1999 the median public school primary fee (a nominal 996 FMG in 1993 prices) was only 14 percent of the fee at church run schools and 8 percent of the fee at secular private schools. There is no clear evidence from the table that the level of fees have changed in real terms since 1993; we should point out that for private schools, especially at the secondary level, the relatively small sample sizes make comparisons somewhat unreliable. ${ }^{42}$

Table 13 looks at medians of total direct school costs, which include fees as well as books, uniforms, transportation, and other school-related expenses. Many or most of these costs, not just fees, are probably obligatory. Comparison with the previous table indicates that fees comprise just a small fraction of total direct costs. As with fees, costs are much higher in private schools at both primary and secondary levels; hence the positive association of the share of private enrollments and expenditure quintile seen above is not surprising. ${ }^{43}$ The table also reports costs per student as a fraction of median household non-food expenditures, calculated separately by region and for households with primary and secondary age children. At the primary level public school costs are modest but private school costs per student amount to nontrivial portions of household non-food expenditures. For secondary school the burden can be quite large-around 20 percent in rural areas for either type of private secondary school (the caution about small sample sizes applies here too, particularly at this school level). Further, this

\footnotetext{
${ }^{42}$ Another reason for caution in intertemporal comparisons is that the way information was gathered on fees and related charges was not identical in the 1993/4 and 1999 surveys.

${ }^{43}$ As Glick et. al. (2000) note, differences between rich and poor in the availability of private school options may also be important. The well-off are more likely to be found in areas-e.g., towns and cities-serviced by private schools.
} 
does not include opportunity costs from giving up or curtailing income-earning activities in order to attend school. For secondary school age children these costs are likely to be significant.

\section{HEALTH CARE}

The health modules of the 1993/94 and 1999 surveys, but not the 1997 survey, recorded whether an individual experienced an illness (or injury) in the two weeks prior to being interviewed. Hence for the first and last surveys we can calculate rates of illness and rates of treatment conditional on being ill. It should be kept in mind that self-reported illness is a subjective indicator. It is standard in developing countries to find that the likelihood of reporting an illness increases rather than falls with income, a counter-intuitive result that reflects wealthier or more educated individuals' greater awareness of, or sensitivity to, poor health. As shown in Table 14, this pattern is found for 1993/94 though not for 1999. Overall, the percentage reporting an illness or injury is quite a bit higher for 1993/94 than 1999: 14 vs. 11 percent. However, this is largely due to seasonal patterns in illness combined with the fact that the earlier survey was collected year round while the later one was collected only during August through November. Considering only these months, the rate of reported illness in the 1993/94 survey falls to 12 percent.

This indicates the importance of controlling for season when comparing health-related information in the initial and later surveys. Therefore in several instances below when examining the 1993/94 data we consider both the full survey year and just the period of August to November. Before proceeding further, however, it is important to stress two limitations of the latter approach. First, the sample size for 1993 is obviously much reduced when we select just a three-month period for analysis, making comparisons less reliable (recall that each of the three EPM are initially of roughly similar size even though the last two were fielded in one season). Second, the 1993 survey was not designed to be strictly representative over time in the same way that it is representative over areas. Still, recognizing the need to account for seasonal factors, the enumeration process was set up so that the survey teams returned to each region over the course of the year. An examination of descriptive statistics suggests that representativeness over time by location was achieved in a broad sense. ${ }^{44}$ However, we should still be cautious in using the data from selected months in the 1993 survey.

Returning to Table 14, we observe that among individuals reporting an illness, those in higher expenditure quintiles are more likely to seek care, especially formal care (which includes hospital, basic care centers, private doctors or clinics, and private pharmacies). Interestingly, the percentage of the self-reported ill seeking treatment is substantially higher in 1999 than 1993/94 (43 vs. 34 percent). The increase in the probability of care occurs across the expenditure distribution and in both rural and urban areas. Further analysis indicates that the increase is not due simply to differences in the months of data collection for the two surveys. In both years,

\footnotetext{
${ }^{44}$ For example, median real per capita household expenditures in the rural data for months 8-11 was about 5 percent higher than the yearly median (209,330 Fmg vs. 199,085 Fmg) while for urban areas it was about 7 percent lower. The rural-urban division of the sample was the same in the shorter period as in the year overall, but the shorter period data were less than perfectly representative at the province (Faritany) level.
} 
there were no gender differences in the likelihood of an ill person receiving formal care. This also was found to be the case when looking at children and adults separately.

The rising share of the ill seeking care suggests an improvement in access to health services during 1993-99, in spite of the cost-recovery policies introduced during the period. However, given the subjectivity of self-reported illness, we should also consider other indicators. Hence we also look at rates of health care utilization not conditioning on reporting an illness. Another reason to do this is that focusing only on those who are ill ignores the use of health services for non-curative care, e.g., checkups or preventative care. The unconditional approach also lets us include the 1997 data in the analysis, since illness information was not collected for that year. Therefore Tables 15 to 17 show for each year the consultations per capita for formal care in the previous two weeks by provider type and expenditure quintile. Since the surveys record the provider type for up to two consultations and each of these visits is counted in the tables, the figures should be interpreted as the total number of consultations ${ }^{45}$ for a provider divided by the total number of individuals in a quintile. The per capita figures naturally are very small since they involve the whole sample, not just those who reported an illness. Next to the consultations per capita are shown the shares of each provider in all formal consultations.

The number of reported formal consultations per capita for 1993/94, 1997, and 1999 are $.071, .098$, and .060 , respectively. Hence the picture is one of an initial increase followed by a fall, with an overall negative trend for the seven-year period. However, closer consideration of the data indicates that the apparent negative trend is misleading. First, as noted, the 1993/94 survey is year-round so records a higher incidence of illness, which by itself will lead to a higher number of consultations. Second, the questions in the 1997 survey on the number of recent visits were worded differently than in the other two surveys. It appears that there was a tendency to record consultations from further back than the last two weeks, thus raising the number of consultations per individual relative to the other surveys, which unambiguously restricted the responses to the two-week reference period. To insure comparability, therefore, we should control for season (while keeping in mind the caveats noted above) and focus on the 1993 and 1999 surveys.

Doing this, we find that per capita formal care consultations were actually very similar in 1993 and 1999: .062 and .060. This is so despite the fact that among individuals getting care, it was less common to have more than one consultation in 1999 than in1993, which all things equal would reduce the number of consultations per capita in the later survey. As we discuss below, there is some ambiguity in interpreting changes in the number of visits per illness episode. We might instead wish to consider an indicator of whether the individual received any formal care in the last two weeks, no matter the number of visits. Focusing again on comparable months in both years, this 'formal care per capita' measure rises from .044 in 1993 to .050 in 1999. For 1997, a reasonably comparable indicator is whether the first recorded visit was to a formal provider. This was 0.57, suggesting again an increase followed by a fall over the 1993-1999 period, though now with an overall increasing trend. Although by this measure the use of formal health care services actually rose over the period as a whole (with the seasonally adjusted per

\footnotetext{
${ }^{45}$ Since third (and higher) visits in the two-week reference period are not counted (because no provider information is given for them) the totals are slightly underestimated. Among those seeking care, 16\% in 1993 and 6\% in 1999 reported more than two consultations.
} 
capita measure remaining about the same), the apparent reduction from 1997 to 1999 might be interpreted as a reflection of recent health care policy changes, in particular cost-recovery. This is a possibility, though the earlier increase from 1993 to1997 it is difficult to reconcile with evidence presented below that the bulk of the price increases actually had already occurred by the time of the 1997 survey.

The numbers we have been discussing are national means, which conceal differences by rural and urban location. For example, our indicator of formal care per capita, which as just noted increased overall from .44 to .50 during 1993-99, actually fell in urban areas, from .067 to .058 , while rising strongly in rural areas (.038 to .048). However, the decline in urban areas is related to the fact that the incidence of reported illness in these areas in 1999 was lower than in 1993 (0.092 vs. 0.123, using August-November for the 1993 figure); in rural areas it was similar in the two surveys (about 0.12). As noted above, the share of the self-reported ill receiving formal care rose in both rural and urban areas. If we use this as our indicator of access to care, we would conclude that there was no relative decline in urban areas, though again the difficulties with using a subjective health indicator should be kept in mind.

Also of interest in assessing changes in health care policies are trends in the shares of private and public care. The shares in the last column of Table 17 confirm that the private forprofit health sector is significant in Madagascar, accounting for about 30 percent of formal provider consultations in 1999. As with schooling, the better-off are more likely to use private providers: the private share of the wealthiest quintile is more than double that of the poorest. The private sector's share appears to be basically the same as it was in 1993/94 (compare Table 15). However, comparison of sector shares at the national level obscures an apparent increase in the relative importance of private providers in rural areas and an opposing trend in urban areas. Breakdowns by area are shown in Tables 18-20. The share of private formal consultations rose from 0.23 to 0.29 in rural areas and fell from 0.38 to 0.30 in urban areas. If we control again for season, using only the August-November period for 1993/4, the reallocation to private providers in rural areas is larger (.19 to .29) and the shift to the public sector in urban areas is smaller (0.35 to 0.30). It should be kept in mind that for the 'seasonally-adjusted' 1993/94 figures, the actual numbers involved are small once we divide the sample by sector and region.

These apparently opposing sectoral shifts in rural and urban areas are intriguing but difficult to interpret unambiguously. One possible explanation for the apparent increase in the relative demand for private services in rural areas is that decentralization in the health sector, despite an apparently 'pro-rural' reallocation of resources, had an initially disruptive effect on public service delivery in rural areas. This would accord with the reports of significant administrative problems in rural health districts, and would have made private alternatives there more attractive. Other potential explanations for the divergence in sector shares involve differences by rural and urban areas in how effectively cost-recovery was implemented, in the price elasticities for public health services, or in offsetting improvements in public provider quality. Obviously, any interpretations at present would be speculative. It is expected that the upcoming INSTAT survey on cost recovery and the health sector will shed some light on these issues. $^{46}$

\footnotetext{
${ }^{46}$ The survey, scheduled to be implemented in September 2001, will be conducted in Tulear, Fianar, and Majunga. Around 850 people will be interviewed.
} 
Another interesting trend in the data, mentioned above, is the change in the number of health care visits in the two-week reference period among those getting formal care. This indicator fell from 0.42 in 1993/4 to 0.19 in 1999. It is tempting to attribute this to cost recovery: people who seek care will demand fewer consultations if the cost is higher. However, if higher costs were the operative factor, we would also have expected a reduction between 1993/4 and 1999 in the number of people seeking any formal care, not just a fall in the number of visits conditional on getting care. As seen above, this did not occur. Similarly, the fact that a higher share of the self-reported ill sought formal care in 1999 than in 1993 argues against a simple price increase interpretation of the change in multiple visits. Note as well that a fall in the incidence of repeat visits may signal an improvement in quality rather than a response to higher prices. If the availability of doctors or other trained staff rises or if more types of drugs become consistently available, people will be less likely to have to return to the facility to be seen by the appropriate care professional or obtain their medication. Therefore the change in the rate of multiple visits, like the sectoral shifts in demand, is not straightforward to interpret. ${ }^{47}$

With regard to the breakdowns by provider type shown in the tables, basic or primary care facilities are by far the most important source of care, accounting for 40 percent of all formal health consultations in 1999, down slightly from 1993/94 (47 percent.). Hospitals account for about a fourth of all consultations, and private doctors about a fifth. ${ }^{48}$ Within the public sector there are significant differences by expenditure quintile in the relative importance of hospital and basic care facilities: the latter are especially important for the poor, while for the rich hospital consultations figure more prominently. Non-governmental organizations, listed as a separate category only in the last survey, do not play a very prominent role in the curative or outpatient health care captured by the survey. To the extent that they do play a role, it is perhaps surprising that they are used by the well off at least as much as by the poor. All in all, the shares of specific provider types in total health care consultations have been relatively stable over time.

Tables 18-20 indicate that rural residents are less likely than urban residents to use formal health services. The importance of basic care facilities for rural residents is noteworthy. In 1999 basic care accounted for almost half of all rural formal consultations, compared with 18 percent for hospitals; for urban areas these shares are essentially reversed. However, even if we control for location, we find the same pattern by expenditure level that we saw at the national level, though less pronounced: that is, in both rural and urban areas, the share of basic care visits in total formal care falls with expenditure quintile while the share of hospital visits rises.

Finally, the surveys allow us to directly examine changes in the costs of care. Information on payments for health services is available in each survey, but there were differences in the questions in each year that make comparability difficult. In particular, in 1999 separate information was collected on consultation fees and costs of medicines, though apparently not all respondents were able to distinguish the amounts paid in fees and for

\footnotetext{
47 The decline in the rate of multiple visits was actually greater for private care, not public care. This would seem to argue against the changes being a result of public sector pricing policy. However, as discussed below, there is evidence that prices also rose for private providers.

${ }^{48}$ Note that hospital care refers to outpatient care, not overnight stays.
} 
medicines; as noted earlier, patients are typically charged a lump sum for both. In the first two surveys only information on consultation fees was collected, though it is possible that some respondents included medicines in this category.

In Table 21 we show the percentage of patients at each provider reporting paying something for their care (for 1999 this counts paying a fee and/or for medicine) as well as the median costs for those reporting a payment. One very striking pattern is that for public providers (hospitals and basic care centers) the share of patients reporting paying for their treatment was much higher in 1997 and 1999 than in 1993/94. For example, for basic care centers in rural areas, 35 percent of patients reported paying a fee in 1993 compared with 71 percent in 1997 and 93 percent in 1999; the changes are similar for urban areas and for hospitals. This of course is consistent with the new emphasis on cost recovery in the public health sector. It is somewhat unexpected to find the major cost increases in the EPM data coming between the 1993/4 and (Fall) 1997 surveys, since the systematic implementation of mandatory cost recovery for drugs in primary care began in early 1998. It is possible that widespread cost recovery in practice anticipated the mandatory policy by several months or more. Still, this discrepancy may point to a lack of comparability of the questionnaires from the two years, so some caution is warranted in interpreting the results. As we would expect, the great majority of private formal providers (which here are restricted to doctors and private clinics) imposed charges, in all years. Private consultation costs also seem to have risen very sharply in real terms after 1993. As it is not obvious why this should be the case-unless private providers felt able to fully match price increases in the public sector-this finding underscores the need for caution in interpreting the data.

Turning to the median costs of treatment for the subsamples reporting paying for their care, note first that the costs shown are per visit, not total, costs. For 1999 these include both consultation fees and medicines. In real terms the cost for each type of care (including private formal care) was as high or higher in 1997 than in 1999, suggesting that respondents in the earlier survey may have been including payments for drugs (or possibly, unofficial payments to personnel) when estimating the cost of a visit. Among public providers, hospital visits are more expensive than consultations at basic care centers, while private formal providers remain more expensive than either type of public provider. Finally, for 1999, analysis of cases for which separate amounts for fees and medicines are reported indicate that medicines take up the bulk of total (fee plus medicine) costs: 73 percent for hospitals, 71 percent for basic care, and 65 percent for private doctors or clinics.

Hence both the proportion of patients paying for care and the amounts paid suggest (subject to caveats about survey comparability) that the costs to households of using public health care services have indeed risen since 1993. This of course is an intended consequence of participation financière. The important question is the effect on the demand for care as well as on the quality of care (in particular, through changes in availability of drugs). As discussed above, the use of health services over the period 1993 to 1999 seems either to have stayed about the same or risen, depending on which of several indicators are used. One indicator does suggest a decline during the shorter interval 1997-1999, though in the context of a longer-term increase. Clearly this is an area that requires continued careful monitoring, and clear positive or negative effects may yet emerge in subsequent EPM surveys. 


\section{PRENATAL CARE}

Prenatal services are an important aspect of public health care. Detailed information on prenatal care was gathered only in the 1993/94 and 1999 surveys. For comparison purposes we restrict the analysis to women age 15-49 who had a pregnancy resulting in a live birth during the previous 12 months. The categorizations of prenatal care providers are rather different for the two surveys. For 1993/4 in particular the categories make it difficult to unambiguously distinguish private and public providers.

In 1999, only two thirds of women (67 percent) consulted a formal care provider during their recent pregnancy, down from 72 percent in 1993 (Table 22). Especially for 1999, we do not see very strong patterns by expenditure quintile; one improvement is that women in the poorest quintile, who had particularly low rates of care in 1993, were not so disadvantaged in 1999. Public care, particular basic care centers, dominate prenatal care, accounting for all but 8 percent of formal prenatal consultations in 1999. Although private providers (doctors or clinics) appear to play only a minor role overall (subject to the difficulties in categorization noted), private care among women in the top quintile rose sharply over the period. Only 2 percent of pregnant women seek informal care from healers or midwives.

Rural-urban breakdowns are presented in Table 23. Rural women are at a disadvantage: they are some 11 percent less likely than urban women to get prenatal care. As with regular health care services, rural residents rely heavily on public basic care centers for prenatal care whereas in urban areas hospitals are more important. Rates of prenatal care differ across Faritany (Table 24), though the differences in 1999 were not necessarily the same as in 1993/94. The relatively small samples involved here should be kept in mind when considering these breakdowns. In 1999, women in Antananarivo were at an advantage, while women in Fianarantsoa and Toliara received lower than average rates of care; these patterns hold for both rural and rural areas in these provinces.

\section{VACCINATIONS}

Information on childhood immunizations against polio, measles, tuberculosis, and diptheria was collected in the 1993/94 and 1999 surveys. Parents generally have a vaccination card recording their children's vaccination histories, but information on immunizations was collected even if there was no card. The survey does not identify the provider of the immunizations. Although private providers are probably not important (at least in rural areas), non-governmental organizations have played a significant role in providing vaccinations along with the Ministry of Health. A major example is the AVA campaign against polio in 1998, which received funding from USAID and UNICEF. 
Table 25 shows by expenditure quintile the shares of children age 12 to 23 months ${ }^{49}$ who have received zero completed vaccinations, between 1 and 3 completed vaccinations, and 4 (the maximum) completed vaccinations. "Completed" means that all shots in the vaccination course for the disease were received. For a program for which 100 percent coverage of the target population is highly desirable from a public health standpoint, the figures are disappointing. One fourth of children in 1999 received no complete vaccinations at all. 49 percent received at least one but less than all 4 immunizations, while only 26 percent got all four. Nevertheless, these numbers represent a noticeable improvement over 1993/94, when 35 percent of the children were completely un-immunized and only 20 percent had received all 4 vaccines. In terms of differences by expenditure level, for 1999 the main distinction is between children in the top quintile and those in the bottom four-fifths (for the no vaccinations and all vaccinations rows, compare the fourth and fifth quintiles). Finally, Table 26 indicates that, while immunization coverage has risen everywhere, it remains significantly higher in urban areas: in 1999 the share of rural children with no vaccinations was twice that for urban children.

\section{PROGRESSIVITY OF PUBLIC SERVICES 1993-1999}

\section{EDUCATION}

Because of their large number, we put all figures and tables relating to this section of the report in the Appendix. The concentration curves for schooling for 1993/94 and 1999 are shown in figures A1 and A2, and the accompanying dominance test results are given in tables A5 -A8. ${ }^{50}$ The most obvious pattern in the graphs is that as the level of schooling increases, the concentration curves become sharply more convex. In other words, primary schooling is more progressive than secondary, which is more progressive than university. Statistically, we can establish dominance of primary over secondary for both years, and secondary over university for 1999. This ordering is a standard pattern for developing counties in general and Africa in particular (Sahn and Younger 2000).

Evaluating these curves relative to our benchmarks of the Lorenz curve for per capita expenditures and the 45-degree line, primary schooling easily dominates the Lorenz for each survey, meaning that primary schooling is (expenditure) progressive. Further, for 1999 the primary concentration curve lies above the 45-degree line, so primary school is per capita progressive as well for that year (confirmed statistically in Table A7). The difference from 1993 represents the effects of the large increase in primary enrollment in rural areas, which are poorer. Secondary schooling, at least in 1999, dominates the curve for expenditures, i.e., is expenditure progressive, though as the graph makes obvious is it per capita regressive. University enrollments are extremely inequitable, as they are distributed more unequally than even expenditures. Clearly, post-primary schooling benefits accrue disproportionately to the well-off.

\footnotetext{
${ }^{49}$ The 1993/94 survey recorded vaccination information for all children under 7 years while the 1999 survey only considered children age 12 to 23 months. For comparability we examine only the latter group for each year.

${ }^{50}$ In the following, our use of the term "dominance" will refer strictly to statistical dominance, not merely the position of one curve above another on the graphs.
} 
The graphs also show the cumulative shares of children age 6 to 14 and 11 to 20, which are broadly defined target populations for primary and secondary schooling, respectively. Both curves lie above the 45-degree line, reflecting the higher concentration of children in poorer quintiles. Comparing these curves to the benefit curves for schooling, for primary education in particular we see a significant change between the two survey years. For 1993/4, the curve for children 6 to 14 and the curve for primary schooling cross at the left of the figure, but throughout the bottom half of the expenditure distribution the former lies above the latter and the differences are significant at each pair of ordinates tested in this range. In contrast, in 1999, as already seen in Section II, the two curves lie very close to each other, meaning that quintile shares of public primary enrollments are now similar to their shares of primary age children. Thus public primary schooling in 1999 comes close to fulfilling the strict equity criterion of being distributed among rich and poor in proportion to 'needs' as defined earlier. Note, however, that this apparent equity refers only to public enrollment. Children from upper quintiles disproportionately attend private schools, so their overall enrollment rates remain significantly higher (Table 9). ${ }^{51}$

Tables A9 through A14 reports the tests of dominance of public schooling benefits across survey years for each school level. For reasons explained earlier these tests involve only 1993 and 1999 with the exception of primary school, which also includes 1997. As Figure A3 shows, the curves for primary schooling for 1997 and 1999 actually both cross the 1993 curve, meaning we cannot establish dominance of the later distributions over the 1993 distribution. However, for the lower half of the expenditure distribution the primary schooling curves for the two later surveys lie mostly well above the curve for 1993, and the difference between 1999 and 1993/94 is significant for all ordinate pairs in this range. Secondary schooling also appears to have become more progressively distributed by 1999, though the dominance tests do not support this statistically.

As alluded to briefly in the methodology section, we can also assess the distribution of the changes in benefits, i.e. the marginal distribution. So far we have compared "average" incidence in different years, finding that the incidence of primary schooling has become more progressive - the poor enjoy a larger share of total public enrollments now than they did earlier. This is not the same thing as saying that most of the change in the benefit (the increase in aggregate enrollments) went to the poor. Consider the case of a benefit that initially is quite regressive, so the poor have a very low share. Increasing the subsidies in equal amounts for rich and poor, or even increasing them more for the rich, can still raise the share of the poor in the total benefit. This is because the poor start from a low base, hence experience a larger proportional change, which is what determines the change in the shares. From a targeting perspective we may care more about whether the incremental or marginal benefits accrue disproportionately to the poor than simply whether the average incidence becomes more progressive; in the example just given, the former is the stricter criterion. To examine this we

\footnotetext{
${ }^{51}$ Even considering just public enrollments, the binary indicator ignores differences in public school quality, which is likely higher for better-off children. This would make the public subsidy less progressive (by any of the criteria we are using) than it appears in the graph.
} 
can calculate a concentration curve for the marginal benefits, analogous to the curves for the average benefits. $^{52}$

Such a curve is graphed for public primary school enrollments in figure A4. ${ }^{53}$ The bulk of the increase in enrollments from 1993 to 1999 indeed was quite disproportionately distributed among the poor: the graph shows that the bottom 40 percent of the population accounted for about two thirds of the aggregate change. As discussed above, this does not seem to be the result of a purposeful public effort to expand enrollments among the poor. As discussed earlier, the rise in enrollments in rural areas was likely related to a number of factors that are not easy to distinguish, though the recovery of overall education spending levels in the period may have played a role.

\section{HEALTH CARE}

Figures A5-A7 show concentration curves for public health services for 1993/94, 1997, and 1999. We should note that the definition of "public" was not always completely clear cut for health services. In particular, the 1993 and 1997 surveys did not distinguish private from public sources of care in the dispensaire category. However, the problems raised with respect to comparability with 1999 are probably slight.

The concentration curves for 1997 and 1999 suggest that basic care services are more progressive than out-patient hospital care. This result, which is in agreement with findings from other countries in the region (Sahn and Younger 2000; Castro-Leal et. al. 1999), to a large extent reflects the urban location of hospitals. Statistically, the extended Gini tests (but not the dominance tests) confirm that basic care was more progressive than hospital care for these years. ${ }^{54}$ However, both hospital and basic care (and their sum, all public care) generally dominate the Lorenz curve, i.e., both sources of outpatient care are expenditure progressive. On the other hand, neither hospital or basic care are per capita progressive; in fact, the extended Gini tests suggest that hospital care is per capita regressive, that is, the rich account for a disproportionate share of outpatient hospital consultations. ${ }^{55}$

\footnotetext{
${ }^{52}$ As explained in footnote 8, the standard benefit concentration curve shows the share of the benefit going the population up to ith percentile of the expenditure distribution, or $\mathrm{B}_{\mathrm{i}} / \mathrm{B}$, where $\mathrm{B}$ represents the total benefit and $\mathrm{B}_{i}$ represents the benefits received by the population up to the ith percentile. The concentration curve for the change in benefits (the marginal benefits) from year $t$ to year $t+1$ is $\left(\mathrm{B}_{\mathrm{i}}^{\mathrm{t}+1}-\mathrm{B}_{\mathrm{i}}{ }^{\mathrm{t}}\right) /\left(\mathrm{B}^{\mathrm{t}+1}-\mathrm{B}^{\mathrm{t}}\right)$. The numerator is the change in the benefits for the population up to $i$, while the denominator is the total change in the benefit. Younger (2000) also analyzes marginal benefits in this way; Glick and Sahn (2002) provide an analytical discussion of these concepts. ${ }^{53}$ We do this only for primary school rather than for all school levels. For secondary and university the aggregate change in enrollments between 1993 and 1999 are small, and for small aggregate changes the cumulative marginal shares are not very meaningful.

${ }^{54}$ The concentration curve for hospital care in 1993/94 shows a somewhat different pattern than for the other surveys, reflecting the relatively high utilization of outpatient hospital care by the poorest quintile (evident in Tables 14 and 15). The reasons for this are not obvious, but the fact that only the 1993/94 EPM was collected year-round should be kept in mind when making comparisons with the later surveys.

${ }^{55}$ Unlike 1993 and 1997, the 1999 questionnaire separated out the category OSTIE (Organisation Sanitaire Tananarivienne Inter-Entreprise), which are primary health facilities in Antananarivo for salaried private sector workers with health insurance. Since they are managed jointly by the state and private sector they have ambiguous sector status. The concentration curves and tests reported in the text exclude OSTIE from basic care, but the alternative of including them did not alter any of the dominance results.
} 
Unlike the case of education, there was little change in the degree of progressivity of health services over time. Statistically we cannot reject the null of no dominance for any pair of surveys for all public care or for basic or hospital care individually (Tables A21-A26). ${ }^{56}$ As shown in figure A8, the concentration curves for public health services for the three years are quite close to one another.

\section{PRENATAL CARE}

Figures A9 and A10 present concentration curves for public prenatal care in 1993/94 and 1999. As noted previously, there is a large array of provider categories in the earlier survey, several of which (such as birthing post and maternite) may include private providers. By including them in the figure (as well as in the concentration curve for all public care) we therefore may be using an overly broad definition of public benefits. Also shown is the cumulative share of the target population, defined here as women who reported a pregnancy resulting in a live birth in the past year. This curve lies above the 45 degree line, which, like the curves for children in the figures for schooling, reflects the higher fertility of women in poorer quintiles.

For 1993/94, the concentration curves for the various prenatal services are clustered around and typically cross the 45-degree line, so none are per capita progressive. However, they (and total public prenatal care) are generally expenditure progressive (Table A27). This is the case for 1999 as well (figure A10, table A29). In addition, basic care services in 1999 statistically dominates the 45-degree line, and at least by the extended Gini test criterion total prenatal care is similarly per capita progressive in 1999.

Hence there appears to have been an improvement in the targeting of public prenatal services, consistent with the apparent shift to private providers among women in the highest quintile and the increase in consultation rates for the poorest quintile seen earlier. This occurred even though, as seen above, overall (national) coverage rates did not increase and in fact fell slightly. Figure A11 and Tables A31-A32 compare the 1993/94 and 1999 concentration curves for all prenatal care directly. Because the curves converge at the upper end of the expenditure distribution we cannot reject the null of no dominance, but the extended Gini tests do suggest greater progressivity in 1999. Finally, comparing the cumulative share of benefits to the target population share, note that the concentration curve for all public prenatal care in 1999 fairly closely tracks the concentration curve for recent births. These services are therefore distributed equitably among pregnant women in different expenditure groups. They do not actually targeting poor women, however, despite being progressive in per capita terms. On the other hand, with regard specifically to visits to basic care facilities, the extended Gini test indicates that such visits are in fact more ‘progressively’ distributed than births.

\footnotetext{
${ }^{56}$ The only exception is that by the extended Gini test (but not the dominance test), basic care was more progressive in 1997 and 1999 than in 1993.
} 


\section{VACCINATIONS}

As above, we consider two benefit indicators: having had 1 or more completed immunizations, and having all 4 completed. Note that the former is not the same as the 'some vaccinations' measure used in looking at coverage because here it also includes those in the 'all' group. For each year the distributions of the two indicators are very similar, as Figures A12 and A13 show. In both 1993/4 and 1999, vaccinations were clearly expenditure progressive but they were not per capita progressive. There was no change in progressivity between 1993 and 1999 (Figure A14, Tables A37-A40). The concentration curves representing the cumulative shares of the target population (defined, based on design of the surveys, as children age 12 to 23 months) generally lie above the benefit curves, and this is more clearly the case for 1999. Because the lines cross near the bottom decile, dominance cannot be established. Nevertheless, the figure suggests that despite the fact that vaccinations are (expenditure) progressive and in per capita terms are not regressive, the benefits per child are smaller in the lower expenditure quintiles. Statistically, the less stringent extended Gini test indicates that distribution of the 1 or more immunizations indicator is less progressive than the 'distribution' of children in the target population age group.

We saw earlier that for vaccinations there has been an overall increase in coverage rates between 1993 and 1999, which also means that benefits per capita have risen. Therefore, as we did above for primary education, we calculated a concentration curve for the marginal benefits, showing the cumulative shares of the aggregate increase in 'all vaccinations completed' (Figure A15). Here the picture is considerably more murky: there really is no discernable pattern in the curve, though in general the ordinates lie below the 45-degree line. ${ }^{57}$ This is not unexpected: the distribution of the benefit started out fairly equal and ended up the more or less the same way (despite an overall increase in benefit levels) so we would not expect any strong distributional pattern in the allocation of the change in benefits.

\section{ROBUSTNESS TO ALTERNATIVE WELFARE RANKINGS OF HOUSEHOLDS}

As noted in the methods section, our use of household expenditures divided by household size as a measure of welfare is arbitrary, if common. Alternate approaches will lead to different welfare rankings of households (and individuals), and quite possibly will affect both whether a given public service is progressive and the ordering of services according to their progressivity. Therefore we considered the robustness of our results to alternative scalings of household expenditures; specifically, we rank households by total household expenditure scaled by household size raised to various powers from 0 to $1 .^{58}$ A value of 1 for the scaling factor $\theta$ yields expenditures divided by household size-our per capita method—which does not admit economies of scale in consumption. Using $\theta=0$ simply ranks households on the basis of total

\footnotetext{
${ }^{57}$ As the figure demonstrates, the concentration curve for a change in benefits, in contrast to the standard curve for the total benefit, can fall below zero or rise above 1, though as always the cumulative share will equal 1 at the 100th percentile.

${ }^{58}$ That is, the general expression of the welfare measure is expenditures $/ n^{\theta}$ where $n$ is the number of persons in the household and the scaling factor $\theta$ takes values from zero to 1 .
} 
expenditure, while values between 0 and 1 allow for varying degrees of economies of scale in household consumption.

A general result of using scaling factors less than 1 is that larger households move up in the welfare ranking, that is, the association (all things equal) of household size and low welfare is somewhat attenuated. Further, since larger households have more children, services that are directed at children or mothers appear somewhat less progressive, since the households that tend to use them most are now deemed less poor. This applies in our data to schooling, prenatal care, and (for 1993/94 only) vaccinations.

Despite this, most of the formal dominance test results discussed above are robust to changes in scaling. The ordering of schooling benefits-with primary being more progressive than secondary, and secondary more than university-is preserved. At values of $\theta$ less than 0.8 , however, public primary in 1999 loses the distinction of being per capita progressive. For health care there were few changes, though for 1993/94 at low values of $\theta$ hospital care no longer dominates expenditures (though basic and all public care continue to do so). Prenatal care remains expenditure progressive, and for some values of $\theta$ less than 1 in 1999 all prenatal care becomes per capita progressive as well, reversing the expected direction of change. Our measures of immunization benefits remain expenditure progressive, with the exception of 'all completed vaccinations’ for 1999.

\section{SUMMARY: INCIDENCE OF PUBLIC SOCIAL SERVICES IN MADAGASCAR}

Having established that the results by and large are not very sensitive to how household expenditures are scaled, we can summarize the findings. When we make comparisons with the (unequal) distribution of consumption in Madagascar, most public services do appear to be progressive. Primary and secondary education, basic health care consultations and outpatient hospital care, prenatal care, and vaccinations are all more equally distributed than consumption expenditures. Among the services considered here, only university enrollments are more concentrated among the wealthy than is consumption. Therefore most public education and health services serve to redistribute welfare from the rich to the poor.

However, from the stricter standard of per capita progressivity-meaning that a benefit accrues disproportionately to the poor in absolute terms rather than merely relative to their consumption expenditures-public services do not make as good a showing. Primary schooling (though only for a limited range of scalings of household expenditures) qualifies as per capita progressive, a result of the apparent growth during the 1990s of enrollments in rural, hence poorer, areas of the country. The only other possible case of per capita progressivity is in prenatal care services.

Our findings for education and health services are consistent with those for the sample of sub-Saharan countries examined in Sahn and Younger (2000). This applies to the progressivity rankings of different services as well as to the evaluation of specific services in terms of per capita and expenditure progressivity. Primary schooling is typically found to be the most progressive of all education and health services, though per capita progressivity for primary 
schooling (as we have found for Madagascar) is not common. Post-secondary schooling is invariably the most regressive service. Also as we have found, public health care in other countries is usually expenditure progressive but not per capita progressive, and basic care is more progressive than hospital care.

We also considered the distribution of services by comparing the cumulative benefit shares to the cumulative shares of the target population. In general this comparison presents a less favorable picture than the yardstick of either per capita or expenditure progressivity because the target populations for education and some health services are more highly concentrated at the lower end of the expenditure distribution. Of particular concern is that vaccinations per child are lower among the poor. As explained above, this looks at distribution from a different perspective than standard benefits incidence analysis. However, it serves to point to a need for more effective targeting of this service.

Finally, because we use binary indicators to represent benefits in this study, we are unable to sum over different benefits, e.g., all schooling, to see how total government spending on broad categories of services differs between rich and poor. ${ }^{59}$ However, this has been done elsewhere, in some cases using EPM data. To add to our perspective it is worth summarizing these findings; this is especially helpful for making cross-country comparisons. For education, World Bank (2002) uses unit cost and enrollment data to calculate Gini coefficients for total public spending on education in Madagascar. The Gini was 0.74 in 1999. This is not only high absolutely but also in regional perspective: the averages for Francophone and Anglophone Africa, respectively, were 0.66 and 0.62 . The share of total education spending going to the richest quintile relative to share of the poorest, in both 1993 and 1997, was 5.1, which also is well above the regional average. Thus even though primary enrollments are relatively equitably distributed in Madagascar, overall education spending appears highly inequitable. This is driven by the much higher unit costs of post-primary education, the benefits of which are narrowly concentrated among the well-off. ${ }^{60}$ Despite this, total education spending may still redistribute resources from rich to poor, if to a limited degree: while the share of the total education subsidy going to the richest fifth of the Malagasy population was five times that going to the poorest, the analogous ratio for consumption expenditures in 1997 was even higher (about 9:1). Note, however, that this conclusion is at odds with the very high Gini coefficient for education spending just cited, as this is much larger than the Gini for expenditures. ${ }^{61}$

For health, World Bank (1996, using the 1993/94 EPM) estimates that the share of the total subsidy for health care going to the poorest quintile in 1993 was 12 percent, compared with

\footnotetext{
${ }^{59}$ To illustrate the point, consider adding binary utilization indicators for primary, secondary and university enrollment to arrive at the total education 'subsidy' for a subgroup of the population. Since the actual public spending per student for these levels is very different (e.g., much higher for university) and rich and poor use different relative amounts of each level, this would be a very misleading way of comparing total education benefits of the rich and poor. As noted in section III, however, it is reasonable compare the distributions of the individual benefits with each other (e.g., primary vs. secondary) and with consumption expenditures using the binary approach. ${ }^{60}$ More to the point, unit costs for post-primary education relative to primary are a lot higher in Madagascar than elsewhere in the region, which serves to worsen the incidence of total education spending relative to other countries. Madagascar's per student spending on secondary education relative to primary in 1993 (3.8) was the next to the highest of 9 African countries surveyed by Castro-Leal et. al. (1999).

${ }^{61}$ We lack the necessary information to rigorously evaluate the progressivity of the total education subsidy.
} 
30 percent for the richest. As the comparative analysis of Castro-Leal et. al (1999) shows, this is not far from the regional norm. It also implies that total health spending is allocated more equitably than total education spending in Madagascar, though even health spending favors the well off by a wide margin. It is to be hoped that the process of decentralization in the health sector will eventually lead to a more progressive incidence of overall public health expenditures; this is taken up again in the next section.

\section{CONCLUSIONS AND POLICY IMPLICATIONS}

Our analysis of education and health services suggest strong differences in access along several important socioeconomic dimensions. Rates of utilization of almost all the services covered in this report are higher for the well-off than for the poor and for those in urban areas relative to those in rural areas. In some cases the disparities are quite large. For example, only 56 percent of children age 6 to 14 from the poorest expenditure quintile were attending school (public or private) in 1999 compared with 82 percent for the top quintile. Enrollment rates are 15 percent lower for rural children than urban children in this age category. Disparities by income level and rural vs. urban location are also found for formal health consultations and prenatal care, though these tend not to be as pronounced as for schooling. On the other hand, for both education and health services, no notable gender differences exist in coverage

Looking at changes over time, a bright spot is that primary enrollments have apparently risen significantly after stagnating during the early to mid-1990s. Furthermore, this improvement has occurred in rural areas, which are poorer, thus narrowing (but far from closing) the gap in the enrollments of poor and wealthy children. Gross primary enrollment ratios appear as good or better than the average for sub-Saharan Africa, while secondary gross enrollments are near the average. However, both remain far too low, and well below the levels achieved in Madagascar two decades ago. The implication is that, despite recent improvements, the average level of skills of the country's workforce is declining and will continue to do so. This obviously does not bode well for Madagascar's development prospects.

A smaller improvement in coverage was seen for vaccinations: the share of young children receiving at least one (complete) immunization rose from 65 to 75 percent, while the share getting all 4 vaccinations rose from 20 to 26 percent. The former change appears to be the outcome in part of the AVA campaign for vaccination against polio, indicating that coverage for immunizations will respond positively to such programs. Less favorably, there was a small decline in the share of pregnant women getting formal prenatal care, though at the same time these services became somewhat better targeted to poor women.

Other than for primary schooling, the changes in utilization rates for services between 1993 and 1999 were modest, as one would expect given the absence of major changes in per capita income and poverty in Madagascar during the period. It is true, of course, that coverage (utilization) rates reflect not just demand, which incomes would affect, but also the supply of services, which for the predominately public services discussed here would be determined by government policies. One sector where there have been major policy initiatives since 1993involving most importantly, decentralization and cost recovery-is health. Based on informal 
evidence, it is likely too early for decentralization to have had major effects on service delivery. On the other hand, our household level data on the cost of care confirms that cost recovery is being implemented more than in the past. While trends in the EPM data in the use of health services are not conclusive, the demand for care appeared to have been no lower in 1999 than in 1993 and by some measures was actually higher. There is the possibility of a decline during the 1997-1999 period, though in the context of a modest longer-term increase in utilization. It is of course important to follow up this analysis with continued monitoring. All in all, it will probably require more time to assess the full effects of the recent changes in health sector policy.

Our analysis of the incidence of social services yields results in line with evidence from other countries in the region. Many, in fact most, social services are progressive in the sense that they are distributed more equally than income (proxied by expenditures). On the other hand, with the possible exceptions of primary schooling and prenatal care, no service meets the stronger criterion of per capita progressivity and some are actually per capita regressive. The latter means that upper income individuals receive a disproportionate share of the benefits. In discussions about targeting social services to the poor, it is usually the per capita criterion that, explicitly or implicitly, is being applied. From this perspective, social spending for the most part would not be considered pro-poor in Madagascar. We can put this another way by saying that even though many services do redistribute resources to the poor, they are far from being equivalent to targeted income transfers to the poor.

This impression is reinforced if we use a generally stronger criterion for equity, which is to consider the share of the benefits the poor receive in relation to their share of the target population for the service. For a majority of the services considered in this report, poorer quintiles have a disproportionate share of the individuals (children, infants, pregnant women) who make up the group of targeted beneficiaries. As a result, this comparison usually presents a less favorable picture than the yardstick of either per capita or expenditure progressivity. In 1999, public primary schooling subsidies and prenatal care visits in Madagascar do come close to being distributed among income groups in proportion to their shares of school-age children and pregnant women, but the benefits do not accrue disproportionately to the poor among these target populations, despite being per capita progressive. Vaccinations are not regressive relative to consumption expenditures or in per capita terms but in fact 'target' non-poor children. In view of these differences, and the fact that the 'per target population' (or 'benefits relative to needs') approach is probably of greater interest to policymakers, it seems to be a good idea to extend standard benefit incidence analysis in this way as a matter of course.

\section{OPTIONS FOR MAKING SOCIAL SPENDING MORE PROGRESSIVE IN MADAGASCAR}

\section{General lessons from the EPM}

In principal, the best method for insuring that that public spending on a service is targeted to the poor or to those who need it most is means testing: information on the household incomes or assets of potential program participants would be used to determine their eligibility for a service and/or the appropriate subsidy (or fee) level. As is well known, however, means testing

of individuals or households is very difficult to carry out administratively as well as politically, 
and where it has been tried in Africa it has been mostly unsuccessful (see Hamner et. al. 1999). Still, the results of this study do point to a number of ways in which the incidence of public expenditures can be improved.

First, standard fiscal incidence analysis suggests that overall public spending can be made more progressive by lowering the cost (i.e., increasing the subsidy) of services used by the poor while raising the cost (reducing the subsidy) of services used by the rich. If there are no major changes in demand, the changes in the subsidies will be distributed approximately in proportion to current demands for each service, so the poor benefit relative to the rich. ${ }^{62}$ In health care, this suggests that a progressive strategy for cost-recovery would be to impose higher charges at hospitals, which are used more by the well-off, than at basic health care centers, which are the primary source of care for the poor. ${ }^{63}$

In education, university enrollment is dominated by individuals from the top expenditure quintile, and secondary enrollments are also highly skewed toward the rich. Unit (per student) subsidies at these levels are very high relative to primary schooling, even in comparison with other countries in the region, with the result that the distribution of overall education spending in Madagascar is highly inequitable. A more pro-poor pattern of education spending could be achieved by reducing the unit subsidy at the secondary and university levels while increasing it for primary, where participation of the poor is highest. From this perspective the shift in the education budget in the last decade away from university toward lower levels has been a favorable development. However, the ultimate effect on the progressivity of public education expenditures will be a function of whether primary or secondary education has benefited the most from the reallocation in resources. At least since 1994, the relative shares of primary and secondary in MinESEB expenditures on salaries as well as investment appear to have been stable; had primary instead increased its share, greater positive effects on equity would have been realized. ${ }^{64}$

By similar reasoning, investments in improving the quality of services will increase the progressivity of social spending if they are directed at the services the poor use the most. In health, this would mean directing quality improvements (increased drug availability, more or better-skilled personnel) toward rural basic care centers instead of, or relative to, urban-based hospitals. This is an intended outcome of the reallocation of resources and administrative control to health districts under the National Health Policy, though as noted, practical barriers to implementation have so far limited the effectiveness of the policy. In education, improvements in school quality at the primary level will be more pro-poor than improvements at secondary and post-secondary levels.

\footnotetext{
${ }^{62}$ Note that targeting by type of service can be considered a crude form of means testing: we are identifying the poor based on the types of services they consume rather than their incomes.

${ }^{63}$ This policy prescription comes with the caveat that, while it is globally true (i.e., at the national level) that health spending would become more equitable, such a policy may penalize some urban poor who rely on hospitals for their care.

${ }^{64}$ In fact, based on analysis of personnel data, World Bank (2002) argues that secondary has probably benefited more than primary.
} 
The key insight informing the discussion in the previous section is that, for a fixed level of public resources and taking the existing patterns of demand of the rich and poor as given, budget reallocations among different types of services can make social spending more progressive. This is a simple and powerful guide to policy, but it does not go far enough in addressing Madagascar's needs. Both current budgets and-certainly-existing patterns of demand are far from ideal: no one would disagree with the assertion that Madagascar's poor currently make inadequate use of education and health services. In fact, when policymakers (and analysts) talk of making social spending more pro-poor, they typically mean an expansion of services to the poor.

Policies to achieve this goal have to be designed carefully. It is not enough to simply set a target for an expansion of primary enrollments or basic health care consultations, despite the fact that these are the services the poor currently use the most intensively. The essential problem is that the rich also consume most types of public services; hence it is possible that they rather than the poor will "capture" (in the terminology of Lanjouw and Ravallion 1999) the increases in the benefits. ${ }^{65}$ This illustrates again the importance of distinguishing the current or 'average' incidence of a service, which may be somewhat tilted toward the poor, and the marginal incidence, which need not be. In cases where the objective is to increase the poor's use of a service that currently is used primarily by the non-poor-for example, secondary education — the problem of preventing capture by the latter looms even larger.

To increase utilization by the poor - to direct the marginal benefits to them-policy must explicitly address the constraints that inhibit the poor's participation (Castro-Leal et. al. 1999). In Madagascar, one such factor clearly is the inaccessibility of health facilities and (secondary) schools. In rural areas health facilities are usually far from an individual's place of residence, and demand analysis has shown that greater distance reduces the likelihood of seeking treatment when ill (Glick et. al 2000). Similarly, distances to lower and upper secondary schools in rural areas are typically quite large and this has been shown to have a strongly negative effect on enrollment. Since rural areas are also poor, a clear implication for policy is that increasing the presence of facilities in rural areas will disproportionately increase the poor's use of these services.

Distance is not the only major constraint, however. Primary school enrollments remain significantly lower for the poor than the non-poor, for rural areas compared with urban areas, and in some provinces relative to others-despite the fact that almost every community throughout the country has access to a local public primary school. As discussed in section III, however, the quality of such schools is generally very low, and parents' enrollment decisions for their children are sensitive to primary school quality (Glick et. al. 2000). Therefore directing school quality improvements (more or better trained teachers, supplies, etc.) to rural areas, or rural areas in the

\footnotetext{
${ }^{65}$ Some services are not likely to be of interest to the well-off, for example, adult literacy campaigns or nutrition programs that require a large commitment of time on the part of the recipient household. Expansion of these services can be assured of primarily benefiting the poor. However, such examples are the exception in developing countries.
} 
poorest Faritany, will also disproportionately raise the participation of the poor. The same is true for investments in the quality of rural basic health services.

A third important barrier is cost. For the poorest households, the direct and indirect costs of schooling or seeking health care can make up a non-trivial portion of household consumption expenditures. Evidence from a number of countries, including Madagascar (Glick et. al. 2000) indicates that the poor are more sensitive than the well-off to the cost of services. All things equal, therefore, policies that raise the costs to households of using education or health services will reduce demand for the poor more than the non-poor, something that policymakers should always be aware of when contemplating changes in user charges. In practice, all things are not usually equal, because revenue from fees may be used to finance much needed improvements in services, such as greater drug availability. Therefore the net effect on participation by the poor, in absolute terms and relative to the non-poor, is uncertain. In the case of Madagascar's health sector cost-recovery, as noted, it may be too early to tell what the results will be. The most we can conclude at this point, again, is that careful monitoring both of changes in service quality and the poor's use of health facilities must continue as implementation of the new policies proceeds.

\section{Poverty mapping and targeting}

As the foregoing has stressed, directing new social expenditures to rural areas will tend to improve overall equity in the distribution of services, because rural areas in Madagascar, as in most developing countries, are poorer. The one significant service expansion we observed over the 90 s - for primary enrollment-disproportionately benefited poorer households in part because the expansion (whether as an outcome of intentional policy or not) in effect targeted rural households. However, simply insuring that new expenditures go disproportionately to rural areas is a crude and relatively inefficient form of targeting. Within rural areas, even within the same province, some areas are poorer than others, and within a geographical unit of any level of aggregation there are poor and non-poor who would gain equally. However, new developments in poverty mapping techniques, currently being applied in Madagascar as in a number of other countries, promise to improve policymakers' ability to target the poor. The approach will combine national census information with the EPM household survey data. ${ }^{66}$ The latter contain the detailed information needed to construct welfare indicators such as household consumption and hence poverty lines, but use too small a sample to estimate poverty rates at a level of disaggregation beyond simple rural and urban breakdowns within each Faritany. Census data do not have this problem as they cover the entire population, but they do not contain the information needed to calculate the welfare indicators. The method imputes welfare (consumption) to all households in the census using regression results for consumption from the EPM based on a set of household characteristics common to both surveys; from these estimates poverty rates can be calculated at highly disaggregated levels. This in turn will make it easier, subject to administrative and political constraints, to direct public expenditures on services to the poorest communities. $^{67}$

\footnotetext{
${ }^{66}$ See Hentshel et. al. (2000) for a general description and application of the method to Ecuador.

67 The initial attempt at poverty mapping for Madagascar, conducted by INSTAT, will combine the 1993 census with the 1999 EPM. It is planned to update the poverty map using the 2003 census and the upcoming 2001 EPM. The latter has been designed to be more compatible with the census questionnaires to facilitate the combining of the datasets.
} 
A highly complimentary development is the collection of the first census of all of the country's 1,400 communes, which at this writing is about to be administered by USAIDMadagascar's Ilo project in collaboration with INSTAT and FOFIFA, the national agricultural research agency. The commune census will provide, among other things, basic data on the local availability of education and health care facilities. Overlaying a disaggregated regional map of service access from this source onto the poverty map will allow policymakers to take into account both income or consumption poverty and shortfalls in access to specific services; the two are expected to be strongly correlated but not perfectly correlated.

\section{Private sector growth and public spending progressivity}

A quite different route to greater progressivity in social spending than targeting the poor directly is to get the well-off to use private providers. As noted, a major problem with targeting expansions or improvements in public services to the poor is that the non-poor also currently use these services. If the rich can be induced to switch from public to private services, the share of the poor in total public spending will automatically rise, and as long as the overall budget is maintained, coverage and/or quality for poor users can be increased as well. In environments where the private sectors in health and education have been held back by government overregulation or outright prohibition, simple legislative or administrative changes could free the private sector to grow to meet the demands of affluent consumers.

Certainly, the well-off in Madagascar, as elsewhere, are more likely than the poor to use private providers. However, the potential for encouraging private sector growth as a means of making public spending more progressive may be limited. Private primary and secondary schools already play a more prominent role in Madagascar than in most African countries. For health care, the share of private providers in total consultations is about 33 percent, on par with the average for the region noted in Castro-Leal et.al. (1999). However, Madagascar stands out because these private providers are (to the best of our ability to tell from the data) overwhelmingly for-profit providers rather than NGOs or charitable organizations. This suggests that rather than being repressed, the country's private health and education sectors are relatively well developed and probably already reflect true market demand. Therefore, short of heavily subsidizing private providers-which contradicts the objective of increasing the progressitivy of public spending - the avenues for policy in this area are unclear. ${ }^{68}$

In closing, since we have devoted so much attention to policies to improve equity in public spending on services, it is appropriate to add the reminder that equity should not be only criterion for investments in education and health. In many cases necessary investments will favor the non-poor, at least in terms of their first-round effects. For example, economic growth will require high as well as low-skilled workers. Thus there is a rationale for spending to improve the quality of post-primary schooling even if most of the direct beneficiaries will be

\footnotetext{
${ }^{68}$ Currently in Madagascar the government does provide some grants to private schools, but the share of these subsidies in the education budget is less than 1 percent (World Bank 2002). In health, it has been proposed that the government subsidize living expenses of private doctors who agree to practice in remote rural areas, but the objective here would be to subsidize the access of the poor, not the wealthy, to doctors' services.
} 
children from affluent families. Since economic growth will also benefit the poor, however, second round effects may be significantly pro-poor. In the same vein, subsidizing urban hospitals may benefit the well-off more than the poor but hospitals are also important as training sites for medical personnel. Many of these will work go on to work in primary care facilities that serve the poor, so again there are potentially large second round effects that help the poor.

Finally, expansions of services (as opposed simply to budget reallocations) obviously will require additional public resources. When compared with regional averages, spending on social services in relation to GDP is low in Madagascar. However, there is some cause for optimism here because of the debt relief provided to Madagascar under the Heavily Indebted Poor Country Initiative. A basic premise of HPIC is that resources made available from debt relief will be channeled into spending to reduce poverty. This together with Madagascar's explicitly stated commitment to poverty reduction should result in greater as well as better directed social spending on education and health. 


\section{REFERENCES}

Bourguignon, F. 2002. "From Income to Endowments: The Difficult Task of Expanding the Income Poverty Paradigm," (Paper prepared for the conference, Conceptual Challenges in Poverty and Inequality Analysis, Cornell University, April 16-17, 2002).

Bourguignon, F., L. Pereira da Silva, and N. Stern. 2002. "Evaluating the Poverty Impact of Economic Policies: Some Analytical Challenges.” Washington, DC: World Bank.

Castro-Leal, Florencia, Julia Dayton, Lionel Demery, and Kaplana Mehra. 1999. "Public Social Spending in Africa: Do the Poor Benefit?” World Bank Research Observer 14(1):49-72.

Culyer, A.J. and Adam Wagstaff. 1993. "Equity and Equality in Health and Health Care." Journal of Health Eeconomics. 12:431-457.

Davidson, Russell and Duclos, Jean-Yves, 1997. "Statistical inference for the measurement of the incidence of taxes and transfers.” Econometrica, 65:1453-1466.

Duclos, Jean-Yves. 1999. “Poverty, Social Welfare and Equity: Measurement and Incidence.” Université Laval. Draft.

Duclos, J.-Y. 2000. “Gini Indices and the Redistribution of Income.” International Tax and Public Finance 7:141-162.

Glick, P. 1999. "Patterns of Employment and Earnings in Madagascar." Cornell University Food and Nutrition Policy Program Working Paper No. 92. Ithaca, NY.

Glick, Peter, Jean Razafindravonona, and Iarivony Randretsa. 2000. “Services d'éducation et de santé à Madagascar: l'utilisation et les déterminants de la demande.” Antananarivo INSTAT (also available as Cornell University Food and Nutrition Policy Program Working Paper No. 107, Ithaca, NY).

Glick, P. and D. Sahn. 2002. "The Demand for Primary Schooling in Rural Madagascar: Price, Quality, and the Choice Between Public and Private Providers.” Cornell University Food and Nutrition Policy Program Working Paper No. 113, Ithaca, NY.

Hamner, Lucia, Graham Pyatt, and Howard White. 1999. "What do the World Bank’s Poverty Assessments Teach Us about Poverty in Sub-Saharan Africa?” Development and Change 30:795-823.

Hentschel, Jesko, Jean Olson Lanjouw, Peter Lanjouw, and Javier Poggi. 2000. “Combining Census and Survey Data to Trace the Spatial Dimensions of Poverty: A Case Study of Ecuador." The World Bank Economic Review 14(2).

Howe, S. 1996. “A New Test for Inferring Dominance from Sample Data.” Draft. 
Institut National de la Statistique. 1995. “Rapport principal de l'enquête intégrale 1993/1994.” Antananarivo (December).

Institut National de la Statistique. 1999. “Rapport principal de l'enquête prioritaire auprès des ménage 1997.” Antananarivo (August).

Institut National de la Statistique. 2000. “Rapport principal de l'enquête prioritaire auprès des ménages 1999.” Antananarivo (August).

Lanjouw, Peter, and Martin Ravallion 1999, "Benefit Incidence, Public Spending Reforms, and the Timing of Program Capture.” The World Bank Economic Review 13(2).

Razafindravonona, Jean, David Stifel, and Stefano Paternostro, 2001. "Evolution de la pauvreté à Madagascar: 1993-1999 (Changes in Poverty in Madagascar: 1993-1999).” Anatanarivo: INSTAT.

Selden, Thomas, and Michael Wasylenko. 1995. "Measuring the Distributional Effects of Public Education in Peru.” In Van de Walle, D. and Nead, K., eds. Public Spending and the Poor: Theory and Evidence. Baltimore and London: The John Hopkins University Press.

Sen, A. 1985. Commodities and Capabilities. Amsterdam: North-Holland Publishing Company.

Strauss, J., and Thomas, D., 1995. "Human Resources: Empirical Modeling of Household and Family Decisions.” In: Srinivasan, T.N., Behrman, J., eds., Handbook of Development Economics Vol. 3. North-Holland Publishing Company, Amsterdam.

Thomas, V., Y. Wang, and X. Fan. 2001. "Measuring Education Inequality: Gini Coefficients of Education.” Country Economics Development Papers, Washington, D.C.: World Bank..

UNDP and Institut National de la Statistique. 1999. Deuxième Rapport National sur le développement humain à Madagascar (Second National Report on Human Development in Madagascar) Antananarivo, Madagascar: INSTAT.

Van de Walle, D. 1998. “Assessing the Welfare Impacts of Public Spending.” World Development 26(3):365-379.

Van Doorslaer, Eddy, Adam Wagstaff, and Frans Rutten, eds. 1993. Equity in the Finance and Delivery of Health Care: An International Perspective. Oxford: Oxford University Press.

World Bank. 2002. Education and Training in Madagascar - Toward a Policy Agenda for Economic Growth and Poverty Reduction. Washington, D.C.: World Bank.

World Bank. 2001. Madagascar: Health Nutrition and Population Status Report: Inputs to the HPIC document and Poverty Reduction Strategy Paper. Antananarivo. Draft. 
World Bank 1999. Project Appraisal Document, Madagascar Second Health Sector Support Project. (Report No. 19801 MAG). Washington, D.C.: World Bank.

World Bank. 1996. Madagascar Poverty Assessment. Washington, D.C.: World Bank.

Yitzhaki, S. and Slemrod, J. 1991. "Welfare Dominance: An Application to Commodity Taxation.” American Economic Review 81(3):480-496.

Younger, Stephen. 1999. “The Relative Progressivity of Social Services in Ecuador.” Public Finance Review 27(3):310-352.

Younger, Stephen, and David E. Sahn. 2000. "Expenditure Incidence in Africa: Microeconomic Evidence.” Fiscal Studies 21(3):329-347.

Younger, Stephen. 2000. “The Incidence of Public Services and Subsidies in Peru.” Cornell University Food and Nutrition Policy Program Working Paper No. 103, Ithaca, NY.

Younger, Stephen, David E. Sahn, Steven Haggblade, and Paul A. Dorosh 1999 "Tax Incidence in Madagascar: An Analysis Using Household Data.” World Bank Economic Review 13(2):303-31. 
Table 1: GDP and Poverty Rates for the EPM Survey Years

\begin{tabular}{lrrr}
\hline & $1993 / 94$ & 1997 & 1999 \\
\hline GDP (billions of 1984 FMG) & 1,900 & 2,046 & 2,225 \\
Per Capita GDP (1984 FMG) & 155,253 & 149,662 & 154,070 \\
& & & \\
Poverty ${ }^{\text {a }}$ & & & \\
National & 70.0 & 73.3 & 71.3 \\
& & & \\
Urban & 50.1 & 63.2 & 52.1 \\
Rural & 74.5 & 76.0 & 76.7 \\
& & & \\
Province & & & \\
Antananarivo & 68.0 & 66.4 & 61.7 \\
Fianarantsoa & 74.2 & 75.1 & 81.1 \\
Taomasina & 77.9 & 79.8 & 71.3 \\
Mahajanga & 53.2 & 73.8 & 76.0 \\
Toliara & 81.1 & 82.0 & 71.6 \\
Antsiranana & 60.2 & 62.3 & 72.6 \\
\hline Source: Razafindravonona et. al. 2001 & & & \\
${ }^{a}$ Shows poverty rates multiplied by 100 & & &
\end{tabular}


Table 2: Public spending on education, Madagascar 1990-2000 (in billions of 1999 FMG)

\begin{tabular}{|c|c|c|c|c|c|c|c|c|c|c|c|}
\hline & 1990 & 1991 & 1992 & 1993 & 1994 & 1995 & 1996 & 1997 & 1998 & 1999 & 2000 \\
\hline Total (recurrent and capital) spending & 606.2 & 582.3 & 526.5 & 500.2 & 411.4 & 340.8 & 393.5 & 485.1 & 549.1 & 646.5 & 731.8 \\
\hline As $\%$ of GDP & 3.0 & 3.2 & 2.8 & 2.6 & 2.1 & 1.8 & 2.0 & 2.3 & 2.6 & 2.8 & 3.1 \\
\hline As $\%$ of total public spending & 17.6 & 19.3 & 13.9 & 12.7 & 10.8 & 10.0 & 11.1 & 13.5 & 13.7 & 17.8 & - \\
\hline $\begin{array}{l}\text { Recurrent spending } \\
\text { As } \% \text { of total public spending on }\end{array}$ & 520.6 & 494.7 & 447.7 & 451.2 & 376.4 & 327.9 & 338.2 & 394.9 & 448.9 & 498.1 & 520.3 \\
\hline education & 85.9 & 84.9 & 85.0 & 90.2 & 91.5 & 96.2 & 85.9 & 81.4 & 81.8 & 77.0 & 71.1 \\
\hline As $\%$ of GDP & 2.6 & 2.7 & 2.4 & 2.4 & 2.0 & 1.7 & 1.7 & 1.9 & 2.1 & 2.1 & 2.2 \\
\hline $\begin{array}{l}\text { As } \% \text { of total current spending net of } \\
\text { debt interest payment }\end{array}$ & 28.3 & 27.5 & 20.2 & 19.4 & 15.3 & 14.9 & 16.1 & 17.6 & 19.9 & 23.7 & - \\
\hline
\end{tabular}

Table 3: Public spending by level of education, Madagascar 1990-2000 (billions of 1999 FMG)

\begin{tabular}{|c|c|c|c|c|c|c|c|c|c|c|c|}
\hline & 1990 & 1991 & 1992 & 1993 & 1994 & 1995 & 1996 & 1997 & 1998 & 1999 & 2000 \\
\hline \multicolumn{12}{|l|}{ Primary and secondary education } \\
\hline Current & 85.2 & 99.0 & 103.7 & 116.4 & 142.4 & 187.8 & 230.1 & 294.1 & 361.6 & 424.8 & 452.9 \\
\hline Investment & 9.0 & 12.0 & 15.6 & 12.6 & 11.6 & 7.1 & 42.3 & 65.9 & 83.1 & 115.4 & 210.3 \\
\hline Total & 94.2 & 111.0 & 119.2 & 129.0 & 154.0 & 194.9 & 272.4 & 360.0 & 444.6 & 540.2 & 663.2 \\
\hline as share of total education spending & 0.68 & 0.71 & 0.76 & 0.77 & 0.79 & 0.82 & 0.85 & 0.85 & 0.85 & 0.84 & 0.87 \\
\hline \multicolumn{12}{|l|}{ Higher education } \\
\hline Current & 33.4 & 32.9 & 29.3 & 35.6 & 36.5 & 39.6 & 44.5 & 50.1 & 64.9 & 73.3 & 90.3 \\
\hline Investment & 10.6 & 11.5 & 7.8 & 4.0 & 5.0 & 1.8 & 2.6 & 12.7 & 12.1 & 33.0 & 10.5 \\
\hline Total & 44.0 & 44.5 & 37.1 & 39.6 & 41.4 & 41.4 & 47.0 & 62.8 & 77.0 & 106.3 & 100.8 \\
\hline as share of total education spending & 0.32 & 0.29 & 0.24 & 0.24 & 0.21 & 0.18 & 0.15 & 0.15 & 0.15 & 0.16 & 0.13 \\
\hline \multicolumn{12}{|l|}{ All levels } \\
\hline Current & 118.6 & 132.0 & 132.9 & 152.0 & 178.8 & 227.4 & 274.6 & 344.2 & 426.5 & 498.1 & 543.2 \\
\hline Investment & 19.6 & 23.5 & 23.4 & 16.6 & 16.6 & 8.9 & 44.9 & 78.6 & 95.2 & 148.4 & 220.8 \\
\hline Total & 138.1 & 155.4 & 156.3 & 168.5 & 195.4 & 236.3 & 319.5 & 422.8 & 521.6 & 646.5 & 764.0 \\
\hline
\end{tabular}

\footnotetext{
Source: Source: World Bank (2000)
} 
Table 4: Public Health expenditures 1997-99

\begin{tabular}{lrrr}
\hline & \multicolumn{3}{c}{ billions of fmg in current prices } \\
\cline { 2 - 4 } GDP & 20,515 & 23,741 & 27,311 \\
Total government expenditure (non-interest) & 2,982 & 3,258 & 3,759 \\
Total Health expenditure & 246 & 262 & 345 \\
of which: & & & \\
Recurrent & 124 & 143 & 172 \\
Investment & 122 & 119 & 173 \\
Total Health expenditure/gov't expenditure & $8.2 \%$ & $8.0 \%$ & $9.2 \%$ \\
Total Health expenditure/GDP & $1.2 \%$ & $1.1 \%$ & $1.3 \%$ \\
\hline
\end{tabular}

Source: Ministry of Health 
Table 5: Functional composition of recurrent (non-salary) Public health budget 19951999

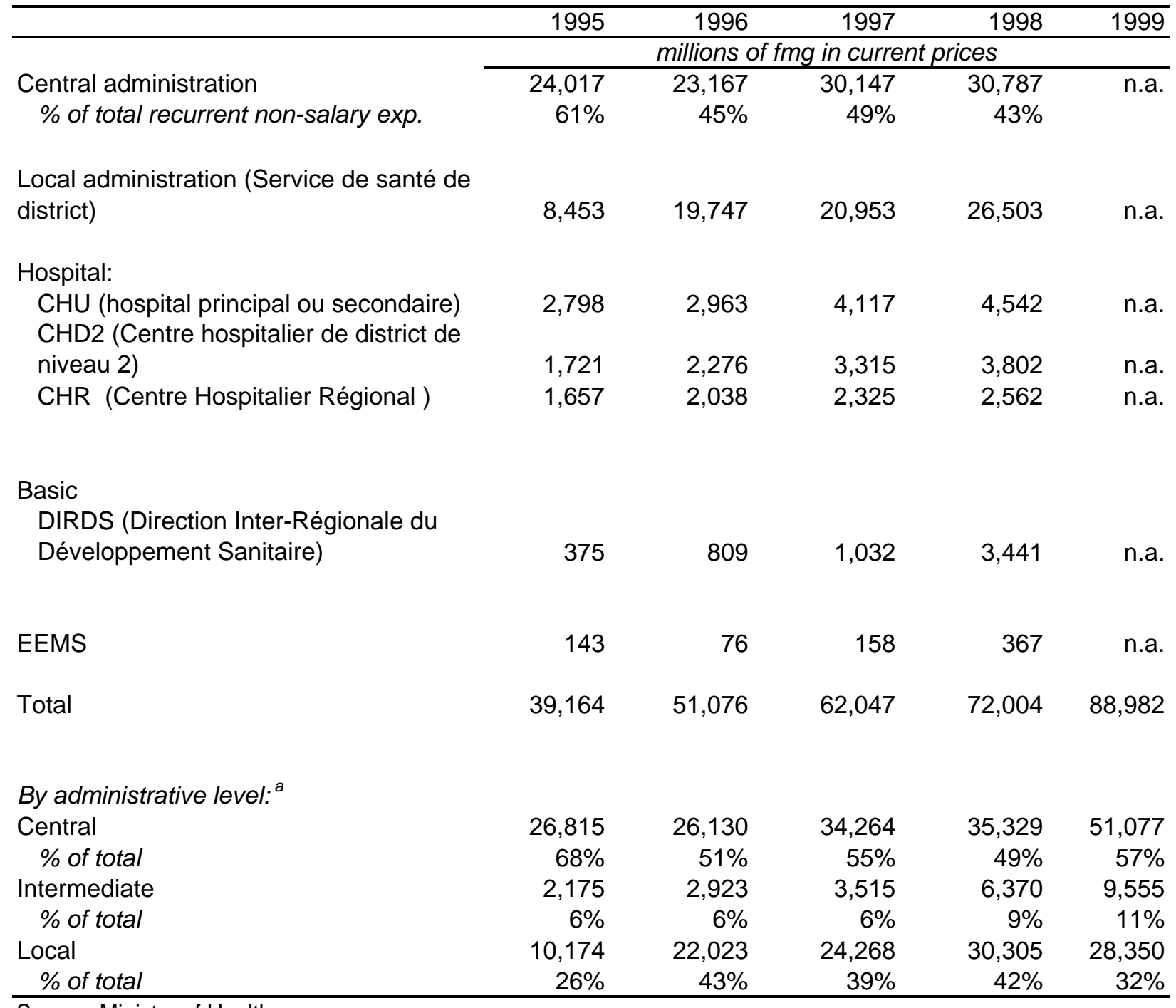

Source: Ministry of Health

${ }^{\mathrm{a}}$ Central $=$ Services centraux $+\mathrm{CHU}+$ Etablissements spécialisés + Ecole des Adjoints de santé publique Intermediate $=$ DIRDS + CHR + EEMS + Sous-ordonnateurs Local $=$ SSD + CHD2 
Table 6: School enrollment rates of children age 6-14 by expenditure quintile 1993/94-1999

\begin{tabular}{lcccccc}
\hline \multirow{2}{*}{ Year } & \multicolumn{7}{c}{ Quintile } \\
\cline { 2 - 7 } $1993 / 94$ & 1 & 2 & 3 & 4 & 5 & All \\
1997 & 31.6 & 48.6 & 59.1 & 61.6 & 63.2 & 51.4 \\
1999 & 53.7 & 64.7 & 66.3 & 72.3 & 78.2 & 66.0 \\
Change (1999-1993/94) & 56.0 & 67.0 & 67.7 & 70.5 & 81.8 & 67.5 \\
\hline
\end{tabular}

Source: EPM

Table 7: Rural and urban enrollment rates, 1993/94-1999

\begin{tabular}{|c|c|c|c|c|c|c|}
\hline \multirow[b]{2}{*}{ Year } & \multicolumn{2}{|c|}{ Children 6-14 } & \multicolumn{2}{|c|}{ Primary $^{\mathrm{a}}$} & \multicolumn{2}{|c|}{ Secondary $^{b}$} \\
\hline & Rural & Urban & Rural & Urban & Rural & Urban \\
\hline $1993 / 94$ & 45.6 & 79.0 & 42.8 & 77.8 & 8.0 & 37.7 \\
\hline$\%$ private & 17.8 & 39.4 & 17.8 & 41.0 & 33.3 & 49.4 \\
\hline 1997 & 62.7 & 79.3 & 60.3 & 74.9 & -- & -- \\
\hline$\%$ private & 19.1 & 41.8 & 19.7 & 44.4 & -- & -- \\
\hline 1999 & 64.0 & 81.0 & 61.2 & 76.9 & 9.0 & 34.9 \\
\hline$\%$ private & 15.0 & 42.5 & 14.0 & 46.2 & 27.8 & 49.1 \\
\hline Change (99-93/94) & 18.4 & 2.0 & 18.4 & -0.9 & 1.0 & -2.8 \\
\hline
\end{tabular}

Notes

${ }^{a}$ Net primary school enrollment (see notes to table 9)

1997 only: pre-school is included in primary.

${ }^{b}$ Net secondary enrollment (see notes to table 10 ) 
Table 8: School enrollment rates of children age 6-14 by province (Faritany), 1993/94-1999

\begin{tabular}{|c|c|c|c|c|c|c|c|c|}
\hline & & Fianarantsoa & Mahajanga & Antsirana & Toliara & Toamasina & Antananarivo & All \\
\hline \multirow[t]{3}{*}{$1993 / 94$} & Public & 31.8 & 43.7 & 58.2 & 27.2 & 47.5 & 38.7 & 39.3 \\
\hline & Private & 6.6 & 5.8 & 8.1 & 4.5 & 8.0 & 25.6 & 12.1 \\
\hline & Total & 38.4 & 49.5 & 66.3 & 31.7 & 55.5 & 64.3 & 51.4 \\
\hline \multirow[t]{3}{*}{1997} & Public & 51.5 & 42.4 & 63.5 & 35.3 & 62.9 & 47.7 & 49.8 \\
\hline & Private & 15.4 & 8.5 & 11.7 & 11.0 & 9.3 & 28.6 & 16.2 \\
\hline & Total & 66.9 & 50.9 & 75.3 & 46.2 & 72.2 & 76.3 & 66.0 \\
\hline \multirow[t]{3}{*}{1999} & Public & 50.5 & 42.8 & 68.7 & 49.6 & 65.6 & 49.4 & 52.8 \\
\hline & Private & 11.2 & 10.6 & 7.5 & 8.4 & 9.1 & 28.2 & 14.7 \\
\hline & Total & 61.7 & 53.4 & 76.2 & 58.0 & 74.7 & 77.6 & 67.5 \\
\hline \multirow{3}{*}{$\begin{array}{l}\text { Change } \\
(1999-1993 / 94)\end{array}$} & Public & 18.7 & -0.9 & 10.5 & 22.4 & 18.1 & 10.7 & 13.5 \\
\hline & Private & 4.6 & 4.9 & -0.6 & 3.9 & 1.1 & 2.5 & 2.6 \\
\hline & Total & 23.3 & 3.9 & 9.9 & 26.3 & 19.2 & 13.2 & 16.1 \\
\hline
\end{tabular}


Table 9: Gross and net primary enrollment ratios by expenditure quintile 1993/94-1999

\begin{tabular}{|c|c|c|c|c|c|c|c|}
\hline & \multirow{2}{*}{\multicolumn{5}{|c|}{ Quintile }} & \multirow[b]{3}{*}{ All } \\
\hline & & & & & & & \\
\hline \multicolumn{2}{|l|}{ Year } & 1 & 2 & 3 & 4 & 5 & \\
\hline \multirow[t]{4}{*}{$1993 / 94$} & Gross enrollment ratio & 51.3 & 82.2 & 101.7 & 98.8 & 93.7 & 82.9 \\
\hline & Net enrollment ratio & 29.3 & 43.4 & 59.0 & 59.7 & 59.6 & 48.3 \\
\hline & private share $^{\mathrm{a}}$ & 0.12 & 0.18 & 0.18 & 0.19 & 0.44 & 0.21 \\
\hline & female share ${ }^{b}$ & 0.46 & 0.52 & 0.52 & 0.49 & 0.50 & 0.50 \\
\hline \multirow[t]{4}{*}{1997} & Gross enrollment ratio & 90.2 & 112.0 & 112.1 & 117.2 & 129.9 & 110.2 \\
\hline & Net enrollment ratio & 52.3 & 62.9 & 64.5 & 66.7 & 74.2 & 63.1 \\
\hline & private share $^{a}$ & 0.17 & 0.20 & 0.25 & 0.30 & 0.35 & 0.25 \\
\hline & female share ${ }^{b}$ & 0.50 & 0.47 & 0.50 & 0.48 & 0.52 & 0.49 \\
\hline \multirow[t]{4}{*}{1999} & Gross enrollment ratio & 98.7 & 109.9 & 117.9 & 123 & 131.6 & 114.4 \\
\hline & Net enrollment ratio & 53.2 & 64.8 & 64.0 & 68.0 & 77.7 & 64.3 \\
\hline & private share $^{\mathrm{a}}$ & 0.10 & 0.14 & 0.19 & 0.21 & 0.36 & 0.19 \\
\hline & female share ${ }^{b}$ & 0.50 & 0.50 & 0.52 & 0.51 & 0.51 & 0.51 \\
\hline \multirow{2}{*}{$\begin{array}{l}\text { Change } \\
(1999-1993 / 94)\end{array}$} & Gross enrollment ratio & 47.4 & 27.7 & 16.2 & 24.2 & 37.9 & 31.5 \\
\hline & Net enrollment ratio & 23.9 & 21.4 & 4.9 & 8.3 & 18.1 & 16.1 \\
\hline
\end{tabular}

Notes:

Gross enrollment $=$ total primary enrollments divided by number of primary age children $\times 100$.

Net enrollment $=$ total primary enrollments of primary school age children divided by number of primary age children $\times 100$

1997 only: pre-school is included in primary.

${ }^{a}$ Share of private enrollments in total primary enrollments

${ }^{b}$ Share of female enrollments in total primary enrollments 
Table 10: Gross and net secondary enrollment ratios by expenditure quintile 1993/94-1999

\begin{tabular}{|c|c|c|c|c|c|c|c|}
\hline \multirow[b]{2}{*}{ Year } & & \multicolumn{5}{|c|}{ Quintile } & \multirow[b]{2}{*}{ All } \\
\hline & & 1 & 2 & 3 & 4 & 5 & \\
\hline \multirow[t]{4}{*}{$1993 / 94$} & Gross enrollment ratio & 3.3 & 10.7 & 13.9 & 25.9 & 47.6 & 19.4 \\
\hline & Net enrollment ratio & 2.9 & 7.3 & 10.6 & 18.6 & 34.5 & 14.1 \\
\hline & private share $^{\mathrm{a}}$ & 0.26 & 0.30 & 0.31 & 0.37 & 0.54 & 0.42 \\
\hline & female share $^{b}$ & 0.57 & 0.47 & 0.48 & 0.45 & 0.48 & 0.47 \\
\hline \multirow[t]{4}{*}{1999} & Gross enrollment ratio & 5.9 & 12.9 & 16.6 & 24.9 & 50.3 & 21.2 \\
\hline & Net enrollment ratio & 4.3 & 10.0 & 11.1 & 18.5 & 33.6 & 14.8 \\
\hline & private share $^{\mathrm{a}}$ & 0.17 & 0.20 & 0.29 & 0.36 & 0.57 & 0.41 \\
\hline & female share ${ }^{b}$ & 0.46 & 0.50 & 0.45 & 0.45 & 0.52 & 0.48 \\
\hline Change & Gross enrollment ratio & 2.6 & 2.2 & 2.7 & -1.0 & 2.7 & 1.8 \\
\hline$(1999-1993 / 94)$ & Net enrollment ratio & 1.4 & 2.7 & 0.5 & -0.1 & -0.9 & 0.7 \\
\hline
\end{tabular}

Notes:

Gross enrollment $=$ total secondary enrollments divided by number of secondary age children $\times 100$.

Net enrollment $=$ total secondary enrollments of secondary school age children divided by number of secondary age children $\times 100$

${ }^{a}$ Share of private enrollments in total secondary enrollments

${ }^{\mathrm{b}}$ Share of female enrollments in total secondary enrollments 
Table 11: Gross and net university enrollment ratios by expenditure quintile 1993/94-1999

\begin{tabular}{|c|c|c|c|c|c|c|c|}
\hline \multirow{2}{*}{ Year } & & \multicolumn{5}{|c|}{ Quintile } & \multirow[b]{2}{*}{ All } \\
\hline & & 1 & 2 & 3 & 4 & 5 & \\
\hline \multirow[t]{3}{*}{$1993 / 94$} & Gross enrollment ratio & $\overline{0.0}$ & 0.3 & 0.7 & 1.5 & 9.2 & 2.6 \\
\hline & Net enrollment ratio & 0.00 & 0.29 & 0.00 & 0.72 & 3.22 & 0.93 \\
\hline & female share ${ }^{b}$ & 0.00 & 0.00 & 0.37 & 0.49 & 0.52 & 0.49 \\
\hline \multirow[t]{3}{*}{1999} & Gross enrollment ratio & 0.0 & 0.2 & 0.2 & 2.0 & 5.2 & 1.6 \\
\hline & Net enrollment ratio & 0.00 & 0.00 & 0.05 & 1.11 & 2.17 & 0.69 \\
\hline & female share ${ }^{b}$ & 0.00 & 0.00 & 0.00 & 0.44 & 0.59 & 0.52 \\
\hline Change & Gross enrollment ratio & 0.00 & -0.10 & -0.50 & 0.50 & -4.00 & -1.00 \\
\hline$(1999-1993 / 94)$ & Net enrollment ratio & 0.00 & -0.29 & 0.05 & 0.39 & -1.04 & -0.25 \\
\hline
\end{tabular}

${ }^{\mathrm{b}}$ Share of female enrollments in total university enrollments 
Table 12: Fees per student $1993 / 4$ and 1999 by school level and type (constant 1993 Fmg)

\begin{tabular}{|c|c|c|c|c|c|c|}
\hline \multirow[b]{3}{*}{ Year } & \multicolumn{3}{|c|}{ Rural } & \multicolumn{3}{|c|}{ Urban } \\
\hline & \multirow[b]{2}{*}{ Public } & \multicolumn{2}{|c|}{ Private } & \multirow[b]{2}{*}{ Public } & \multicolumn{2}{|c|}{ Private } \\
\hline & & Religious & Non-relig, & & Religious & Non-relig, \\
\hline & \multicolumn{6}{|c|}{ Primary } \\
\hline \multicolumn{7}{|l|}{$1993 / 4$} \\
\hline$\%$ paying fees & $74.1 \%$ & $85.5 \%$ & $73.8 \%$ & $75.1 \%$ & $82.2 \%$ & $78.9 \%$ \\
\hline median fee $e^{a}$ & 709 & 3,605 & 9,943 & 1,599 & 26,012 & 36,673 \\
\hline \multicolumn{7}{|l|}{1999} \\
\hline$\%$ paying fees & $97.4 \%$ & $99.4 \%$ & $98.6 \%$ & $99.7 \%$ & $89.6 \%$ & $98.5 \%$ \\
\hline median fee ${ }^{a}$ & 996 & 6,985 & 12,484 & 2,690 & 14,640 & 20,203 \\
\hline & \multicolumn{6}{|c|}{ Secondary } \\
\hline \multicolumn{7}{|l|}{$1993 / 4$} \\
\hline$\%$ paying fees & $80.5 \%$ & $83.6 \%$ & $86.4 \%$ & $83.7 \%$ & $75.7 \%$ & $78.3 \%$ \\
\hline median fee ${ }^{a}$ & 3,310 & 20,933 & 58,967 & 5,175 & 37,982 & 50,166 \\
\hline \multicolumn{7}{|l|}{1999} \\
\hline$\%$ paying fees & $100.0 \%$ & $100.0 \%$ & $100.0 \%$ & $99.7 \%$ & $100.0 \%$ & $99.5 \%$ \\
\hline median fee ${ }^{a}$ & 2,687 & 12,491 & 13,758 & 7,657 & 17,173 & 19,530 \\
\hline
\end{tabular}


Table 13: Household schooling costs per student by school level and type 1993/94 and 1999 (constant $1993 \mathrm{Fmg}$ )

\begin{tabular}{|c|c|c|c|c|c|c|}
\hline \multirow[b]{3}{*}{ Year } & \multicolumn{3}{|c|}{ Rural } & \multicolumn{3}{|c|}{ Urban } \\
\hline & \multirow[b]{2}{*}{ Public } & \multicolumn{2}{|c|}{ Private } & \multirow[b]{2}{*}{ Public } & \multicolumn{2}{|c|}{ Private } \\
\hline & & Religious & Non-relig. & & Religious & Non-relig. \\
\hline & \multicolumn{6}{|c|}{ Primary } \\
\hline $\begin{array}{l}1993 / 94 \\
\quad \text { as \% of non-food }\end{array}$ & 4,717 & 9,848 & 27,999 & 10,840 & 49,128 & 61,220 \\
\hline expenditures ${ }^{a}$ & $3.0 \%$ & $6.2 \%$ & $17.8 \%$ & $2.3 \%$ & $10.6 \%$ & $13.2 \%$ \\
\hline $\begin{array}{l}1999 \\
\quad \text { as \% of non-food }\end{array}$ & 4,995 & 15,249 & 24,806 & 10,980 & 30,203 & 47,213 \\
\hline \multirow[t]{2}{*}{ expenditures $^{a}$} & $3.1 \%$ & $9.6 \%$ & $15.5 \%$ & $2.4 \%$ & $6.5 \%$ & $10.1 \%$ \\
\hline & \multicolumn{6}{|c|}{ Secondary } \\
\hline $\begin{array}{l}1993 / 94 \\
\text { as \% of non-food }\end{array}$ & 25,074 & 55,851 & 110,699 & 32,552 & 63,429 & 87,589 \\
\hline expenditures $^{a}$ & $15.1 \%$ & $33.6 \%$ & $66.7 \%$ & $6.3 \%$ & $12.3 \%$ & $17.0 \%$ \\
\hline $\begin{array}{l}1999 \\
\quad \text { as \% of non-food }\end{array}$ & 17,910 & 33,493 & 32,940 & 29,646 & 43,773 & 45,127 \\
\hline expenditures $^{a}$ & $10.7 \%$ & $20.1 \%$ & $19.8 \%$ & $5.7 \%$ & $8.4 \%$ & $8.7 \%$ \\
\hline
\end{tabular}

Notes:

fees, books, transportion, uniforms and other school related items.

a Shows per student cost as a share of median non-food expenditures for rural or urban households with one or more 
Table 14: Rates of reported illness/injury and treatment by expenditure quintile 1993/94 and 1999

\begin{tabular}{|c|c|c|c|c|c|c|c|}
\hline \multirow{2}{*}{ Year } & & \multicolumn{5}{|c|}{ Quintile } & \multirow[b]{2}{*}{ All } \\
\hline & & 1 & 2 & 3 & 4 & 5 & \\
\hline \multirow[t]{5}{*}{$1993 / 94$} & $\begin{array}{l}\text { Percent reporting recent }{ }^{\mathrm{a}} \text { illness or } \\
\text { injury } \\
\text { of which: }\end{array}$ & 11.8 & 12.6 & 14.2 & 14.6 & 16.1 & 13.9 \\
\hline & $\%$ consulting a formal care provider & 232 & 310 & 302 & 374 & 132 & 336 \\
\hline & females & 28.3 & 28.8 & 34.8 & 39.0 & 41.1 & 35.0 \\
\hline & all & 25.6 & 29.8 & 32.5 & 38.3 & 42.1 & 34.3 \\
\hline & $\%$ consulting informal provider & 3.2 & 4.6 & 3.5 & 3.4 & 4.2 & 3.8 \\
\hline \multirow[t]{6}{*}{1999} & $\begin{array}{l}\text { Percent reporting recent }{ }^{\mathrm{a}} \text { illness or } \\
\text { injury } \\
\text { of which: }\end{array}$ & 10.1 & 11.2 & 11.0 & 10.6 & 11.3 & 10.8 \\
\hline & $\%$ consulting a formal care provider & & & & & & \\
\hline & males & 31.9 & 38.5 & 45.8 & 45.8 & 49.9 & 42.5 \\
\hline & females & 35.0 & 36.5 & 48.2 & 47.6 & 52.0 & 44.1 \\
\hline & all & 33.5 & 37.5 & 47.1 & 46.7 & 51.0 & 43.3 \\
\hline & $\%$ consulting informal provider & 1.7 & 2.5 & 2.3 & 2.1 & 4.2 & 2.6 \\
\hline $\begin{array}{l}\text { Notes: } \\
\text { Illness inc } \\
\mathrm{a}^{\text {in the tw }}\end{array}$ & $\begin{array}{l}\text { dence data are available for } 1993 / 4 \text { and } 19 \\
\text { weeks preceding the interview }\end{array}$ & & & & & & \\
\hline \multicolumn{8}{|c|}{$\begin{array}{l}\text { Formal care includes hospitals, basic care centers, private doctors and clinics, and pharmacies. } \\
\text { Informal care refers to traditional healers (guerisseur) or other private informal treatment. }\end{array}$} \\
\hline
\end{tabular}


Table 15: Formal care consultations per capita by provider type and expenditure quintile, 1993/94

\begin{tabular}{|c|c|c|c|c|c|c|c|c|c|c|c|c|}
\hline \multirow[b]{3}{*}{ Hospital } & \multicolumn{10}{|c|}{ Quintile } & \multirow{2}{*}{\multicolumn{2}{|c|}{ All }} \\
\hline & \multicolumn{2}{|c|}{1} & \multicolumn{2}{|c|}{2} & \multicolumn{2}{|c|}{3} & \multicolumn{2}{|c|}{4} & \multicolumn{2}{|c|}{5} & & \\
\hline & 0.021 & 44.0 & 0.013 & 24.0 & 0.013 & 18.7 & 0.019 & 22.9 & 0.021 & 20.6 & 0.017 & 24.4 \\
\hline Basic care facility & 0.020 & 42.7 & 0.032 & 57.9 & 0.037 & 54.4 & 0.039 & 47.7 & 0.042 & 40.8 & 0.034 & 47.9 \\
\hline Private doctor & 0.004 & 9.1 & 0.007 & 13.6 & 0.017 & 25.2 & 0.020 & 24.5 & 0.035 & 34.0 & 0.017 & 23.7 \\
\hline Private clinic & 0.001 & 2.1 & 0.001 & 1.3 & 0.001 & 1.7 & 0.004 & 5.0 & 0.005 & 4.4 & 0.002 & 3.2 \\
\hline $\begin{array}{l}\text { Pharmacy/depot } \\
\text { de medicaments }\end{array}$ & 0.001 & 2.2 & 0.002 & 3.2 & 0.000 & 0.0 & 0.000 & 0.0 & 0.000 & 0.2 & 0.001 & 0.9 \\
\hline All public care ${ }^{a}$ & 0.041 & 86.6 & 0.045 & 81.9 & 0.050 & 73.1 & 0.057 & 70.5 & 0.063 & 61.4 & 0.051 & 72.3 \\
\hline All private care ${ }^{\mathrm{b}}$ & 0.006 & 13.4 & 0.010 & 18.1 & 0.018 & 26.9 & 0.024 & 29.5 & 0.040 & 38.6 & 0.020 & 27.7 \\
\hline All formal care & 0.047 & 100.0 & 0.055 & 100.0 & 0.068 & 100.0 & 0.081 & 100.0 & 0.103 & 100.0 & 0.071 & 100.0 \\
\hline
\end{tabular}

Notes:

Shows number of visits to the provider by individuals in a quintile divided by the total number of people (ill or not) in the quintile.

Figures in italics show the provider's share of all formal care consultations for the quintile.

Hospital includes primary or secondary hospitals

Basic care facility includes dispensaire, post sanitaire, post d'infirmerie, CSSP (Centre de Soins de Santé Primaire)

a public care includes all hospital and basic care facilities. Note some Dispensaire may be private.

${ }^{b}$ private care includes doctors, private clinics, and pharmacie/depot de medicaments

Table 16: Formal care consultations per capita by provider type and expenditure quintile, 1997

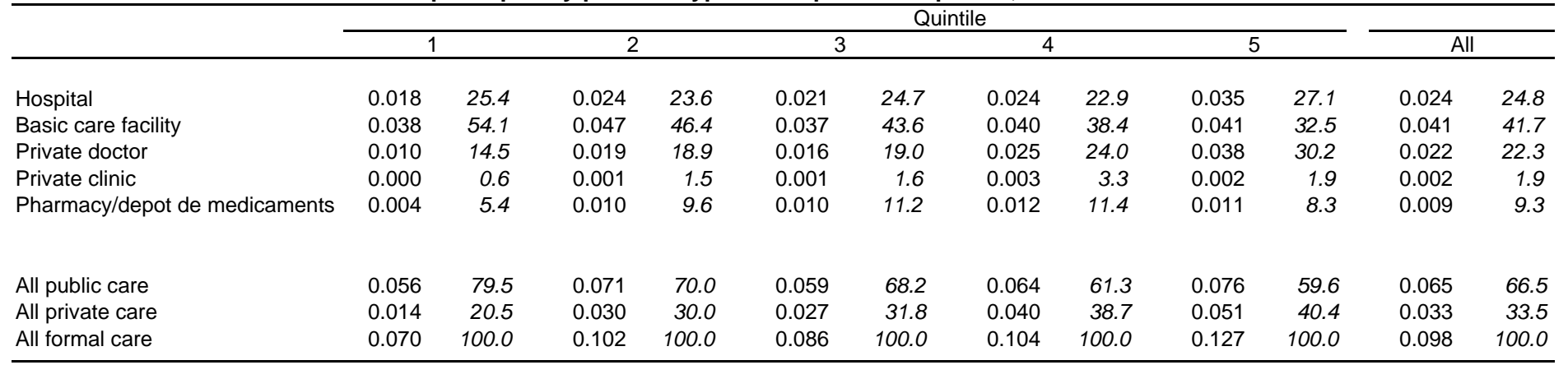

\section{Notes:}

Shows number of visits to the provider by individuals in a quintile divided by the total number of people (ill or not) in the quintile.

Figures in italics show the provider's share of all formal care consultations for the quintile.

Hospital includes primary or secondary hospitals

Basic care facility includes dispensaire, post sanitaire, post d'infirmerie, CSSP (Centre de Soins de Santé Primaire)

${ }^{a}$ public care includes all hospital and basic care facilities. Note some Dispensaire may be private.

${ }^{b}$ private care includes doctors, private clinics, and pharmacie/depot de medicaments 
Table 17: Formal care consultations per capita by provider type and expenditure quintile, 1999

\begin{tabular}{|c|c|c|c|c|c|c|c|c|c|c|c|c|}
\hline \multirow[b]{3}{*}{ Hospital } & \multicolumn{12}{|c|}{ Quintile } \\
\hline & \multicolumn{2}{|c|}{1} & \multicolumn{2}{|c|}{2} & \multicolumn{2}{|c|}{3} & \multicolumn{2}{|c|}{4} & \multicolumn{2}{|c|}{5} & \multicolumn{2}{|c|}{ All } \\
\hline & 0.006 & 16.6 & 0.010 & 19.8 & 0.018 & 26.8 & 0.019 & 29.0 & 0.020 & 26.5 & 0.015 & 24.7 \\
\hline Basic care facility (excl. OSTIE) & 0.023 & 58.7 & 0.029 & 58.1 & 0.028 & 40.6 & 0.024 & 37.3 & 0.016 & 21.1 & 0.024 & 40.3 \\
\hline OSTIE ${ }^{a}$ & 0.000 & 0.2 & 0.000 & 0.8 & 0.001 & 0.8 & 0.003 & 4.0 & 0.004 & 4.8 & 0.001 & 2.4 \\
\hline Private doctor & 0.005 & 13.1 & 0.006 & 11.9 & 0.012 & 17.7 & 0.010 & 15.8 & 0.023 & 30.2 & 0.011 & 18.8 \\
\hline Private clinic & 0.003 & 7.5 & 0.003 & 6.3 & 0.006 & 9.2 & 0.004 & 5.4 & 0.009 & 11.8 & 0.005 & 8.3 \\
\hline $\begin{array}{l}\text { Pharmacy/depot } \\
\text { de medicaments }\end{array}$ & 0.001 & 1.5 & 0.001 & 2.1 & 0.002 & 2.3 & 0.002 & 3.6 & 0.002 & 3.1 & 0.002 & 2.6 \\
\hline $\begin{array}{l}\text { Non-governmental } \\
\text { organization }\end{array}$ & 0.001 & 2.4 & 0.000 & 1.0 & 0.002 & 2.6 & 0.003 & 4.9 & 0.002 & 2.6 & 0.002 & 2.8 \\
\hline All public care ${ }^{b}$ & 0.030 & 77.9 & 0.040 & 79.7 & 0.048 & 70.8 & 0.049 & 75.2 & 0.041 & 54.9 & 0.042 & 70.2 \\
\hline All private care ${ }^{c}$ & 0.009 & 22.1 & 0.010 & 20.3 & 0.020 & 29.2 & 0.016 & 24.8 & 0.034 & 45.1 & 0.018 & 29.8 \\
\hline All formal care & 0.039 & 100.0 & 0.050 & 100.0 & 0.068 & 100.0 & 0.066 & 100.0 & 0.075 & 100.0 & 0.060 & 100.0 \\
\hline
\end{tabular}

\section{Notes:}

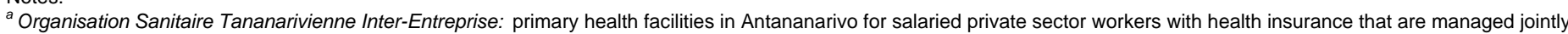
by the state and private sector.

${ }^{b}$ public care includes same categories as above. In addition, OSTIE and NGO providers are grouped with public providers.

${ }^{c}$ private care includes doctors, private clinics, and pharmacie/depot de medicaments 
Table 18: Rural and urban consultations per capita by provider type, 1993/94

\begin{tabular}{|c|c|c|c|c|}
\hline \multirow[b]{2}{*}{ Formal care: } & \multicolumn{2}{|c|}{ Rural } & \multicolumn{2}{|c|}{ Urban } \\
\hline & 0.061 & 100.0 & 0.114 & 100.0 \\
\hline Hospital & 0.015 & 24.9 & 0.026 & 23.2 \\
\hline Basic care facility & 0.032 & 51.8 & 0.044 & 38.7 \\
\hline Private doctor & 0.012 & 18.9 & 0.040 & 35.0 \\
\hline Private clinic & 0.002 & 3.3 & 0.003 & 3.0 \\
\hline Pharmacy/depot de medicaments & 0.001 & 1.2 & 0.000 & 0.1 \\
\hline All public formal care & 0.047 & 76.6 & 0.071 & 61.9 \\
\hline All private formal care & 0.014 & 23.4 & 0.043 & 38.1 \\
\hline Informal care & 0.006 & & 0.004 & \\
\hline
\end{tabular}

Notes:

Shows number of visits to the provider by rural or urban residents divided by the total number of people (ill or not) in rural or urban areas.

Figures in italics show the provider's share of all formal care consultations for rural or urban areas.

See also notes to tables 15-17.

Table 19: Rural and urban consultations per capita by provider type, 1997

\begin{tabular}{lrrrr}
\hline & \multicolumn{2}{c}{ Rural } & \multicolumn{3}{c}{ Urban } \\
\hline & & & & \\
Formal care: & 0.093 & 100.0 & 0.116 & 100.0 \\
$\quad$ Hospital & 0.021 & 22.4 & 0.037 & 31.7 \\
$\quad$ Basic care facility & 0.042 & 44.9 & 0.037 & 32.2 \\
$\quad$ Private doctor & 0.018 & 19.1 & 0.037 & 31.6 \\
$\quad$ Private clinic & 0.002 & 2.3 & 0.001 & 0.8 \\
& & & & \\
Pharmacy/depot de medicaments & 0.010 & 11.2 & 0.004 & 3.7 \\
& & & & \\
All public formal care & 0.063 & 67.4 & 0.074 & 64.0 \\
All private formal care & 0.030 & 32.6 & 0.042 & 36.0 \\
& & & & \\
Informal care & 0.9 & & 0.004 & \\
\hline
\end{tabular}

Notes:

Shows number of visits to the provider by rural or urban residents divided by the total number of people (ill or not) in rural or urban areas.

Figures in italics show the provider's share of all formal care consultations for rural or urban areas.

See also notes to tables $15-17$. 
Table 20: Rural and urban consultations per capita by provider type, 1999

\begin{tabular}{lrrrr}
\hline & \multicolumn{2}{c}{ Rural } & \multicolumn{2}{c}{ Urban } \\
\hline Formal care: & 0.056 & 100.0 & 0.072 & 100.0 \\
$\quad$ Hospital & 0.010 & 18.3 & 0.030 & 42.1 \\
Basic care facility (excl. OSTIE) & 0.027 & 48.4 & 0.013 & 18.0 \\
OSTIE & 0.001 & 1.8 & 0.003 & 4.1 \\
$\quad$ Private doctor & 0.010 & 17.3 & 0.017 & 23.0 \\
$\quad$ Private clinic & 0.005 & 8.6 & 0.005 & 7.5 \\
$\quad$ Pharmacy/depot de medicaments & 0.002 & 3.5 & 0.000 & 0.2 \\
$\quad$ Non-governmental org. & 0.001 & 2.0 & 0.004 & 5.0 \\
& & & & \\
All public formal care & 0.040 & 70.6 & 0.050 & 69.2 \\
All private formal care & 0.016 & 29.4 & 0.022 & 30.8 \\
& & & & \\
Informal care & 0.006 & & 0.016 & \\
\hline
\end{tabular}

Notes:

Shows number of visits to the provider by rural or urban residents divided by the total number of people (ill or not) in rural or urban areas.

Figures in italics show the provider's share of all formal care consultations for rural or urban areas.

See also notes to tables 15-17. 
Table 21: Health care costs per visit by provider and location, 1993/941999 (constant 1993 FMG)

\begin{tabular}{|c|c|c|c|c|}
\hline \multirow[b]{2}{*}{ Year } & \multicolumn{2}{|c|}{ Rural } & \multicolumn{2}{|c|}{ Urban } \\
\hline & $\%$ paying $^{a}$ & Median Cost ${ }^{\mathrm{D}}$ & $\%$ paying $^{a}$ & Median Cost ${ }^{\mathrm{D}}$ \\
\hline \multicolumn{5}{|l|}{ Hospital } \\
\hline $1993 / 94$ & $47 \%$ & 631 & $24 \%$ & 3,015 \\
\hline 1997 & $90 \%$ & 5,457 & $85 \%$ & 7,932 \\
\hline 1999 & $91 \%$ & 3,582 & $95 \%$ & 5,051 \\
\hline \multicolumn{5}{|l|}{ Basic Care } \\
\hline 1993/94 & $35 \%$ & 2,425 & $29 \%$ & 1,382 \\
\hline 1997 & $71 \%$ & 2,788 & $79 \%$ & 4,068 \\
\hline 1999 & $93 \%$ & 2,196 & $80 \%$ & 1,852 \\
\hline \multicolumn{5}{|c|}{ Private formal care } \\
\hline $1993 / 94$ & $87 \%$ & 2,321 & $88 \%$ & 3,312 \\
\hline 1997 & $85 \%$ & 5,091 & $96 \%$ & 7,892 \\
\hline 1999 & $99 \%$ & 4,478 & $97 \%$ & 6,943 \\
\hline \multicolumn{5}{|l|}{ Notes: } \\
\hline \multicolumn{5}{|c|}{$\begin{array}{l}\text { Provider categories are as defined in tables } 15-17 \text { except that private formal care excludes } \\
\text { pharmacies. }\end{array}$} \\
\hline \multicolumn{5}{|c|}{$\begin{array}{l}\text { apercent of visits for which patient reported paying for the consultation }(1993,1997) \text { or for the } \\
\text { consultation and/or medicines }(1999)\end{array}$} \\
\hline $\begin{array}{l}{ }^{b} \text { for the subs } \\
1999, \text { the co }\end{array}$ & $\begin{array}{l}\text { ting positive cc } \\
\text { ees and medic }\end{array}$ & $\begin{array}{l}\text { sts. For 1993,97, } \\
\text { ines }\end{array}$ & nsultation fees & were reported \\
\hline
\end{tabular}


Table 22: Women 15-49 giving birth in the last 12 months: consultation rates for prenatal care by expenditure quintile 1993/94 and 1999

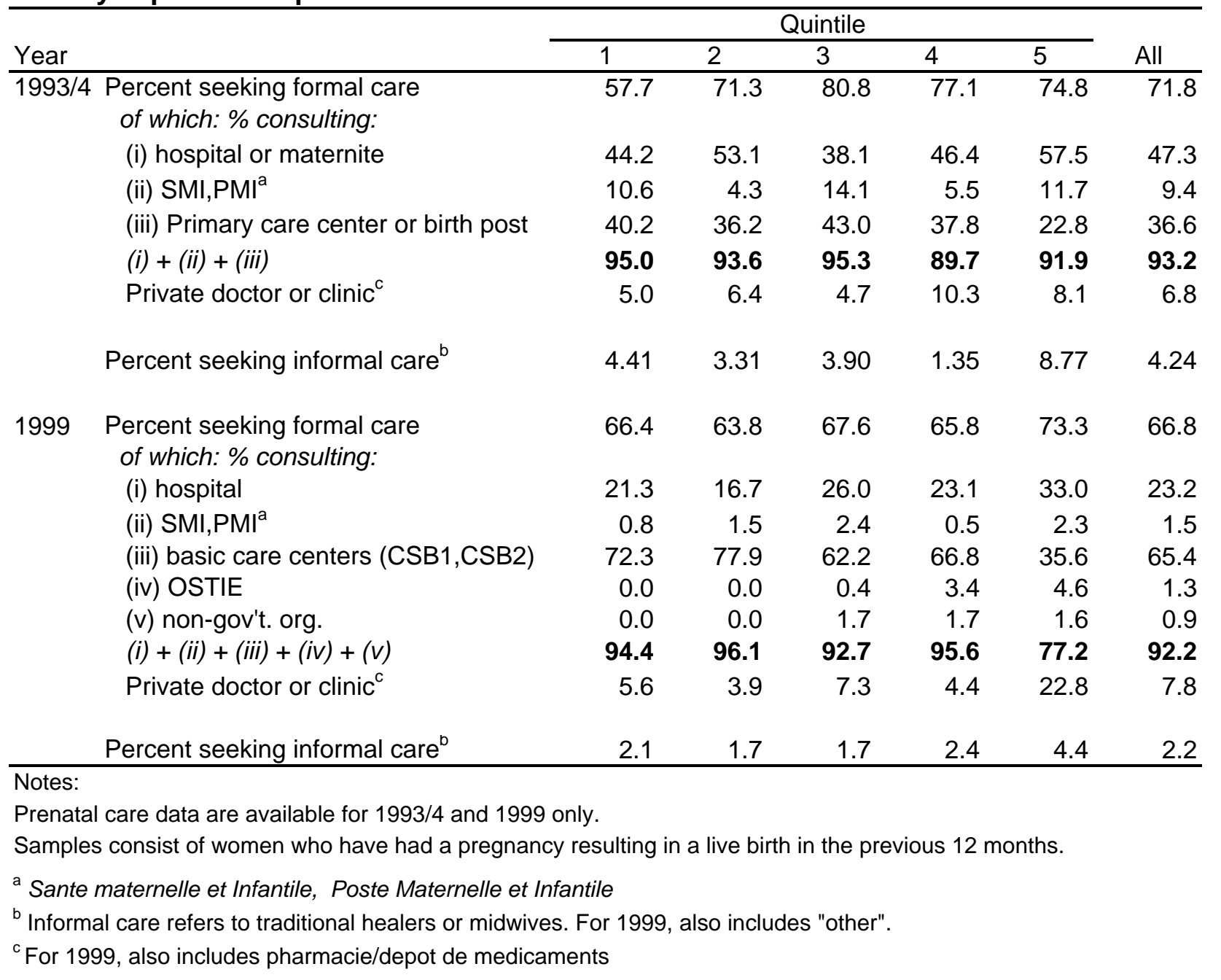


Table 23: Women 15-49 giving birth in the last 12 months - Rural and urban consultation rates for prenatal care 1993/94 and 1999

\begin{tabular}{|c|c|c|c|}
\hline & & Rural & Urban \\
\hline \multirow[t]{7}{*}{$1993 / 94$} & $\begin{array}{l}\text { Percent seeking formal care } \\
\text { of which: \% consulting: }\end{array}$ & 69.6 & 84.6 \\
\hline & (i) hospital or maternite & 45.2 & 56.8 \\
\hline & (ii) $\mathrm{SMI}, \mathrm{PMI}^{\mathrm{a}}$ & 6.5 & 22.9 \\
\hline & (iii) Primary care center or birth post & 43.2 & 5.2 \\
\hline & (i) + (ii) + (iii) & 94.9 & 85.0 \\
\hline & Private doctor or clinic ${ }^{c}$ & 5.1 & 15.1 \\
\hline & Percent seeking informal care ${ }^{\mathrm{b}}$ & 4.7 & 1.8 \\
\hline \multirow[t]{9}{*}{1999} & $\begin{array}{l}\text { Percent seeking formal care } \\
\text { of which: \% consulting: }\end{array}$ & 64.8 & 76.1 \\
\hline & (i) hospital & 17.96 & 44.3 \\
\hline & (ii) $\mathrm{SMI}, \mathrm{PMI} \mathrm{a}^{\mathrm{a}}$ & 0.18 & 6.59 \\
\hline & (iii) basic care centers & 74.69 & 27.78 \\
\hline & (iv) OSTIE & 1.06 & 2.45 \\
\hline & (v) non-gov't. org. & 0.67 & 1.72 \\
\hline & (i) $+($ ii $)+($ iii $)+($ iv $)+(v)$ & 94.56 & 82.84 \\
\hline & Private doctor or clinic ${ }^{c}$ & 5.44 & 17.15 \\
\hline & Percent seeking informal care ${ }^{b}$ & 1.9 & 3.8 \\
\hline
\end{tabular}

Notes:

Prenatal care data are available for 1993/4 and 1999 only.

Samples consist of women who have had a pregnancy resulting in a live birth in the previous 12 months.

a Sante maternelle et Infantile, Poste Maternelle et Infantile

b Informal care refers to traditional healers or midwives. For 1999, also includes "other".

${ }^{c}$ For 1999, also includes pharmacie/depot de medicaments 
Table 24: Women 15-49 giving birth in the last 12 months: consultation rates for formal prenatal care by Faritany, 1993/94 and 1999

\begin{tabular}{|c|c|c|c|c|c|c|c|c|}
\hline & & Antananarivo & Fianarantsoa & Toamasina & Fianarantsoa & Toliara & Antsirana & All \\
\hline \multirow[t]{3}{*}{$1993 / 94$} & Rural & 92.8 & 72.3 & 85.4 & 100.0 & 64.9 & 86.3 & 84.6 \\
\hline & Urban & 88.5 & 53.7 & 58.5 & 75.3 & 47.9 & 84.9 & 69.6 \\
\hline & All & 89.3 & 55.7 & 61.4 & 78.3 & 51.6 & 85.1 & 71.8 \\
\hline \multirow[t]{3}{*}{1999} & Rural & 79.9 & 63.1 & 61.4 & 55.7 & 54.2 & 65.8 & 64.8 \\
\hline & Urban & 82.0 & 64.2 & 47.6 & 94.5 & 62.2 & 92.4 & 76.1 \\
\hline & All & 80.4 & 63.3 & 59.9 & 62.7 & 55.6 & 69.9 & 66.8 \\
\hline
\end{tabular}

Notes: see notes to Table 22 
Table 25: Children 12-23 months: Rates of completed vaccinations by expenditure quintile 1993/94 and 1999

\begin{tabular}{llllllll}
\hline & & \multicolumn{5}{c}{ Quintile } & \\
\cline { 3 - 6 } Year & & 1 & 2 & 3 & 4 & 5 & All \\
\hline \multirow{2}{*}{$1993 / 94$} & No vaccinations & 38.2 & 34.7 & 31.2 & 34.5 & 33.2 & 34.5 \\
& Some (1-3) vaccinations & 46.8 & 38.9 & 54.3 & 44.1 & 43.5 & 45.7 \\
& All (4) vaccinations & 15.0 & 26.4 & 14.5 & 21.4 & 23.4 & 19.9 \\
& & & & & & & \\
1999 & No vaccinations & 30.8 & 23.1 & 28.3 & 26.9 & 14.0 & 25.2 \\
& Some (1-3) vaccinations & 43.7 & 55.0 & 47.5 & 53.0 & 44.3 & 48.9 \\
& All (4) vaccinations & 25.5 & 21.9 & 24.2 & 20.1 & 41.7 & 26.0 \\
\hline
\end{tabular}

Notes:

Child vaccination data are available for 1993 and 1999 only.

"Some vaccinations" means the child has completed the vaccination course at least one, but not all, of the following: tuberculosis, polio, measles, Dtcoq.

"All vaccinations" means the child has received complete vaccinations for each of the four diseases.

Table 26: Children 12-23 months - Rural and Urban rates of completed vaccinations, 1993/94 and 1999

\begin{tabular}{llll}
\hline & & Rural & Urban \\
\hline \multirow{2}{*}{$1993 / 94$} & No vaccinations & 36.5 & \\
& Some (1-3) vaccinations & 43.3 & 21.2 \\
& All (4) vaccinations & 20.2 & 60.9 \\
& & & 17.9 \\
1999 & No vaccinations & 27.8 & 13.7 \\
& Some (1-3) vaccinations & 48.5 & 50.5 \\
& All (4) vaccinations & 23.8 & 35.8 \\
& & \\
\hline
\end{tabular}

Notes:

Child vaccination data are available for 1993 and 1999 only.

or more, but not all, of the following: tuberculosis, polio, measles, Dtcoq.

the four diseases. 
Figure 1 - Concentration curves and welfare dominance

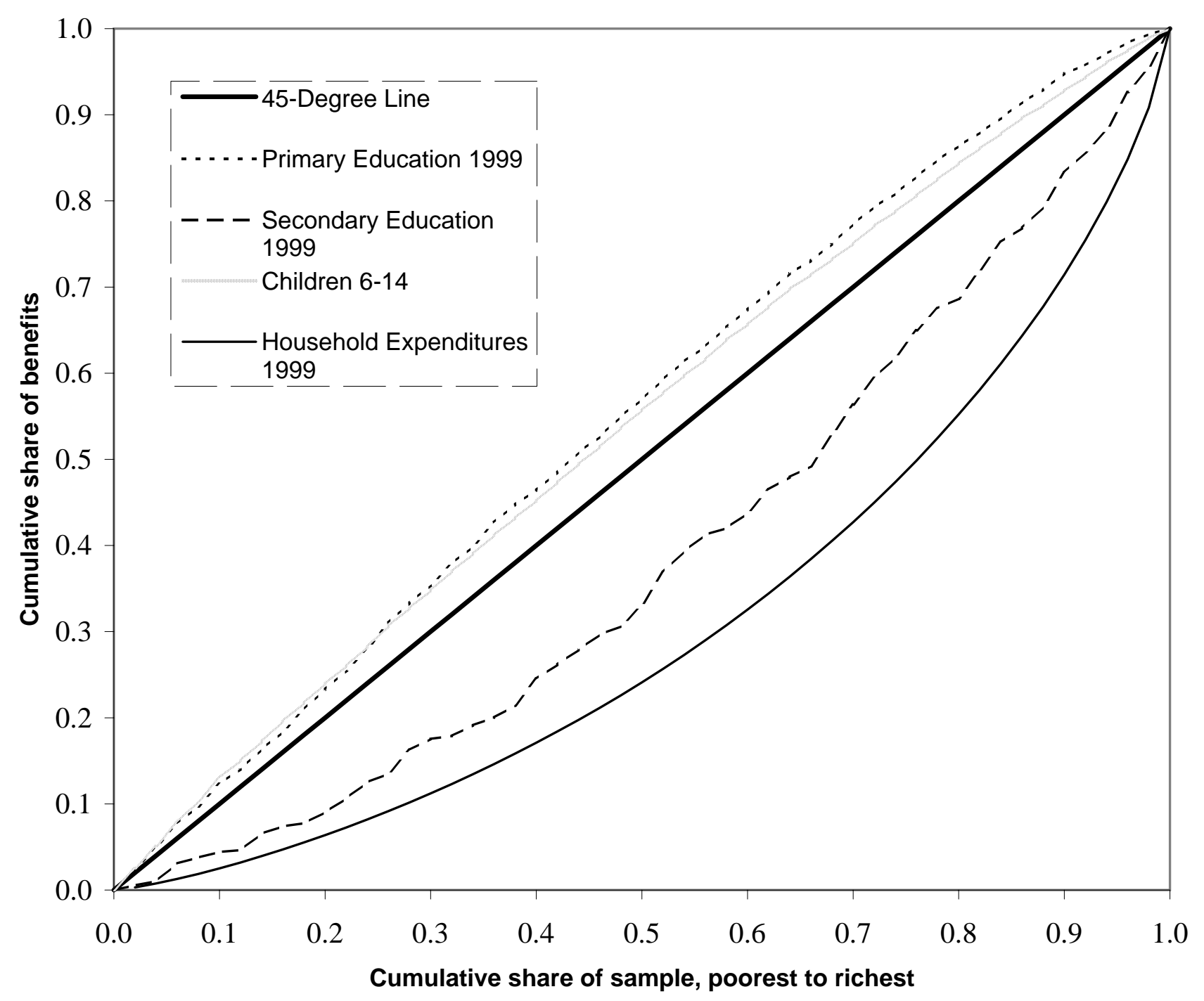


Figure 2 - Enrollment rates by age, 1993, 1997, and 1999

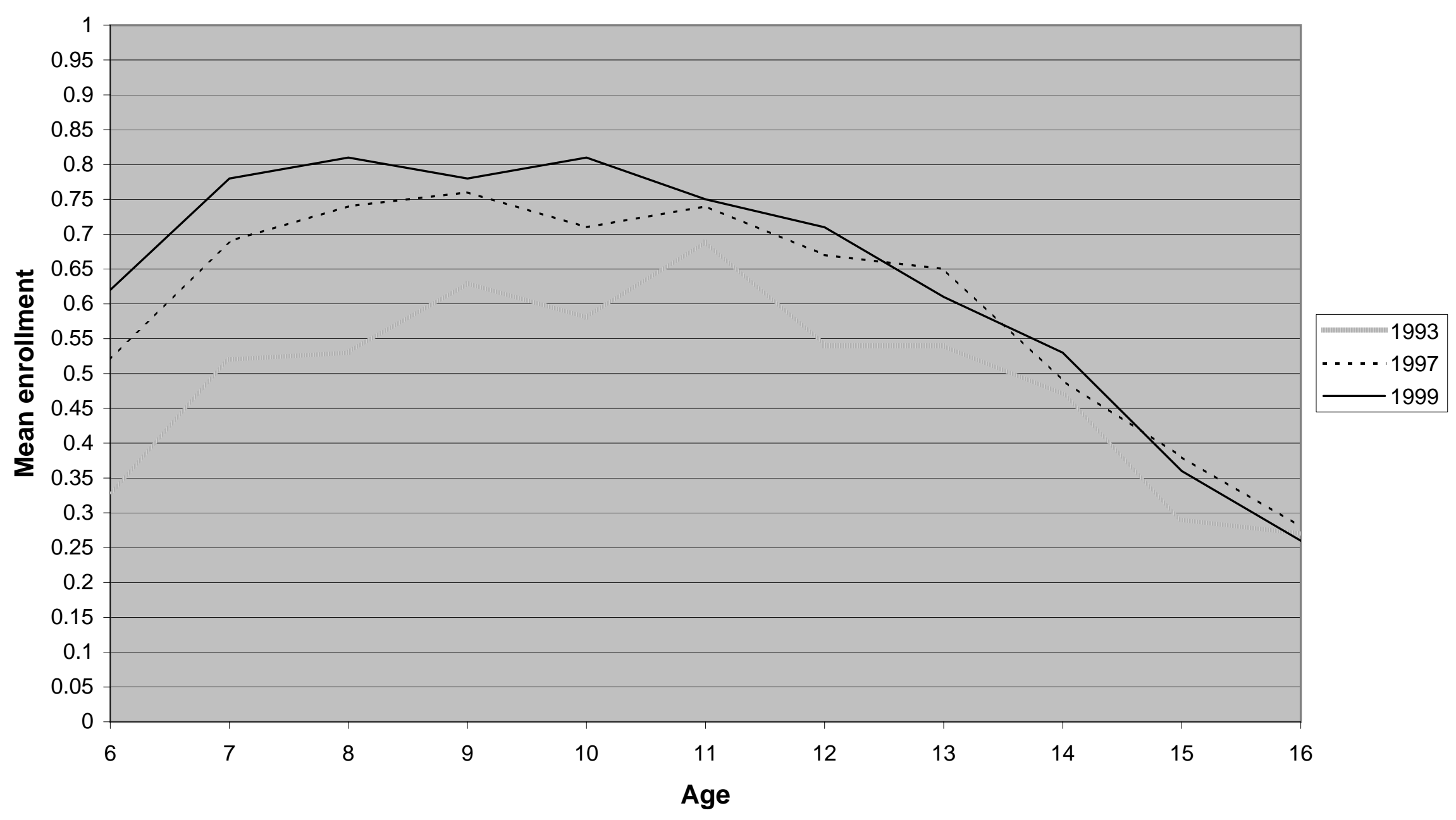


Table A.1. - Expenditures of MINESEB by level of education/program 1994-1999

\begin{tabular}{|c|c|c|c|c|c|c|}
\hline \multicolumn{7}{|l|}{ (millions of FMG in current prices) } \\
\hline Activités/Activities & 1994 & 1995 & 1996 & 1997 & 1998 & 1999 \\
\hline \multicolumn{7}{|l|}{ 1. Salaires/Wages } \\
\hline Primaire & 59,856 & 64,608 & 65,562 & 66,969 & 78,972 & 132,650 \\
\hline Secondaire I & 41,954 & 45,285 & 45,953 & 46,939 & 55,063 & 92,490 \\
\hline Second II & 15,166 & 16,692 & 16,827 & 21,250 & 24,833 & 41,712 \\
\hline Formation initiale/Initial formation (for teachers) & 150 & 165 & 166 & 210 & 248 & 417 \\
\hline Formation continue et recherche / Continual formation : & 246 & 271 & 273 & 345 & 408 & 686 \\
\hline Administration générale & 20,052 & 22,068 & 22,267 & 28,107 & 33,271 & 55,886 \\
\hline Total Salaires/ Wages & 137,423 & 149,088 & 151,048 & 163,820 & 192,795 & 323,839 \\
\hline \multicolumn{7}{|l|}{ 2.Fonctionnement } \\
\hline Primaire & 4,908 & 18,644 & 13,805 & 5,295 & 25,248 & 31,471 \\
\hline Secondaire I & 1,200 & 1,249 & 1,662 & 1,330 & 2,636 & 3,796 \\
\hline Second II & 1,810 & 1,653 & 1,472 & 1,495 & 1,994 & 2,253 \\
\hline Formation initiale & 530 & 684 & 675 & 846 & 1,055 & 1,758 \\
\hline Formation continue et recherche & 365 & 453 & 700 & 900 & 1,000 & 1,100 \\
\hline \multicolumn{7}{|l|}{ Administration } \\
\hline Central & 3,823 & 4,382 & 8,093 & 12,716 & 11,042 & 12,211 \\
\hline DIRESEB & 1,592 & 1,222 & 2,257 & 7,265 & 5,757 & 5,768 \\
\hline CISCO & 628 & 1,002 & 1,851 & 6,481 & 7,381 & 9,243 \\
\hline \multicolumn{7}{|l|}{ Programme d'appui } \\
\hline Transfert et subvention / Subsidy & 1,376 & 2,521 & 2,618 & 4,263 & 4,850 & 4,920 \\
\hline Total Fonctionnement & 16,233 & 31,812 & 33,133 & 40,589 & 60,961 & 72,521 \\
\hline \multicolumn{7}{|l|}{ 3.Investissement } \\
\hline Primaire & 35,398 & 40,101 & 45,428 & 39,195 & 47,529 & 69,317 \\
\hline Secondaire I & 5,272 & 5,972 & 6,766 & 5,838 & 9,483 & 13,137 \\
\hline Second II & 4,670 & 5,291 & 5,994 & 5,171 & 8,687 & 12,720 \\
\hline Formation initiale (EN1) & - & - & - & - & - & - \\
\hline Formation continue et recherche & - & - & - & - & - & - \\
\hline Administration générale & 1,963 & 2,224 & 2,519 & 2,174 & 9,705 & 4,755 \\
\hline Total investissement & 47,304 & 53,588 & 60,707 & 52,378 & 75,405 & 99,929 \\
\hline Total Général & 200,960 & 234,488 & 244,888 & 256,787 & 329,160 & 496,289 \\
\hline
\end{tabular}

Source: Mineseb, Direction de Planification de l'Education. Service de la Programmation et de l'Education. Août 1998

Note: 1994, 1995 et 1996: Budgets ordonnancés, 1997 et 1998: budgets rectifiés, LF 2000 
Table A.2. Evolution of school enrollments by school level, 1990-1999

\begin{tabular}{|c|c|c|c|c|c|c|c|c|c|}
\hline & $1990-91$ & $1991-92$ & $1992-93$ & $1993-94$ & $1994-95$ & $1995-96$ & $1996-97$ & $1997-98$ & $1998-99$ \\
\hline \multicolumn{10}{|l|}{ Primary } \\
\hline \multicolumn{10}{|l|}{ Rural } \\
\hline Number of students & $1,374,143$ & $1,299,467$ & $1,287,233$ & $1,300,761$ & $1,301,241$ & $1,431,265$ & $1,520,723$ & $1,669,131$ & -- \\
\hline Population age 6-10 & $1,356,781$ & $1,393,007$ & $1,430,201$ & $1,468,387$ & $1,507,669$ & $1,548,011$ & $1,589,473$ & $1,632,057$ & -- \\
\hline Gross enrollment ratio & 1.01 & 0.93 & 0.90 & 0.89 & 0.86 & 0.92 & 0.96 & 1.02 & -- \\
\hline \multicolumn{10}{|l|}{ Urban } \\
\hline Number of students & 196,288 & 197,378 & 203,084 & 203,909 & 210,624 & 206,922 & 211,090 & 223,814 & -- \\
\hline Population age 6-10 & 160,795 & 165,286 & 169,903 & 174,648 & 179,526 & 184,539 & 189,693 & 194,990 & -- \\
\hline Gross enrollment ratio & 1.22 & 1.19 & 1.20 & 1.17 & 1.17 & 1.12 & 1.11 & 1.15 & -- \\
\hline \multicolumn{10}{|l|}{$A / l$} \\
\hline Number of students & $1,570,431$ & $1,496,845$ & $1,490,317$ & $1,504,670$ & $1,511,865$ & $1,638,187$ & $1,731,813$ & $1,892,945$ & $2,018,707$ \\
\hline Population age 6-10 & $1,517,576$ & $1,558,294$ & $1,600,103$ & $1,643,035$ & $1,687,195$ & $1,732,550$ & $1,779,166$ & $1,827,047$ & $1,876,217$ \\
\hline Gross enrollment ratio & 1.03 & 0.96 & 0.93 & 0.92 & 0.90 & 0.95 & 0.97 & 1.04 & 1.08 \\
\hline Private/total enrollments & -- & -- & -- & 0.21 & 0.22 & 0.21 & 0.21 & 0.22 & 0.22 \\
\hline \multicolumn{10}{|l|}{ Lower Secondary } \\
\hline Number of students & -- & -- & -- & 237,909 & 235,766 & 232,817 & 250,858 & 258,934 & 273,613 \\
\hline Private/total enrollments & -- & -- & -- & 0.43 & 0.45 & 0.44 & 0.46 & 0.44 & 0.45 \\
\hline \multicolumn{10}{|l|}{ Upper Secondary } \\
\hline Number of students & -- & -- & -- & 60,332 & 57,813 & 56,316 & 56,416 & 61,233 & 60,637 \\
\hline Private/total enrollments & -- & -- & -- & 0.50 & 0.51 & 0.51 & 0.49 & 0.49 & 0.48 \\
\hline
\end{tabular}

\section{Source: MinESEB}

Note: Estimates of primary age population are derived by extrapolating from 1993 census data, assuming annual growth rates of 1.0267 and 1.028 for rural and urban areas, respectively. 
Table A.3. Number of teachers by school level and type, 1993-1999

\begin{tabular}{|c|c|c|c|c|c|c|}
\hline & $1993-94$ & $1994-95$ & $1995-96$ & $1996-97$ & 1997-98 & 1998-99 \\
\hline \multicolumn{7}{|l|}{ Primary } \\
\hline \multicolumn{7}{|l|}{ Private } \\
\hline teaching & 8,091 & 9,885 & 9,236 & 11,375 & 12,111 & 13,020 \\
\hline non-teaching & -- & -- & 1,396 & 1,679 & 1,502 & 1,623 \\
\hline Total & -- & -- & 10,632 & 13,054 & 13,613 & 14,643 \\
\hline \multicolumn{7}{|l|}{ Public } \\
\hline teaching & 29,585 & 29,828 & 28,349 & 28,410 & 28,537 & 29,658 \\
\hline non-teaching & -- & -- & 5,164 & 3,197 & 2,216 & 2,034 \\
\hline Total & -- & -- & 33,513 & 31,607 & 30,753 & 31,692 \\
\hline \multicolumn{7}{|l|}{ All } \\
\hline teaching & 37,676 & 39,713 & 37,585 & 39,785 & 40,648 & 42,678 \\
\hline non-teaching & -- & -- & 6,560 & 4,876 & 3,718 & 3,657 \\
\hline Total & -- & -- & 44,145 & 44,661 & 44,366 & 46,335 \\
\hline \multicolumn{7}{|c|}{$\begin{array}{l}\text { Lower Secondary } \\
\text { private }\end{array}$} \\
\hline teaching & 3,473 & 3,796 & 4,275 & 4,714 & 5,283 & 5,690 \\
\hline non-teaching & -- & -- & 904 & 670 & 799 & 907 \\
\hline Total & -- & -- & 5,179 & 5,384 & 6,082 & 6,597 \\
\hline \multicolumn{7}{|l|}{ Public } \\
\hline teaching & 7,688 & 8,421 & 7,893 & 7,606 & 7,632 & 7,838 \\
\hline non-teaching & -- & -- & 2,349 & 3,165 & 3,038 & 3,125 \\
\hline Total & -- & -- & 10,242 & 10,771 & 10,670 & 10,963 \\
\hline \multicolumn{7}{|l|}{ All } \\
\hline teaching & 11,161 & 12,217 & 12,168 & 12,320 & 12,915 & 13,528 \\
\hline non-teaching & -- & -- & 3,253 & 3,835 & 3,837 & 4,032 \\
\hline Total & -- & -- & 15,421 & 16,155 & 16,752 & 17,560 \\
\hline \multicolumn{7}{|c|}{$\begin{array}{l}\text { Upper Secondary } \\
\text { private }\end{array}$} \\
\hline teaching & 1,402 & 1,700 & 1,993 & 2,572 & 2,763 & 2,989 \\
\hline non-teaching & -- & -- & 584 & 473 & 530 & 575 \\
\hline Total & -- & -- & 2,577 & 3,045 & 3,293 & 3,564 \\
\hline \multicolumn{7}{|l|}{ Public } \\
\hline teaching & 2,434 & 2,574 & 2,629 & 2,579 & 2,557 & 2,470 \\
\hline non-teaching & -- & -- & 1,561 & 1,358 & 1,344 & 1,302 \\
\hline Total & -- & -- & 4,190 & 3,937 & 3,901 & 3,772 \\
\hline \multicolumn{7}{|l|}{ All } \\
\hline teaching & 3,836 & 4,274 & 4,622 & 5,151 & 5,320 & 5,459 \\
\hline non-teaching & -- & -- & 2,145 & 1,831 & 1,874 & 1,877 \\
\hline Total & -- & -- & 6,767 & 6,982 & 7,194 & 7,336 \\
\hline
\end{tabular}

Source: MinESEB

Note: "non-teaching" refers to teachers assigned to non-classroom duties. 
Table A.4. - Probit model of current enrollment, rural children age 6-14, 1993-1999

\begin{tabular}{|c|c|c|c|}
\hline Variable & Coefficient & t-value & Marginal effect ${ }^{a}$ \\
\hline \multicolumn{4}{|c|}{ Survey Year (excluded=1993) } \\
\hline 1997 & 0.253 & $8.34 * \star \star$ & 0.097 \\
\hline 1999 & 0.325 & $10.20 * \star \star$ & 0.123 \\
\hline Fianarantsoa & -0.347 & 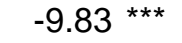 & -0.136 \\
\hline Toamasina & 0.010 & 0.25 & 0.004 \\
\hline Mahajanga & -0.531 & $-12.67 * \star \star$ & -0.209 \\
\hline Toliara & -0.597 & $-14.74 * \star \star$ & -0.234 \\
\hline Antsirana & 0.117 & 2.54 ** & 0.045 \\
\hline child age & 0.018 & $3.49 \star \star \star$ & 0.007 \\
\hline female child & 0.041 & 1.64 * & 0.016 \\
\hline head years schooling & 0.119 & $26.99 * \star \star$ & 0.046 \\
\hline head age & 0.008 & $5.00 * \star \star$ & 0.003 \\
\hline children $0-5$ & -0.016 & -1.44 & -0.006 \\
\hline children 6-10 & 0.034 & $2.62 * * *$ & 0.013 \\
\hline males $11-20$ & 0.016 & 1.30 & 0.006 \\
\hline females $11-20$ & 0.030 & 2.30 ** & 0.012 \\
\hline males $21-50$ & 0.024 & 1.21 & 0.009 \\
\hline females $21-50$ & 0.062 & $2.66 * \star \star$ & 0.024 \\
\hline males over 50 & -0.087 & $-2.28 * \star$ & -0.034 \\
\hline females over 50 & -0.011 & -0.31 & -0.004 \\
\hline Intercept & -0.805 & $-8.64 * * \star$ & \\
\hline
\end{tabular}

Notes:

Number of observations: 12,211

Excluded Faritany category is Antananarivo.

${ }^{a}$ Change in probability from a unit change in the independent variable. For discrete variables, shows the difference in probabilities when the variable

* significant at $10 \%$; ** significant at $5 \%$; *** significant at $1 \%$ 
Explanation of the tables: The tables are to be read by row. Thus the first row indicates whether the first benefit statistically dominates the benefits shown in the columns (as well as the 45-degree line and the Lorenz curve for expenditures). $D$ indicates dominance; $\mathbf{X}$ indicates that the curves cross and at least one pair of t-statistics in opposite directions are significant. A blank space indicates no dominance and no crossing.

Dominance obtains if the difference in ordinates is significant at $5 \%$ for all 20 pairs of ordinates. For the the Gini comparisons, the Ginis must be significantly different at $5 \%$ for all 7 pairs of extended Ginis from 1.01 to 4.0 . See section II of text for details

Table A5. Dominance test results for public education services, 1993/4

\begin{tabular}{lccccccc}
\hline & Children 6-14 & Primary & Children 11-20 & 45-Deg. line & Secondary & Expenditures & University \\
\hline Children 6-14 & & $\mathrm{X}$ & $\mathrm{D}$ & $\mathrm{D}$ & $\mathrm{D}$ & $\mathrm{D}$ & $\mathrm{D}$ \\
Primary & $\mathrm{X}$ & & $\mathrm{X}$ & $\mathrm{X}$ & $\mathrm{D}$ & $\mathrm{D}$ & $\mathrm{D}$ \\
Children 11-20 & & $\mathrm{X}$ & & & $\mathrm{D}$ & $\mathrm{D}$ & $\mathrm{D}$ \\
45-Deg. line & & $\mathrm{X}$ & & & $\mathrm{D}$ & $\mathrm{D}$ & $\mathrm{D}$ \\
Secondary & & & & & $\mathrm{X}$ & $\mathrm{X}$ & $\mathrm{D}$ \\
Expenditures & & & & & & $\mathrm{D}$ \\
University & & & & & & & \\
\hline
\end{tabular}

Table A6. Test results for Extended Gini coefficients for public education services, 1993/4

\begin{tabular}{|c|c|c|c|c|c|c|c|}
\hline & Children 6-14 & Primary & Children 11-20 & 45-Deg. line & Secondary & Expenditures & University \\
\hline Children 6-14 & & & $\mathrm{D}$ & $\mathrm{D}$ & $\bar{D}$ & $\mathrm{D}$ & $\mathrm{D}$ \\
\hline Primary & & & & & D & D & D \\
\hline Children 11-20 & & & & & $D$ & $\mathrm{D}$ & D \\
\hline 45-Deg. line & & & & & D & D & D \\
\hline Secondary & & & & & & & D \\
\hline Expenditures & & & & & & & D \\
\hline University & & & & & & & \\
\hline
\end{tabular}


Table A7. Dominance test results for public education services, 1999

\begin{tabular}{|c|c|c|c|c|c|c|c|}
\hline & Primary & Children 6-14 & Children 11-20 & 45-Deg. line & Secondary & Expenditures & University \\
\hline Primary & & & & D & D & D & D \\
\hline Children 6-14 & & & & D & D & D & D \\
\hline Children 11-20 & & & & D & D & D & D \\
\hline 45-Deg. line & & & & & D & D & D \\
\hline Secondary & & & & & & D & D \\
\hline Expenditures & & & & & & & D \\
\hline University & & & & & & & \\
\hline
\end{tabular}

Table A8. Test results for Extended Gini coefficients for public education services, 1999

\begin{tabular}{|c|c|c|c|c|c|c|c|}
\hline & Primary & Children 6-14 & Children 11-20 & 45-Deg. line & Secondary & Expenditures & University \\
\hline Primary & & & $\mathrm{D}$ & $\mathrm{D}$ & $\mathrm{D}$ & $\mathrm{D}$ & $\mathrm{D}$ \\
\hline Children 6-14 & & & $\mathrm{D}$ & D & $\mathrm{D}$ & D & $\mathrm{D}$ \\
\hline Children 11-20 & & & & $\mathrm{D}$ & $\mathrm{D}$ & $\mathrm{D}$ & $\mathrm{D}$ \\
\hline 45-Deg. line & & & & & $\mathrm{D}$ & D & $\mathrm{D}$ \\
\hline Secondary & & & & & & $\mathrm{D}$ & $\mathrm{D}$ \\
\hline Expenditures & & & & & & & $\mathrm{D}$ \\
\hline University & & & & & & & \\
\hline
\end{tabular}


Table A9. Cross-survey dominance test results for

Primary schooling, 1993/4-1999

\begin{tabular}{|c|c|c|c|}
\hline & $1993 / 4$ & 1997 & 1999 \\
\hline $1993 / 4$ & & $X$ & $X$ \\
\hline 1997 & & & \\
\hline 1999 & $x$ & & \\
\hline
\end{tabular}

Table A10. Cross-survey test results for Extended Gini coefficients for Primary schooling, 1993/4-1999

\begin{tabular}{|c|c|c|c|}
\hline & $1993 / 4$ & 1997 & 1999 \\
\hline \multicolumn{4}{|c|}{$1993 / 4$} \\
\hline \multicolumn{4}{|l|}{1997} \\
\hline 1999 & & & \\
\hline
\end{tabular}

Table A11. Cross-survey dominance test results for secondary schooling, 1993/4-1999

\begin{tabular}{lcc}
\hline & $1993 / 4$ & 1999 \\
\hline $1993 / 4$ & & \\
1999 & & \\
\hline
\end{tabular}

Table A12. Cross-survey test results for Extended Gini coefficients for secondary schooling, 1993/4-1999

\begin{tabular}{lcc}
\hline & $1993 / 4$ & 1999 \\
\hline $1993 / 4$ & & \\
1999 & & \\
\hline
\end{tabular}

Table A13. Cross-survey dominance test results for University, 1993/4-1999

\begin{tabular}{lll}
\hline & $1993 / 4$ & 1999 \\
\hline $1993 / 4$ & & \\
1999 & & \\
\hline
\end{tabular}

Table A14. Cross-survey test results for Extended Gini coefficients for University, 1993/4-1999

\begin{tabular}{lll}
\hline & $1993 / 4$ & 1999 \\
\hline $1993 / 4$ & & \\
1999 & & \\
\hline
\end{tabular}


Table A15. Dominance test results for outpatient public health services, 1993/4

\begin{tabular}{|c|c|c|c|c|c|c|}
\hline & 45-Deg. line & Hospital & Ill/injured & All public & Basic care & Expenditures \\
\hline 45-Deg. line & & & $\mathrm{D}$ & & & $\mathrm{D}$ \\
\hline Hospital & & & & & & D \\
\hline Ill/injured & & & & & & D \\
\hline All public & & & & & & D \\
\hline Basic care & & & & & & D \\
\hline Expenditures & & & & & & \\
\hline
\end{tabular}

Table A16. Test results for Extended Gini coefficients for outpatient public health services, 1993/4

\begin{tabular}{|c|c|c|c|c|c|c|}
\hline & 45-Deg. line & Hospital & Ill/injured & All public & Basic care & Expenditures \\
\hline 45-Deg. line & & & $\mathrm{D}$ & $\mathrm{D}$ & $\mathrm{D}$ & $\mathrm{D}$ \\
\hline Hospital & & & & & & D \\
\hline Ill/injured & & & & & & D \\
\hline All public & & & & & & D \\
\hline Basic care & & & & & & D \\
\hline Expenditures & & & & & & \\
\hline
\end{tabular}

Table A17. Dominance test results for outpatient public health services, 1997

\begin{tabular}{|c|c|c|c|c|c|}
\hline & Basic care & 45-Deg. line & All public & Hospital & Expenditures \\
\hline Basic care & & & & & $D$ \\
\hline 45-Deg. line & & & & & D \\
\hline All public & & & & & D \\
\hline Hospital & & & & & D \\
\hline Expenditures & & & & & \\
\hline
\end{tabular}

Table A18. Test results for Extended Gini coefficients for outpatient public health services, 1997

\begin{tabular}{|c|c|c|c|c|c|}
\hline & Basic care & 45-Deg. line & All public & Hospital & Expenditures \\
\hline Basic care & & & D & $\mathrm{D}$ & D \\
\hline 45-Deg. line & & & & $\mathrm{D}$ & D \\
\hline All public & & & & D & D \\
\hline Hospital & & & & & D \\
\hline Expenditures & & & & & \\
\hline
\end{tabular}


Table A19. Dominance test results for outpatient public health services, 1999

\begin{tabular}{|c|c|c|c|c|c|c|}
\hline & Basic care & 45-Deg. line & Ill/injured & All public & Hospitalital & Expenditures \\
\hline Basic care & & & & & & $\mathrm{D}$ \\
\hline 45-Deg. line & & & & & & D \\
\hline Ill/injured & & & & & & D \\
\hline All public & & & & & & D \\
\hline \multicolumn{7}{|l|}{ Hospital } \\
\hline Expenditures & & & & & & \\
\hline
\end{tabular}

Table A20. Test results for Extended Gini coefficients for outpatient public health services, 1999

\begin{tabular}{|c|c|c|c|c|c|c|}
\hline & Basic care & 45-Deg. line & Ill/injured & All public & Hospital & Expenditures \\
\hline Basic care & & & & $\mathrm{D}$ & $\mathrm{D}$ & $\mathrm{D}$ \\
\hline 45-Deg. line & & & & & D & D \\
\hline III/injured & & & & & D & D \\
\hline All public & & & & & D & D \\
\hline Hospital & & & & & & D \\
\hline Expenditures & & & & & & \\
\hline
\end{tabular}

Table A21. Cross-survey dominance test results for outpatient hospital care, 1993/4-1999

\begin{tabular}{llll}
\hline & $1993 / 4$ & 1997 & 1999 \\
\hline $1993 / 4$ & & & \\
1997 & & & \\
1999 & & & \\
\hline
\end{tabular}

Table A22. Cross-survey test results for Extended Gini coefficients for outpatient hospital care, 1993/4-1999

\begin{tabular}{llll}
\hline & $1993 / 4$ & 1997 & 1999 \\
\hline $1993 / 4$ & & & \\
1997 & & & \\
1999 & & & \\
\hline
\end{tabular}


Table A23. Cross-survey dominance test results for basic care, 1993/4-1999

\begin{tabular}{llll}
\hline & $1993 / 4$ & 1997 & 1999 \\
\hline $1993 / 4$ & & & \\
1997 & & & \\
1999 & & & \\
\hline
\end{tabular}

Table A24. Cross-survey test results for Extended Gini coefficients for basic care, 1993/4-1999

\begin{tabular}{|c|c|c|c|}
\hline & $1993 / 4$ & 1997 & 1999 \\
\hline \multicolumn{4}{|c|}{$1993 / 4$} \\
\hline 1997 & D & & \\
\hline 1999 & D & & \\
\hline
\end{tabular}

Table A25. Cross-survey dominance test results for all public (hospital + basic) care, 1993/4-1999

\begin{tabular}{llll}
\hline & $1993 / 4$ & 1997 & 1999 \\
\hline $1993 / 4$ & & & \\
1997 & & & \\
1999 & & & \\
\hline
\end{tabular}

Table A26. Cross-survey test results for Extended Gini coefficients for all public (hospital + basic) care, 1993/4-1999

\begin{tabular}{llll}
\hline & $1993 / 4$ & 1997 & 1999 \\
\hline $1993 / 4$ & & & \\
1997 & & & \\
1999 & & \\
\hline
\end{tabular}


Table A27. Dominance test results for public pre-natal care, 1993/4

\begin{tabular}{|c|c|c|c|c|c|c|c|c|}
\hline & Primary Care Cntr & Live Birth & Birth post & All Public & SMI/PMI & 45-Deg. line & Maternite/Hosp. & Expendit! \\
\hline Primary Care Cntr & & $\bar{X}$ & & & & $\bar{x}$ & & \\
\hline Live Birth & $x$ & & $x$ & & $\mathrm{x}$ & & & D \\
\hline Birth post & & $x$ & & & & & & D \\
\hline All Public & & & & & & & & D \\
\hline SMI/PMI & & $\mathrm{X}$ & & & & & & \\
\hline 45-Deg. line & $x$ & & & & & & & D \\
\hline Maternite/Hosp. & & & & & & & & D \\
\hline Expenditures & & & & & & & & \\
\hline
\end{tabular}

Table A28. Test results for Extended Gini coefficients for public pre-natal care, 1993/4

\begin{tabular}{|c|c|c|c|c|c|c|c|c|}
\hline & Primary Care Cntr & Live Birth & Birth post & All Public & SMI/PMI & 45-Deg. line & Maternite/Hosp. & Expendit। \\
\hline Primary Care Cntr & & & & & & & & $\mathrm{D}$ \\
\hline Live Birth & & & & & & $\mathrm{D}$ & $\mathrm{D}$ & $\mathrm{D}$ \\
\hline Birth post & & & & & & & & $\mathrm{D}$ \\
\hline All Public & & & & & & & & $\mathrm{D}$ \\
\hline SMI/PMI & & & & & & & & $\mathrm{D}$ \\
\hline 45-Deg. line & & & & & & & & $\mathrm{D}$ \\
\hline Maternite/Hosp. & & & & & & & & $\mathrm{D}$ \\
\hline
\end{tabular}


Table A29. Dominance test results for public pre-natal care, 1999

\begin{tabular}{|c|c|c|c|c|c|c|}
\hline & Basic/SMI/PMI & All Public & Live Birth & Hospital & 45-Deg. line & Expenditures \\
\hline Basic/SMI/PMI & & & & & D & D \\
\hline All Public & & & & & & D \\
\hline Live Birth & & & & & & D \\
\hline \multicolumn{7}{|l|}{ Hospital } \\
\hline 45-Deg. line & & & & & & D \\
\hline Expenditures & & & & & & \\
\hline
\end{tabular}

Table A30. Test results for Extended Gini coefficients

for public pre-natal care, 1999

\begin{tabular}{|c|c|c|c|c|c|c|}
\hline & Basic/SMI/PMI & All Public & Live Birth & Hospital & 45-Deg. line & Expenditures \\
\hline Basic/SMI/PMI & & D & D & D & D & D \\
\hline All Public & & & & & D & D \\
\hline Live Birth & & & & & D & D \\
\hline Hospital & & & & & & D \\
\hline 45-Deg. line & & & & & & D \\
\hline Expenditures & & & & & & \\
\hline
\end{tabular}


Table A31. Cross-survey dominance test results for all public pre-natal care, 1993/41999

\begin{tabular}{lcc}
\hline & $1993 / 4$ & 1999 \\
\hline $1993 / 4$ & & \\
1999 & & \\
\hline
\end{tabular}

Table A32. Cross-survey test results for Extended Gini coefficients for all public prenatal care, 1993/4-1999

\begin{tabular}{lcc}
\hline & $1993 / 4$ & 1999 \\
\hline $1993 / 4$ & & $D$ \\
1999 & & \\
\hline
\end{tabular}


Table A33. Dominance test results for immunizations, 1993/4

\begin{tabular}{|c|c|c|c|c|c|}
\hline & $\begin{array}{c}\text { Children } \\
12-23 \text { mos. }\end{array}$ & $\begin{array}{c}1 \text { or more } \\
\text { Vaccinations }\end{array}$ & $\begin{array}{c}\text { All } \\
\text { vaccinations }\end{array}$ & $\begin{array}{l}\text { 45-Deg. } \\
\text { line }\end{array}$ & Expenditures \\
\hline Children 12-23 mos. & & & & & $\mathrm{D}$ \\
\hline 1 or more Vaccinations & & & & & D \\
\hline All vaccinations & & & & & D \\
\hline 45-Deg. line & & & & & D \\
\hline Expenditures & & & & & \\
\hline
\end{tabular}

Table A34. Test results for Extended Gini coefficients for immunizations, 1993/4

\begin{tabular}{|c|c|c|c|c|c|}
\hline & $\begin{array}{c}\text { Children } \\
12-23 \text { mos. }\end{array}$ & $\begin{array}{c}1 \text { or more } \\
\text { Vaccinations }\end{array}$ & $\begin{array}{c}\text { All } \\
\text { vaccinations }\end{array}$ & $\begin{array}{l}\text { 45-Deg. } \\
\text { line }\end{array}$ & Expenditures \\
\hline Children 12-23 mos. & & & & $\mathrm{D}$ & $\mathrm{D}$ \\
\hline 1 or more Vaccinations & & & & D & D \\
\hline All vaccinations & & & & & D \\
\hline 45-Deg. line & & & & & D \\
\hline Expenditures & & & & & \\
\hline
\end{tabular}

Table A35. Dominance test results for immunizations, 1999

\begin{tabular}{lccccc}
\hline & Children & 1 or more & All & 45-Deg. & \\
& $12-23$ mos. & Vaccinations & vaccinations & line & Expenditures \\
\hline Children 12-23 mos. & & & & $\mathrm{D}$ \\
1 or more Vaccinations & & & & $\mathrm{D}$ \\
All vaccinations & & & $\mathrm{D}$ \\
45-Deg. line & & & $\mathrm{D}$ \\
Expenditures & & & \\
\hline
\end{tabular}

Table A36. Test results for Extended Gini coefficients for immunizations, 1999

\begin{tabular}{lccccc}
\hline & Children & 1 or more & All & 45-Deg. & \\
& $12-23$ mos. & Vaccinations & vaccinations & line & Expenditures \\
\hline Children 12-23 mos. & & $\mathrm{D}$ & & $\mathrm{D}$ & $\mathrm{D}$ \\
1 or more Vaccinations & & & & $\mathrm{D}$ \\
All vaccinations & & & $\mathrm{D}$ \\
45-Deg. line & & & $\mathrm{D}$ \\
Expenditures & & & & \\
\hline
\end{tabular}


Table A37. Cross-survey dominance test results for 1 or more vaccinations, 1993/41999

\begin{tabular}{lcc}
\hline & $1993 / 4$ & 1999 \\
\hline $1993 / 4$ & & \\
1999 & & \\
\hline
\end{tabular}

Table A38. Cross-survey test results for Extended Gini coefficients for 1 or more vaccinations, 1993/4-1999

\begin{tabular}{lll}
\hline \multicolumn{3}{c}{ vaccinations, 1993/4-1999 } \\
\hline $1993 / 4$ & & 1999 \\
1999 & & \\
\hline
\end{tabular}

Table A39. Cross-survey dominance test results for all vaccinations, 1993/4-1999

\begin{tabular}{lll}
\hline & $1993 / 4$ & 1999 \\
\hline $1993 / 4$ & & \\
1999 & & \\
\hline
\end{tabular}

Table A40. Cross-survey test results for Extended Gini coefficients for all vaccinations, 1993/4-1999

\begin{tabular}{lll}
\hline & $1993 / 4$ & 1999 \\
\hline $1993 / 4$ & & \\
1999 & & \\
\hline
\end{tabular}


Figure A1 - Concentration curves for public schooling, 1993/94

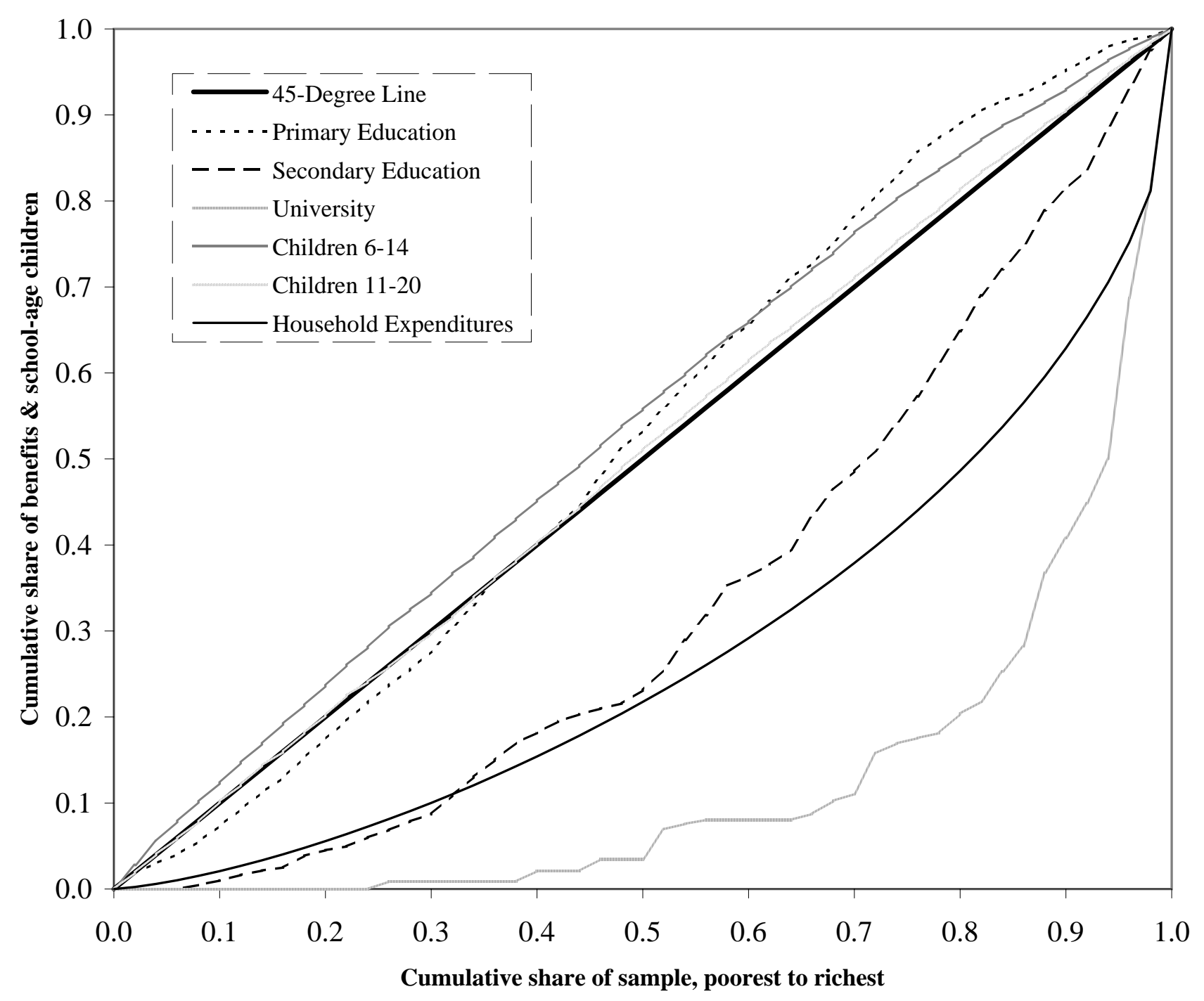


Figure A2 - Concentration curves for public schooling, 1999

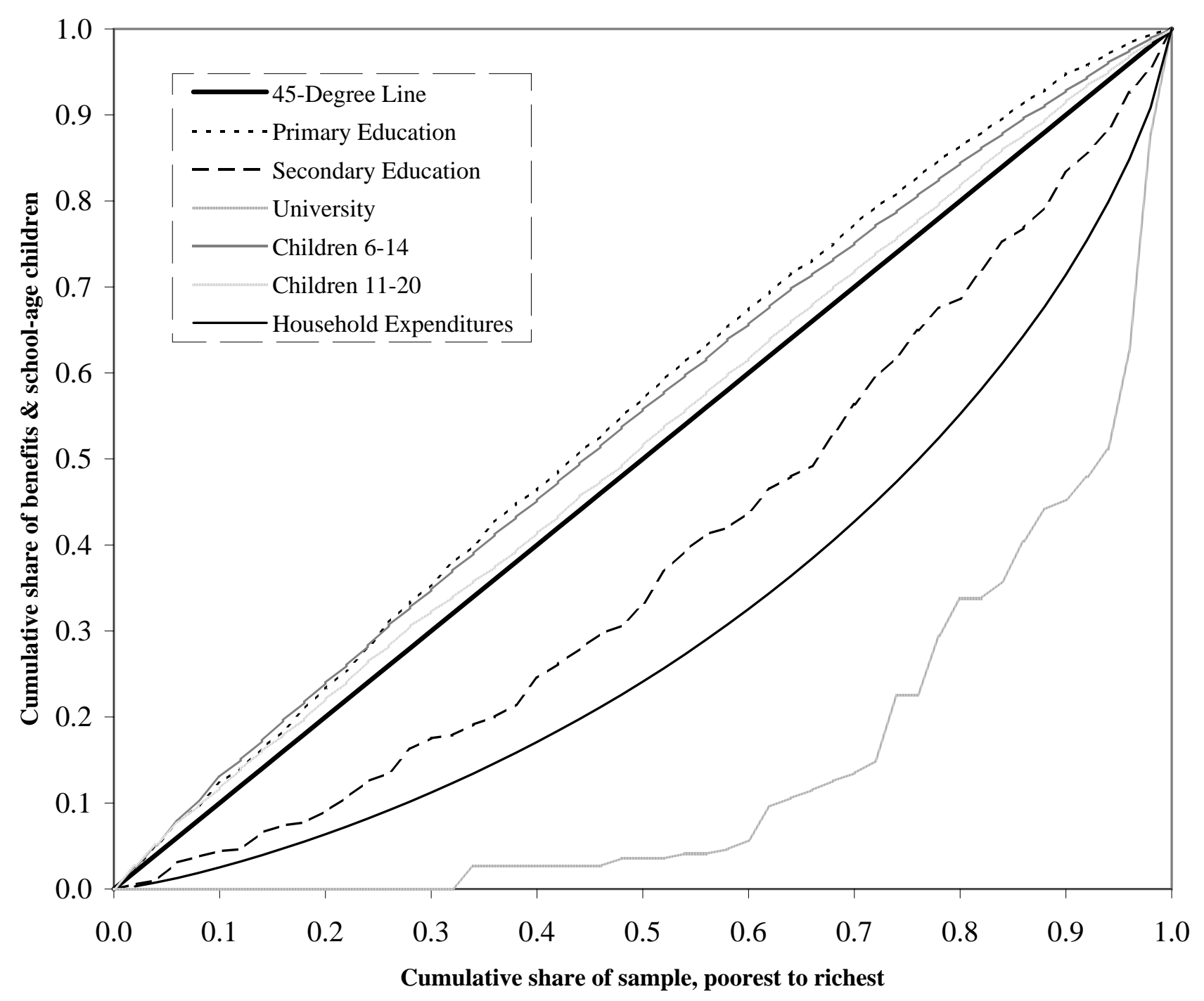


Figure A3 - Concentration curves for public schooling, 1993/94 - 1999

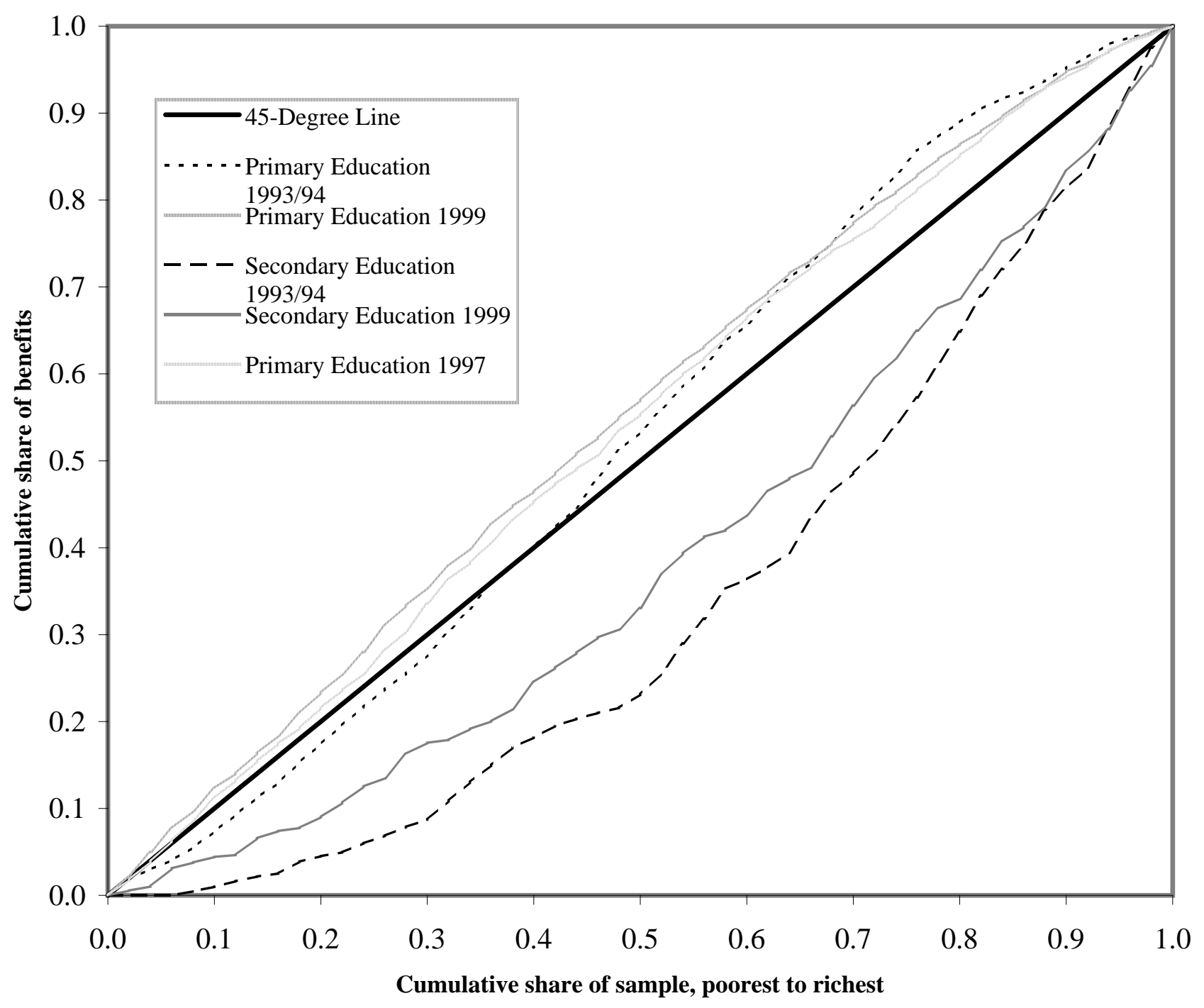


Figure A4 - Concentration curves for marginal benefits: public primary enrollments, 1993/94-1999

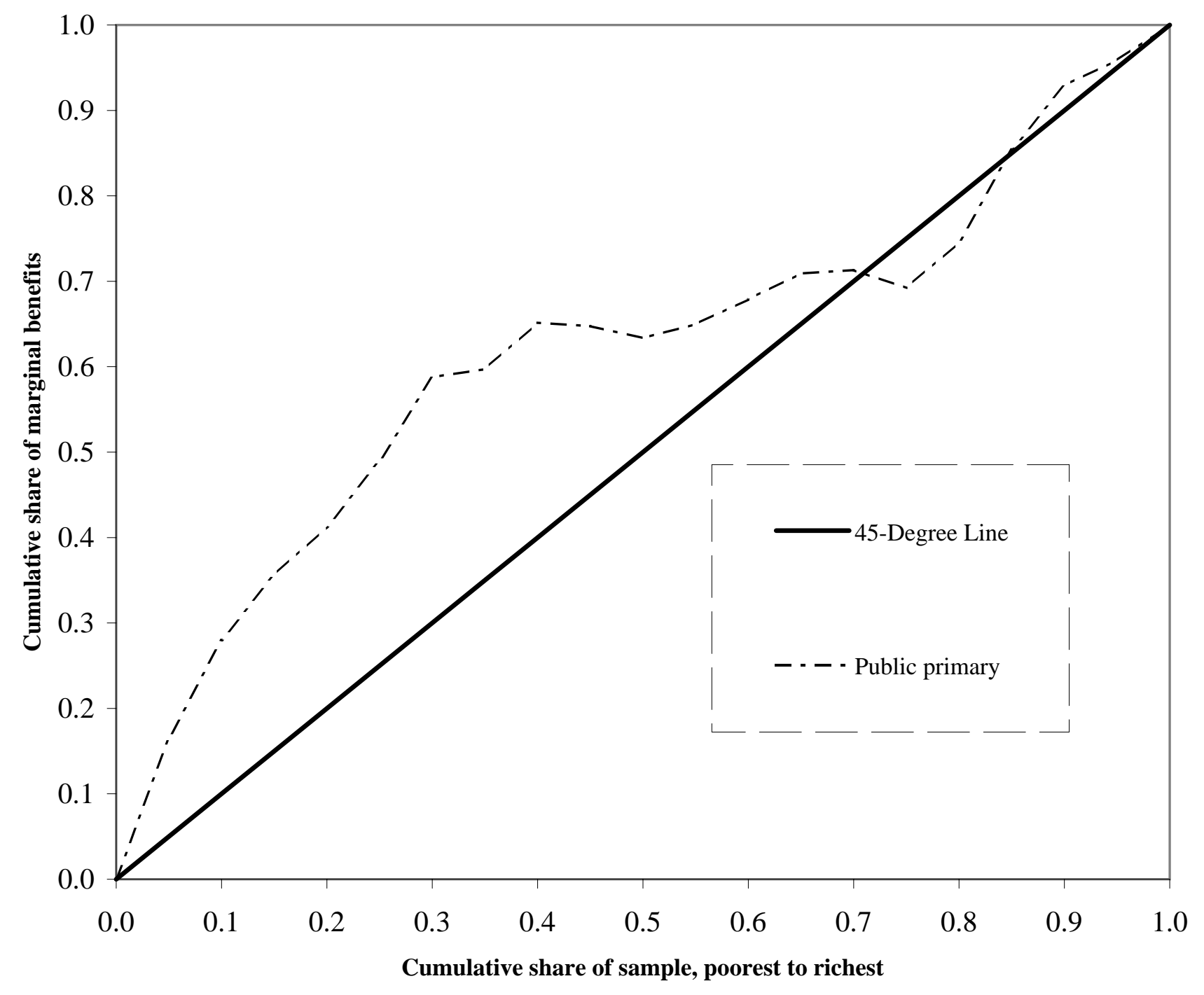


Figure A5 - Concentration curves for out-patient public health services, 1993/94

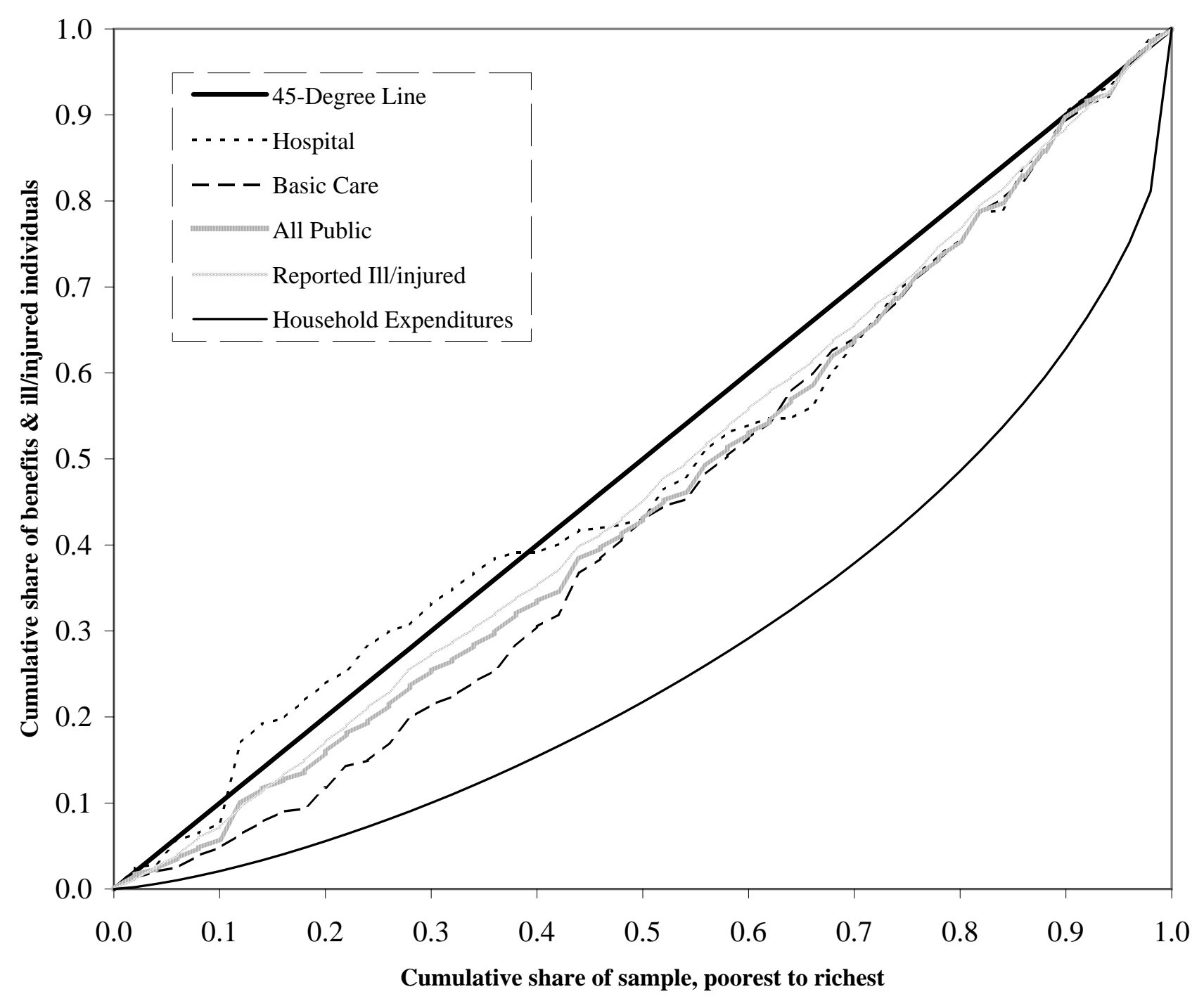


Figure A6 - Concentration curves for out-patient public health services, 1997

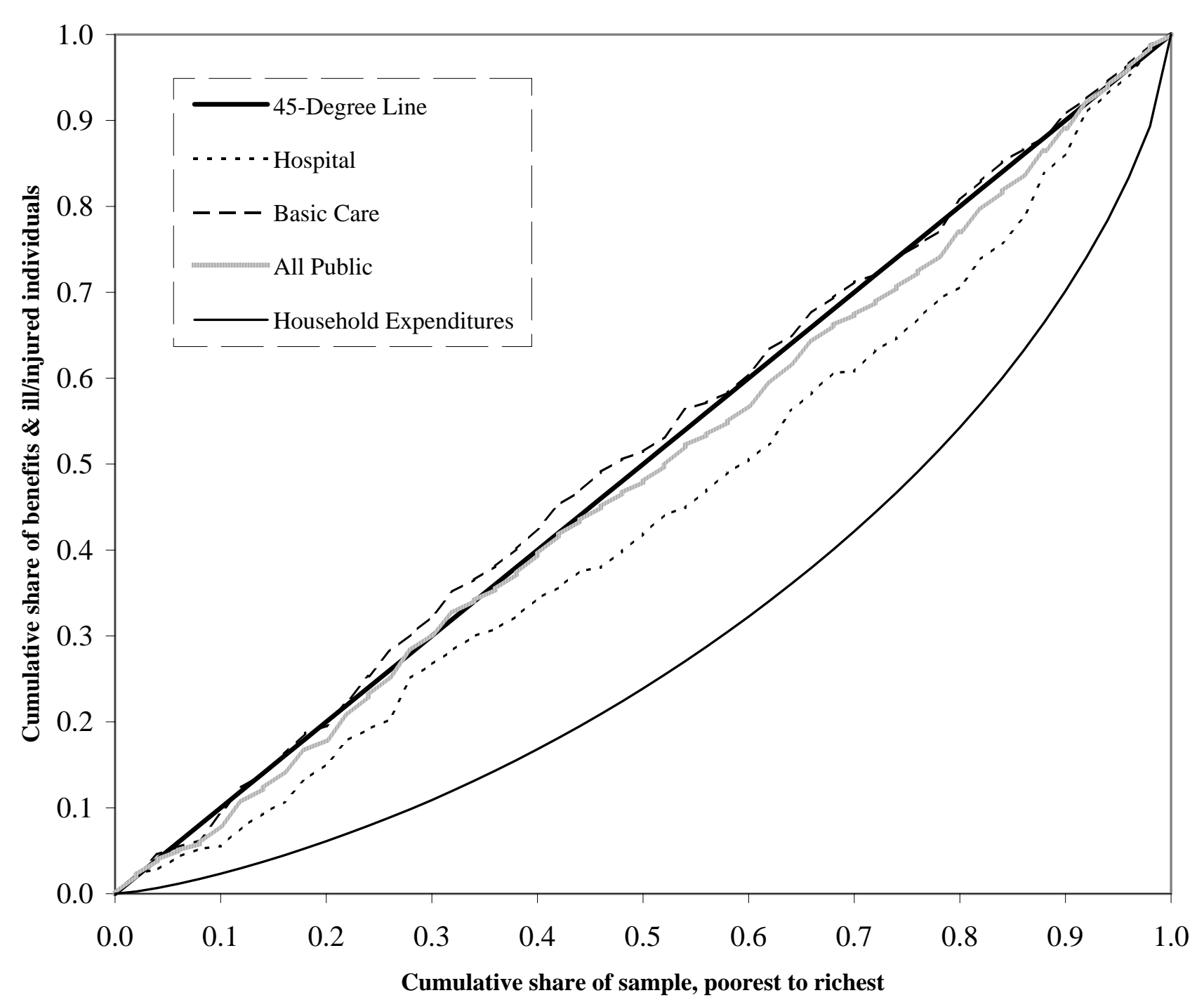


Figure A7 - Concentration curves for out-patient public health services, 1999

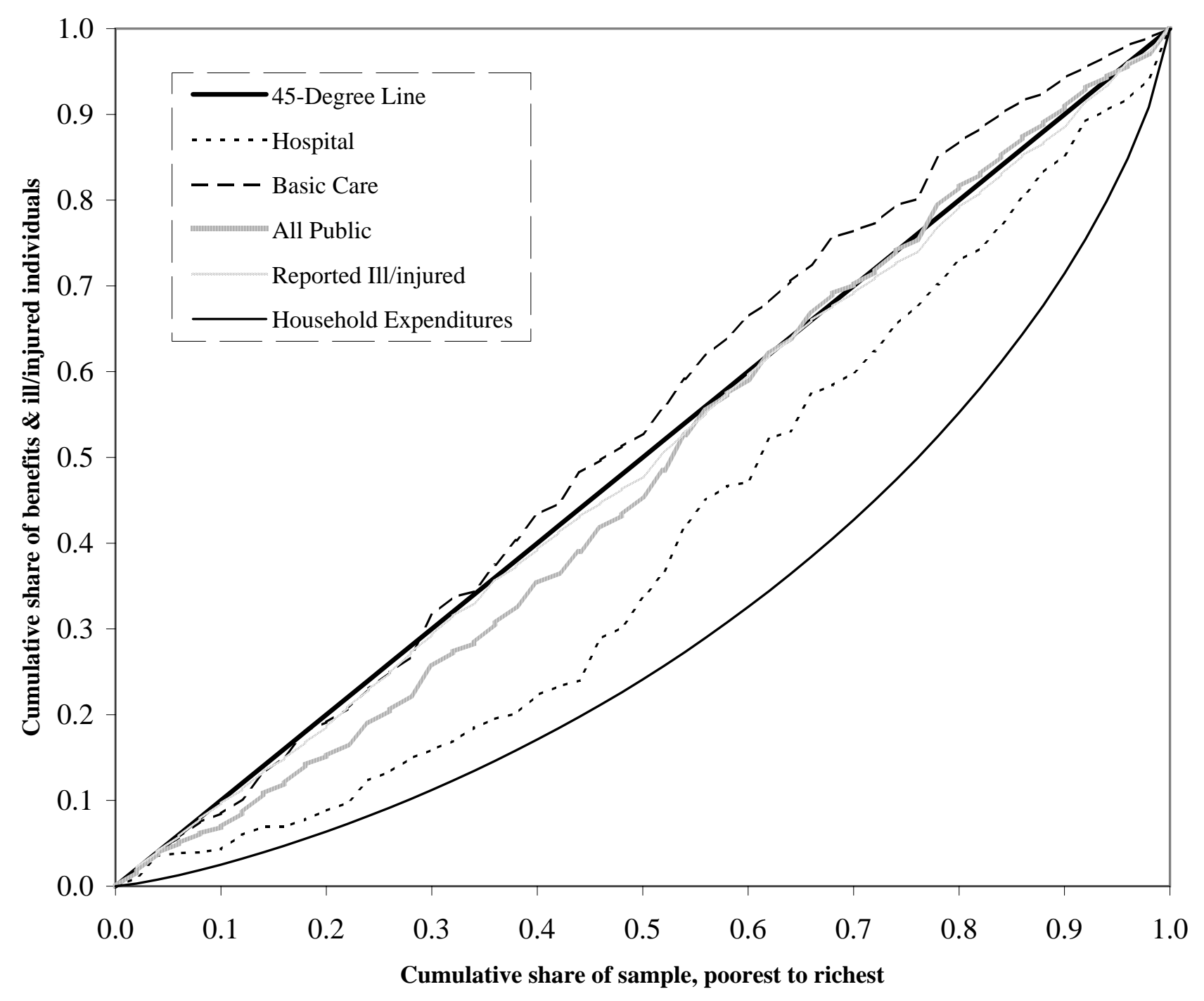


Figure A8 - Concentration curves for out-patient public health services, 1993/94-1999

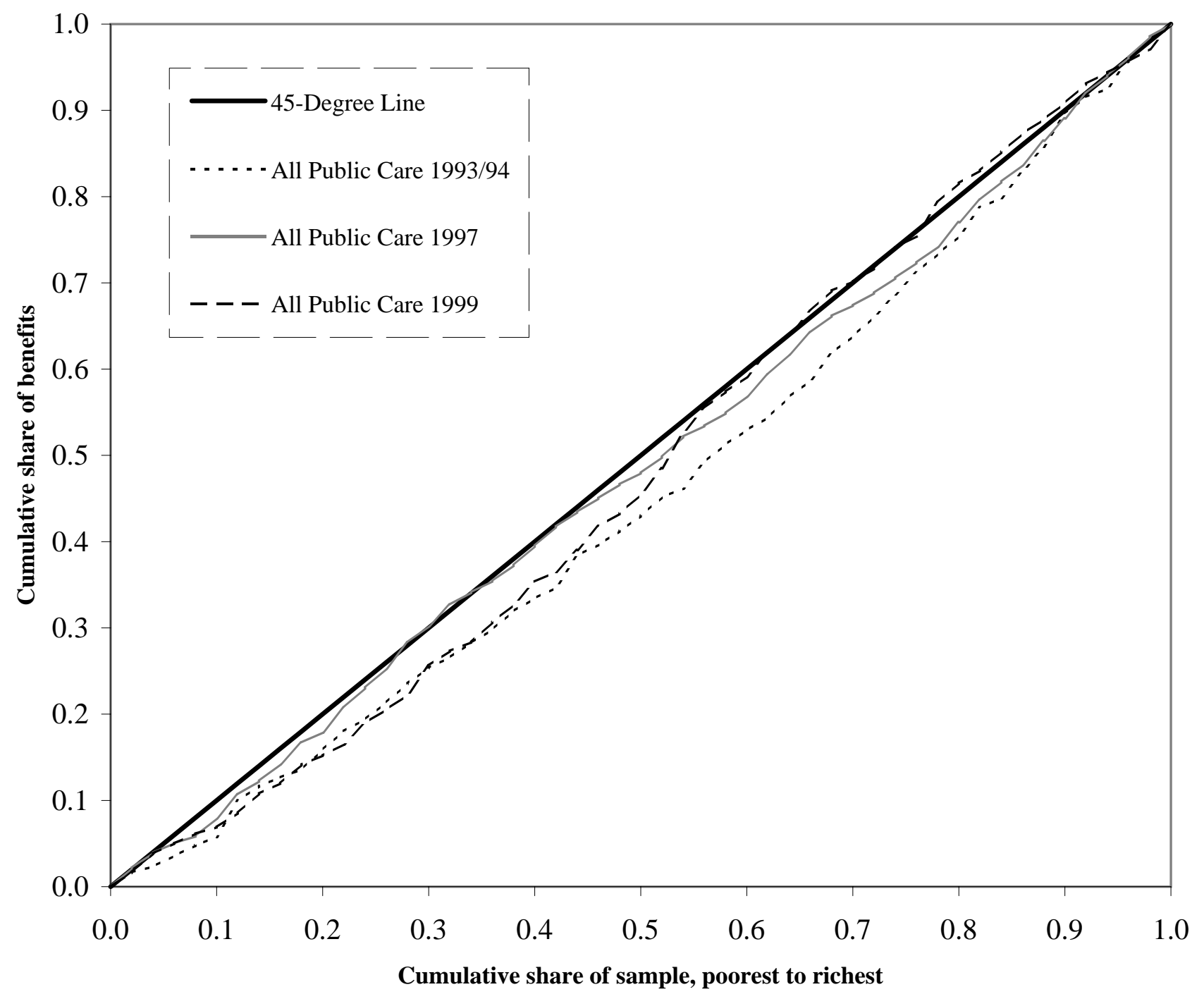


Figure A9 - Concentration curves for public prenatal care, 1993/94

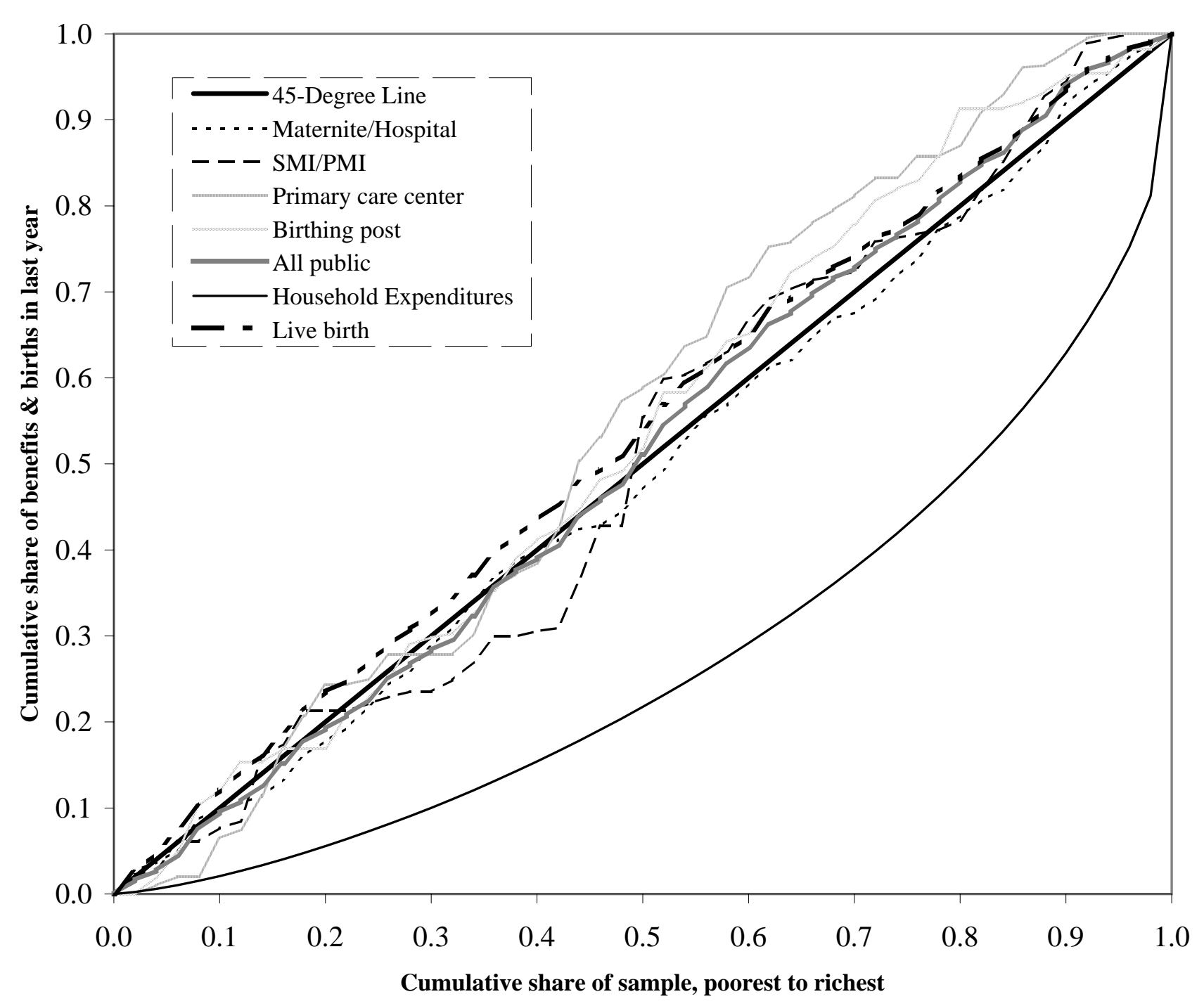


Figure A10 - Concentration curves for public prenatal care, 1999

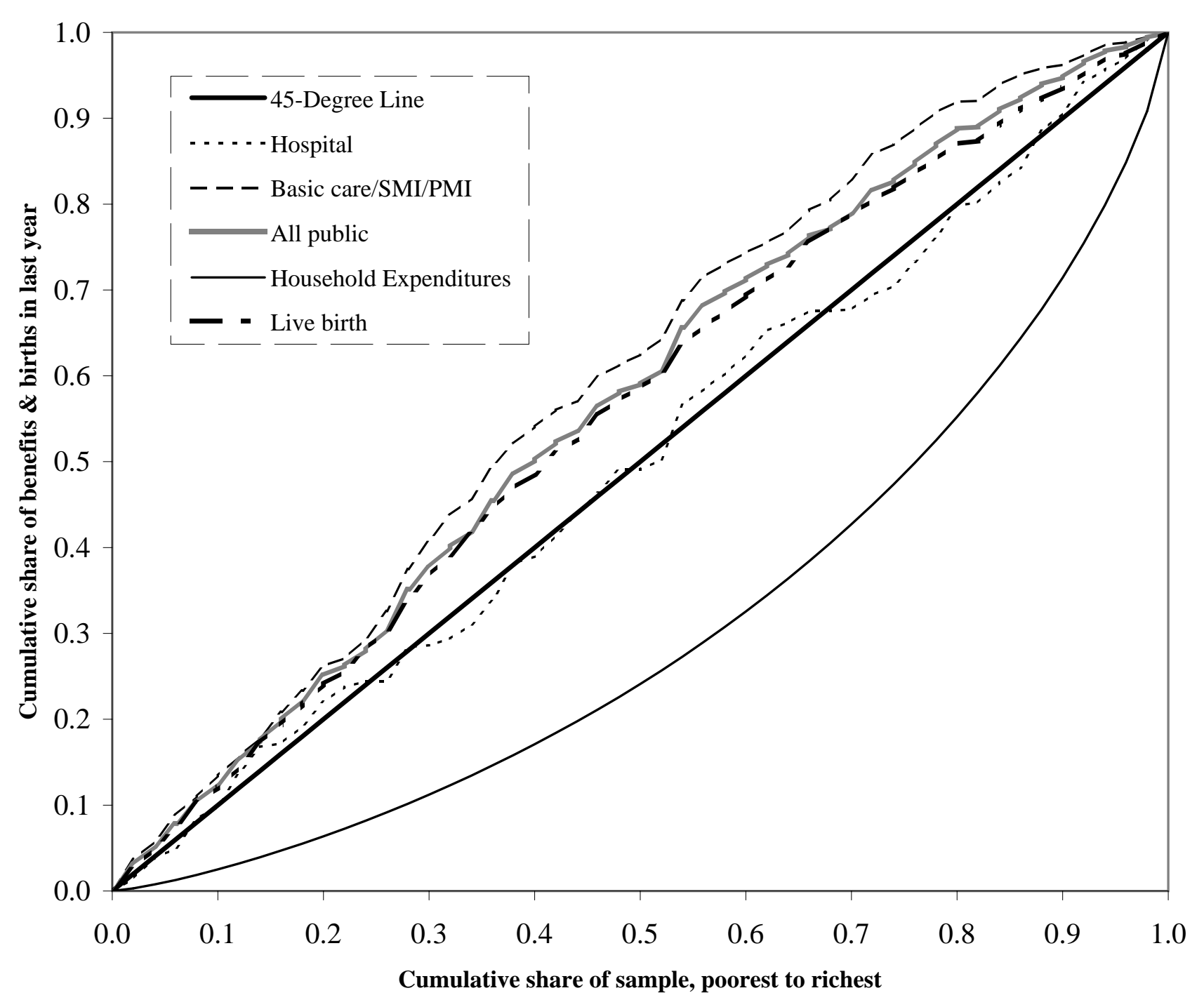


Figure A11 - Concentration curves for public prenatal care, 1993/94 -1999

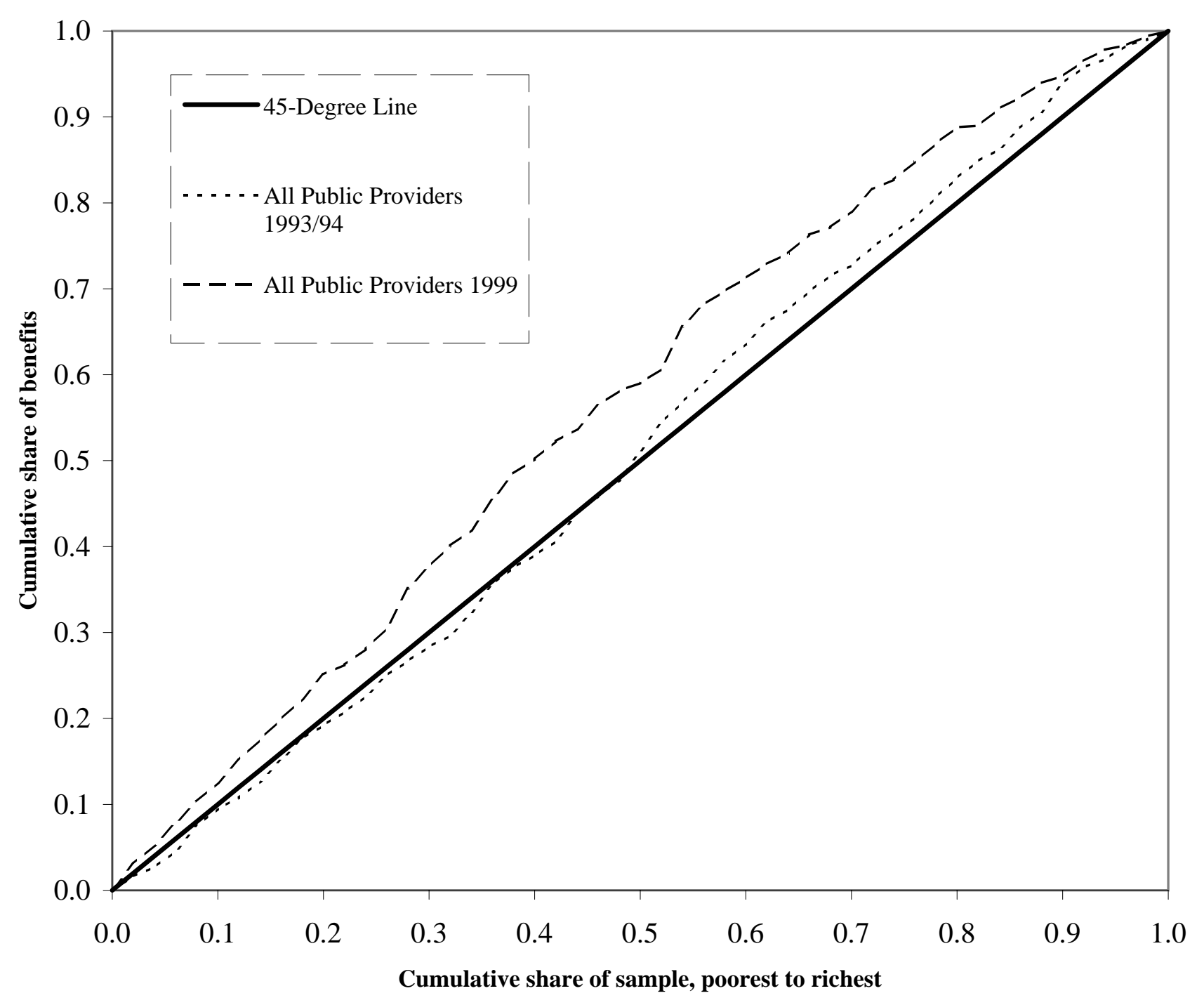


Figure A12 - Concentration curves for vaccinations (children 12-23 months), 1993/94

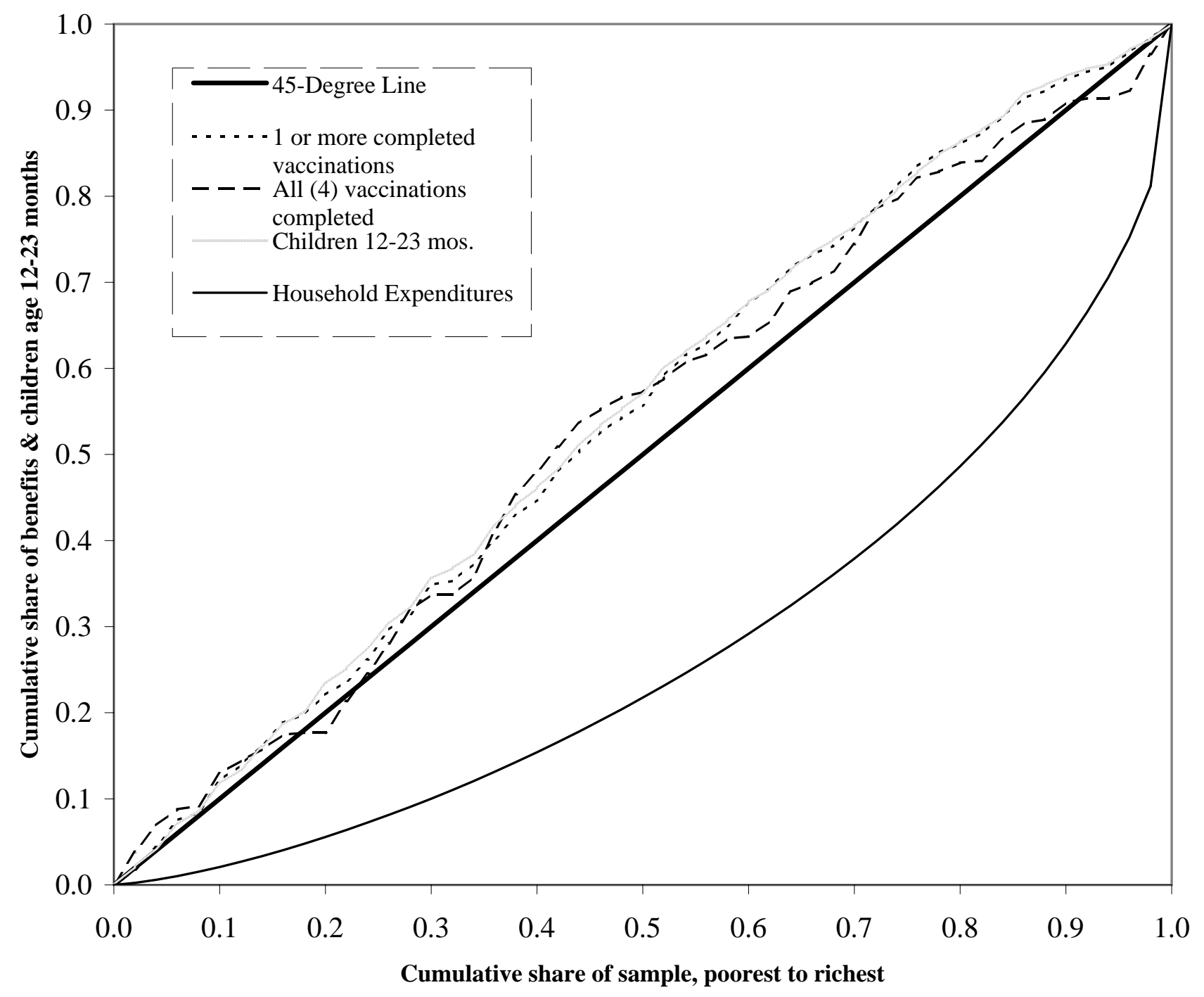


Figure A13 - Concentration curves for vaccinations (children 12-23 months), 1999

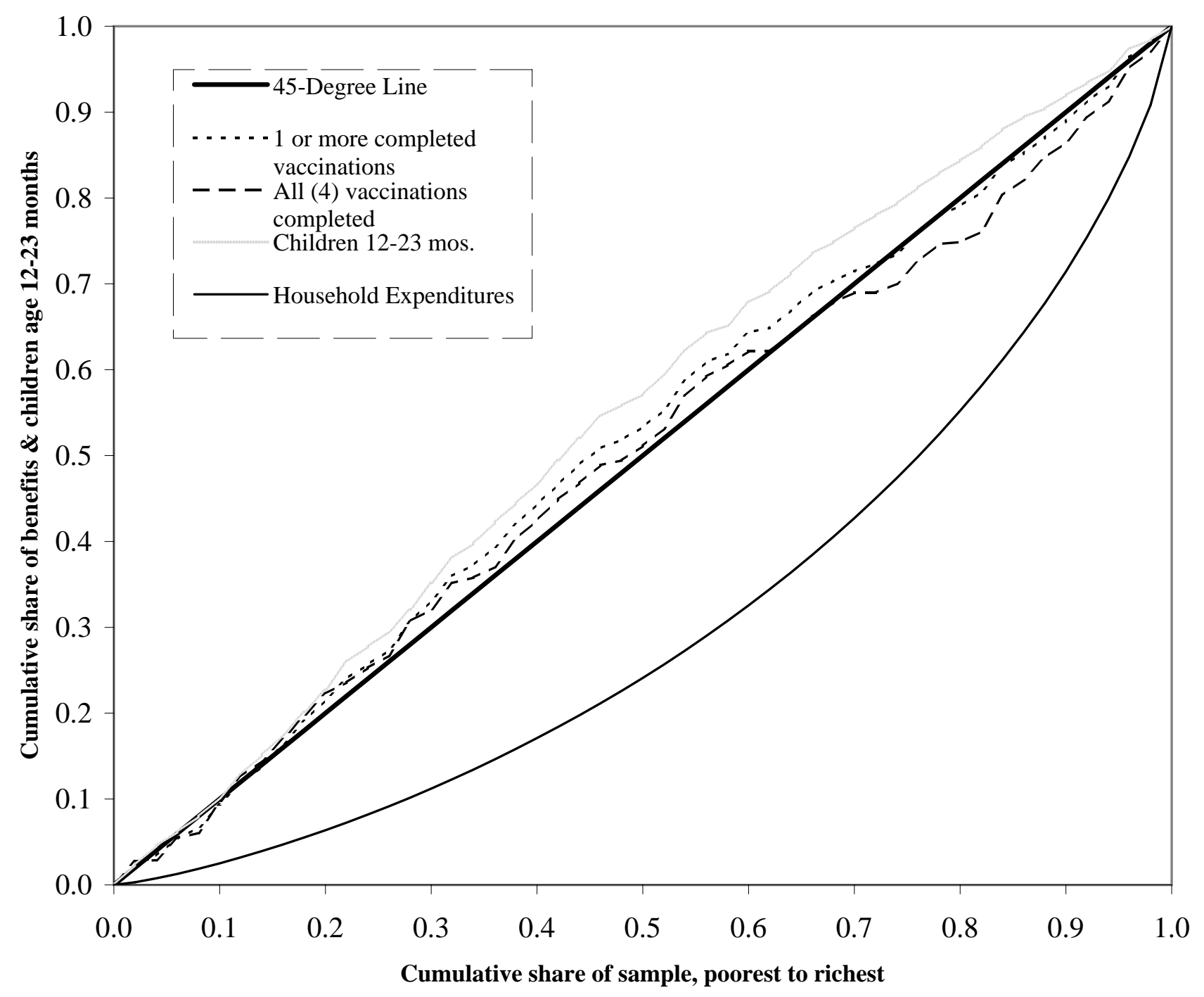


Figure A14 - Concentration curves for vaccinations (children 12-23 months), 1993/94 and 1999

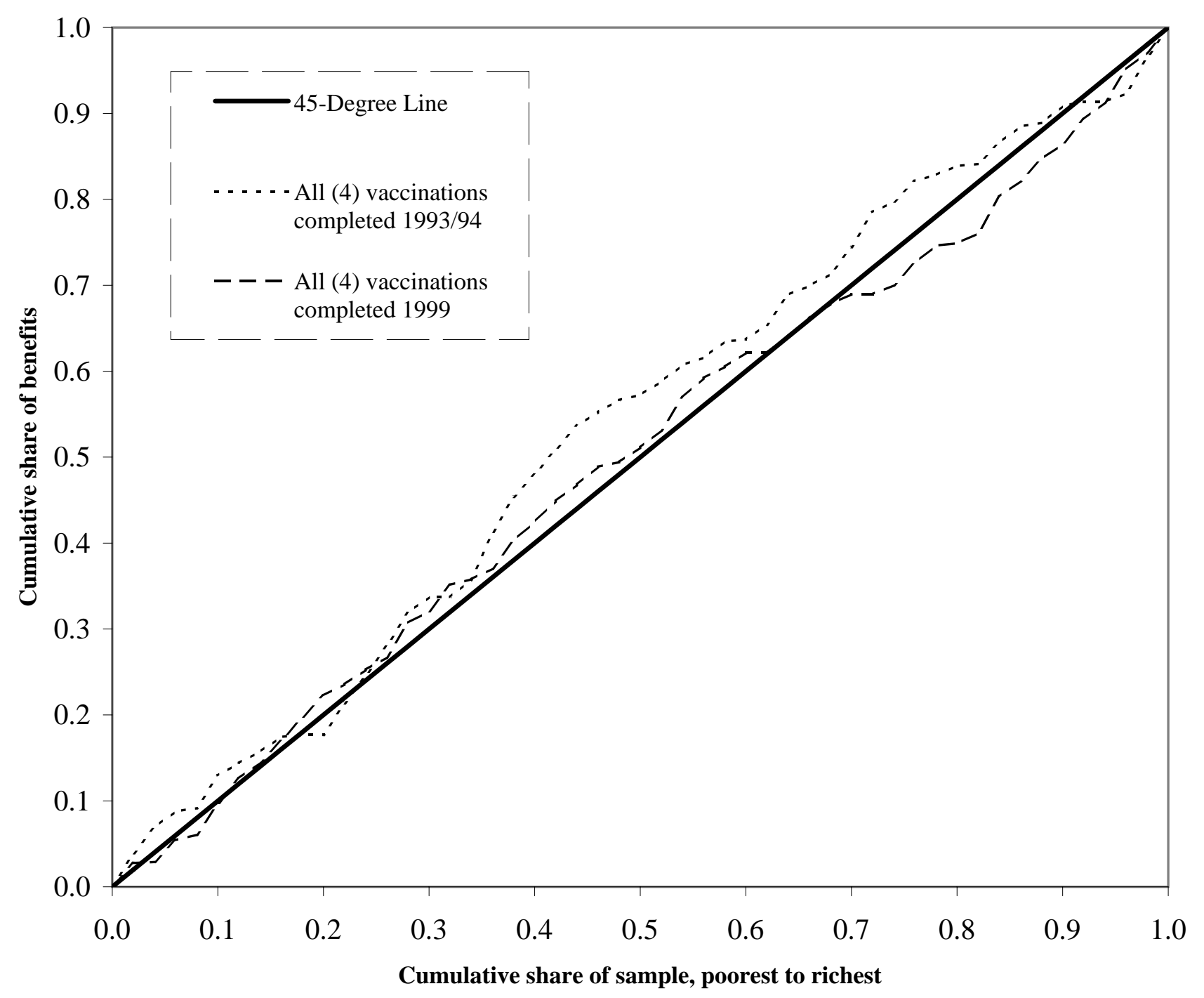


Figure A15 - Concentration curves for marginal benefits: vaccinations, 1993/94-1999

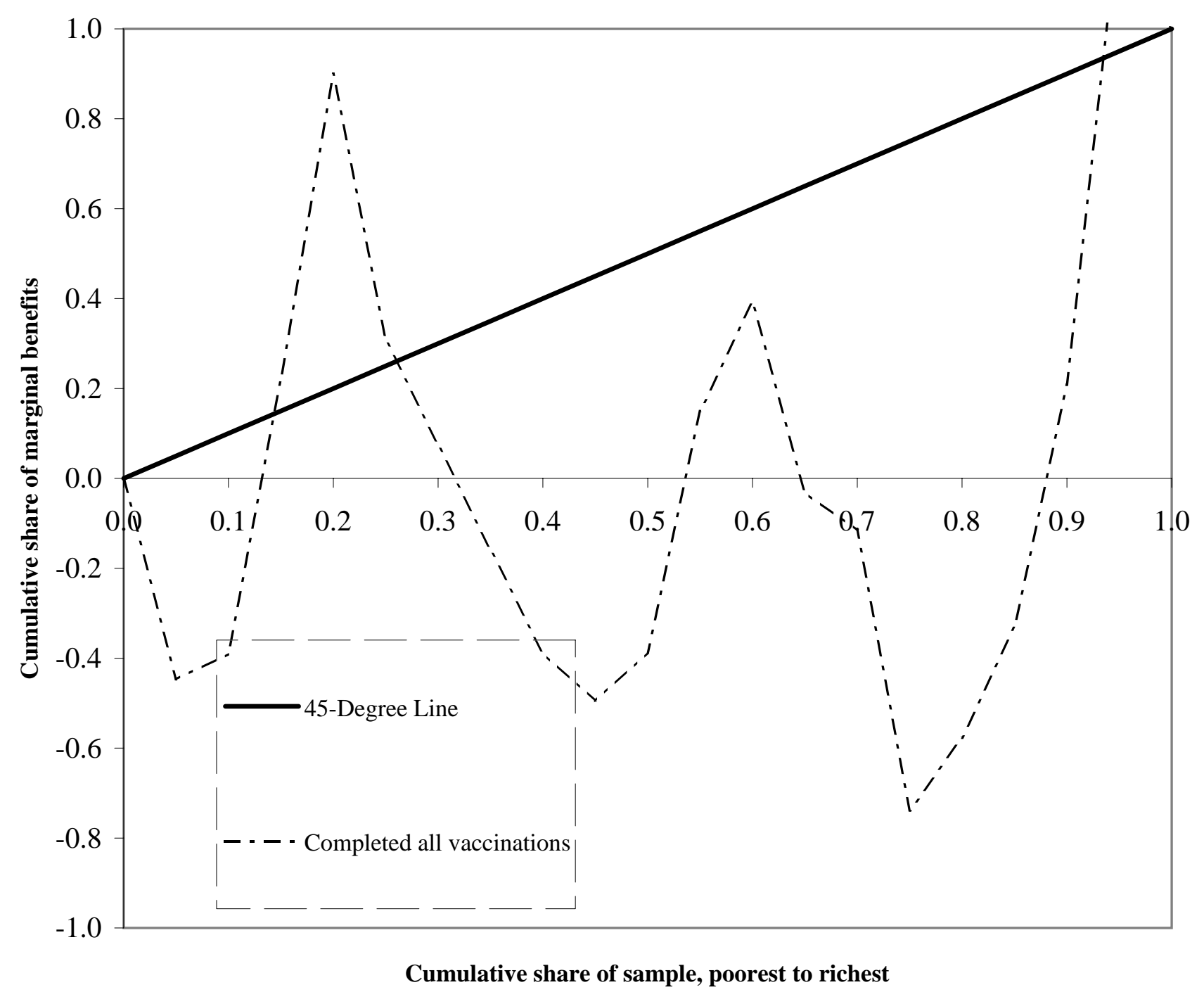

